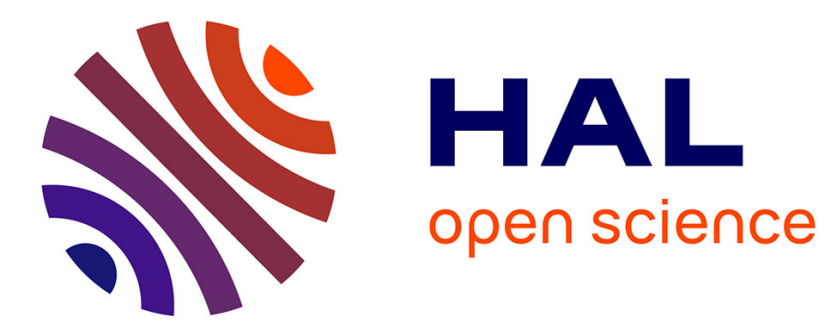

\title{
Fleet management in the humanitarian sector
}

Mahyar Eftekhar

\section{To cite this version:}

Mahyar Eftekhar. Fleet management in the humanitarian sector. Business administration. HEC;

École des hautes études commerciales, 2013. English. NNT : 2013EHEC0003 . tel-01087868

\section{HAL Id: tel-01087868 \\ https://pastel.archives-ouvertes.fr/tel-01087868}

Submitted on 27 Nov 2014

HAL is a multi-disciplinary open access archive for the deposit and dissemination of scientific research documents, whether they are published or not. The documents may come from teaching and research institutions in France or abroad, or from public or private research centers.
L'archive ouverte pluridisciplinaire HAL, est destinée au dépôt et à la diffusion de documents scientifiques de niveau recherche, publiés ou non, émanant des établissements d'enseignement et de recherche français ou étrangers, des laboratoires publics ou privés. 
ECOLE DOCTORALE

Sciences du Management

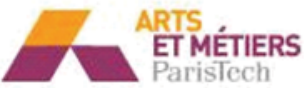

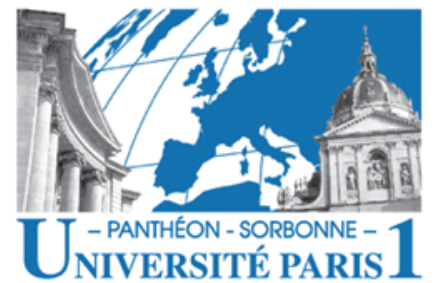

UNIVERSITÉ PARIS 1

Gestion - Organisation

Décision - Information

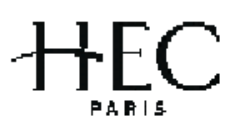

ECOLE DES-HHAUTES ETUDES COMMERCIALES DE PARIS

Ecole Doctorale « Sciences du Management/GODI » - ED 533

Gestion Organisation Décision Information

« Fleet Management in the Humanitarian Sector »

THESE

présentée et soutenue publiquement le 27 MAI 2013

en vue de l'obtention du

DOCTORAT EN SCIENCES DE GESTION

Par

\section{Mahyar EFTEKHAR}

\section{JURY}

Président :

Monsieur Luk VAN WASSENHOVE

Professeur

INSEAD - FONTAINEBLEAU - France

Directeurs de Recherche : Monsieur Laoucine KERBACHE

Professeur HDR

HEC Paris - France

Monsieur Andrea MASINI

Professeur Associé

HEC Paris - France

Rapporteurs :

Monsieur Charles CORBETT

Professeur

UCLA Anderson School of Management,

Los Angeles - Etats-Unis

Madame Marianne JAHRE

Professeur

Norwegian Business School Oslo - Norvège

Suffragants :

Monsieur Bertrand MUNIER

Professeur des Universités

IAE de Paris 1 - Panthéon Sorbonne - France

Monsieur Frédéric DALSACE

Professeur Associé

HEC Paris - France 


\section{Ecole des Hautes Etudes Commerciales}

Le Groupe HEC Paris n'entend donner aucune approbation ni improbation aux

opinions émises dans les thèses ; ces opinions doivent être considérées

comme propres à leurs auteurs. 


\section{Fleet Management in Humanitarian Organizations}

A DISSERTATION PRESENTED

BY

MAHYAR EFTEKHAR

TO

The Operations Management \& Information Technology Department

IN PARTIAL FULFILLMENT OF THE REQUIREMENTS

FOR THE DEGREE OF

DOCTOR OF PHILOSOPHY

IN THE SUBJECT OF

Operations Management

HEC School of Management

PARIs, France

FEBRUARY 2013 


\title{
Fleet Management in Humanitarian Organizations
}

\begin{abstract}
This dissertation concentrates on Fleet Management in Humanitarian Development Programs. Fleet management is a major concern for international humanitarian organizations because of (1) the magnitude of transportation-related costs in humanitarian operations, second only to personnel costs and, (2) the pivotal role that transportation plays in order-fulfillment processes. In addition, given the unique challenges attached to humanitarian logistics, it represents extreme situations of commercial supply chain. Therefore, the rationale to focus on humanitarian logistics has both theoretical and practical foundations. Not only has the work of humanitarian organizations assumed increasing relevance but also has an awareness of the potential to make improvements in this area. However, the lack of solid, theory-based models to guide the actions of humanitarian organizations is obvious.
\end{abstract}

Yet because of the conditions in which humanitarians work, e.g. poor infrastructures, extreme operating conditions and budget limitations, most existing models derived from commercial supply chains are inapplicable to humanitarian operations. Consequently, a new set of tools and theories are required. This dissertation is composed of two parts that address two questions in humanitarian fleet management: (1) fleet sizing and procurement strategy over time and, (2) fleet management policies at the field level. To address to these questions, both analytical modeling and empirical/statistical analysis were used.

The first part of the present thesis, Chapters 2 and 3, concentrates on optimal fleet sizing and 
procurement policy. This part studies on how to optimally determine fleet capacity over time and to minimize procurement costs for different demand requirements in the absence of detailed data. Lack of data is the main challenge that bans humanitarian organizations to adopt data-intensive models developed for commercial supply chain.

To achieve this goal, we study vehicle usage patterns empirically across different countries where the International Committee of the Red Cross (ICRC) runs humanitarian operations. We then construct a linear programming model to estimate optimal vehicle fleet sizing at the National Delegation level. From the results obtained via the LP model, we apply a linear quadratic control model to analyze vehicle procurement decisions at an aggregate level for different demand scenarios.

Our study provides interesting and counter-intuitive results. Contrary to conventional wisdom in humanitarian organizations - an approach usually leading to implement a chase procurement strategy - our findings show that a mixed policy of level and chase procurement strategies minimizes procurement costs. Moreover, our model suggests that a level strategy is the optimal procurement strategy in most humanitarian missions. The results of this part of the dissertation has been reported as an academic paper, accepted for publication in Production and Operations Management.

The second part of the dissertation, Chapter 4, concentrates on fleet management policies at the field level. To optimize fleet performance and maximize demand coverage, humanitarian organizations implement policies to enhance the utilization of vehicles and minimize their physical depreciation. In this part, we first investigate whether delegations follow the Headquarters recommended 
policies. Then, we examine the impact of different components of a vehicle's usage policy on its utilization and physical depreciation. Furthermore, we determine whether a utilization-depreciation trade-off exists, or if humanitarian organizations can improve both simultaneously.

Using field data provided by the ICRC, we construct and test several econometrics models in order to analyze: (1) how to optimally allocate vehicles to different types of missions, (2) how to modify a vehicle's utilization over its lifetime and, (3) how to set up an efficient replacement policy.

In contrast to our initial assumptions, the results illustrate that there is no rationale in assigning vehicles to mission types. Furthermore, an optimal vehicle usage policy exists that should universally be implemented; in fact, all vehicles should be used following the same usage policy regardless of their mission type. We also demonstrate that, on average, a utilization-depreciation trade-off does not exist and that a well-conceived fleet management policy leads to higher vehicle utilization, and to lower physical depreciation. Moreover, our results illustrate that the vehicle replacement policy implemented by most humanitarian organizations is not effective and needs reconsideration. The results of Chapter 4 is currently being finalized for submission to the Journal of Operations Management.

Given the lack of academic work in this field, this dissertation contributes to the basis of humanitarian literature. In addition, availability of data is rather rare in humanitarian sector, therefore our results, that are based on empirical study, shed further light on humanitarian fleet management. Although we specifically study fleet management at ICRC, our results are not limited only to the operations of this organizations. Given the lack of data is a major challenge for most of humani- 
tarian organizations, the results of Chapters 2 and 3 provide a guideline for humanitarian organizations that follow a centralized vehicle procurement model. Also, Chapter 4 is an empirical study on field vehicle fleet management that depends neither on the organization's vehicle procurement policy nor its specific projects in those regions. Therefore, the insights gained from this section are useful for other humanitarian organizations.

In this thesis, we concentrate on ICRC's operations in four countries because:

- Most of humanitarian organizations do not have a proper database while ICRC is one of the most advanced humanitarian organizations in data collection.

- ICRC follows a centralized vehicle procurement policy that is the most cost efficient model. Hence, a further improvement to its vehicle procurement makes sense.

- We chose four countries of operations; Afghanistan, Sudan, Ethiopia and Georgia following the ICRC fleet manager's suggestion. These countries are the best representatives of ICRC's operations because: (1) ICRC had owned its largest fleet sizes in these countries from 2000 to $2010,(2)$ ICRC had run different types of projects in these countries and, (3) all countries represent very abnormal conditions of humanitarian operations (e.g., high level of conflict and low quality of infrastructure). 


\section{Contents}

1 INTRODUCTION AND OVERVIEW 1

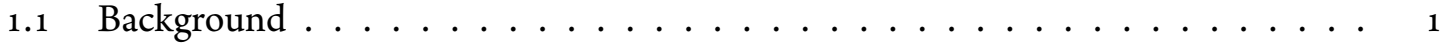

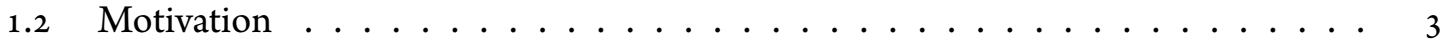

1.3 Research Objectives and Questions _. . . . . . . . . . . . . 7

1.4 Relevance and Contribution of Research . . . . . . . . . . . . . . . 8

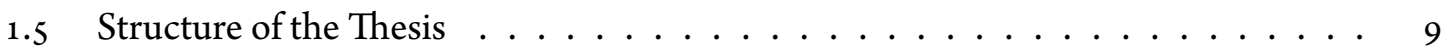

2 Optimal Fleet Sizing 10

2.1 Abstract . . . . . . . . . . . . . . . . . 10

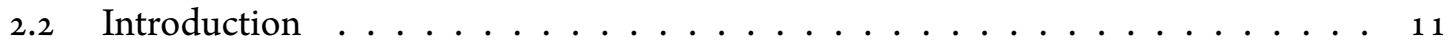

2.3 Literature Review . . . . . . . . . . . . . . . . . . . . 14

2.4 Research Setting . . . . . . . . . . . . . . . . . 18

2.5 Linear Programming Model for Vehicle Fleet Sizing . . . . . . . . . . . . 21

3 Optimal Procurement Policy 33

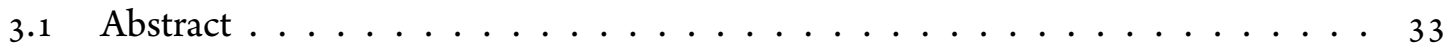

3.2 Quadratic Control Model for Determining Optimal Policies under General Demand Scenarios . . . . . . . . . . . . . . . . . . . . . 34

3.3 Conclusions, Limitations, and Future Research _ . . . . . . . . . . . 47

4 FLEet MANAGEMENT POLICIES IN HUMANITARIAN OPERATIONS: AN EMPIRICAL INVESTIGATION 
4.1 Introduction $\ldots \ldots \ldots \ldots \ldots \ldots \ldots \ldots$

4.2 Literature Review . . . . . . . . . . . . . . . . . 54

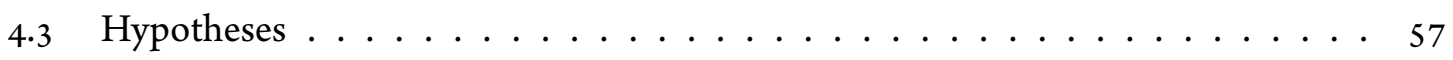

4.4 Methodology ........................ 62

4.5 Analysis and Discussion of Results . . . . . . . . . . . . . . 72

4.6 Managerial Insights . . . . . . . . . . . . . . . . 77

4.7 Conclusions, Limitations and Future Research . . . . . . . . . . . . . . 79

5 Conclusion $\quad \mathbf{8 2}$

5.1 Key Findings and Contributions . . . . . . . . . . . . . . 83

5.2 Limitations and Future Research . . . . . . . . . . . . . . . 85

$\begin{array}{llr}6 & \text { Appendix } & 87\end{array}$

$\begin{array}{ll}\text { REFERENCES } & 92\end{array}$ 


\section{Listing of figures}

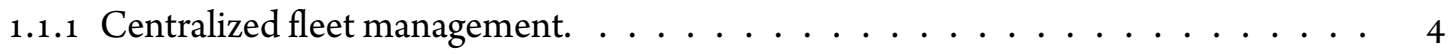

2.5.1 Vehicle Usage As a Function of Vehicle Age in Afghanistan, Sudan, and Ethiopia . 25

2.5.2 Optimal Capacity vs. Demand (in kilometers) . . . . . . . . . . . 30

2.5 .3 Optimal vs. Actual fleet sizes . . . . . . . . . . . . . . 31

3.2.1 Budget Allocation in period $t$ (with respect to $r$ and $q) \ldots \ldots \ldots$

3.2.2 Optimal QC Policy versus Optimal LP Policy: Sudan . . . . . . . . . . . . . 47

4.3.1 Average fleet utilization vs. average residual values in 21 delegations . . . . . . 61

4.4.1 Example of observation period vs. vehicle operational life cycle (OLC) . . . . . 63

4.4.2 Level of conflict in the countries of operations $2003-2011 \ldots \ldots 6$

4.5 .1 Failure rate vs. total mileage $\ldots \ldots \ldots \ldots \ldots$ 
TO MY COMPASSIONATE MOTHER, WHO STILL ENJOYS WHEN I LEARN SOMETHING.

TO MY HARDWORKING FATHER, WHO TAUGHT ME TO HOPE.

To my lovely Panieh, Who has Changed the Color of My Life.

THIS THESIS WOULD CERTAINLY NOT HAVE EXISTED WITHOUT THEM WHO HAVE BEEN A CONSTANT SOURCE OF SUPPORT. 


\section{Acknowledgments}

First and foremost I would like to thank Professor Luk Van Wassenhove for having involved me in the research area of Humanitarian Logistics. I am grateful to him for the support and guidance he showed me throughout my dissertation. I believe, I have learned an attitude from him. I do believe in Albert Einsteins quotation 'Try not to become a man of success but rather to become a man of value', and I have no doubt that he is a man of value (although, he has already been a man of success).

Also, I am grateful to my advisor, Professor Andrea Masini. He helped me learn how to conduct an empirical research and how to report an academic article. I have been indebted in the preparation of this thesis to him, whose attention, as well as academic experience, have been invaluable to me. Also, I thank him for his financial supports; for example I acknowledge that

- I had his support in attending the Annual Fleet Forum Meeting in 2011 in Geneva, Switzerland.

- I used his RA budget during the fifth year of my $\mathrm{PhD}$.

Also, I wish to thank Professor Laoucine Kerbache, the former Head of our Ph.D. Program and the Co-Chair of the jury. I am very grateful as he allowed me to work on a research topic that I had been very interested in, though I had to choose my supervisor out of our school. I thank him for all his support, in particular, my academic visits and conferences. I acknowledge that

- in June-July 2008, I was supported by our Ph.D. Office to attend the MIT-Zaragoza Summer School, Spain. 
- in May 2010, I was supported by our Ph.D. Office to attend the POMS Annual Meeting in Vancouver, Canada.

- in November 2010, I was supported by the Groupement de Recherche et d'Etudes en Gestion d'HEC (GREGHEC) to attend INFORMS Annual Conference, Austin, TX.

- in May 2011, I was supported by our Ph.D. Office to attend the POMS Annual Meeting in Reno, NV.

- in April 2012, I was supported by GREGHEC to to attend the POMS Annual Meeting in Chicago, IL.

- in July 2012 , our Ph.D. Office helped me to attend the Euroma Conference, Amsterdam, The Netherlands.

- in October 2012, I was supported by our Ph.D. Office to attend INFORMS Annual Conference, Phoenix, AZ.

Last, but not least, are my parents. They have always supported me emotionally, morally and of course financially to pursue my studies. I should, heartily and sincerely, be thankful to them forever. 


\title{
La gestion de la flotte dans le secteur humanitaire
}

\author{
Mahyar Eftekhar \\ Ecole des Hautes Etudes Commerciales de Paris \\ Résumé de la thèse
}

\section{Le contexte de l'étude :}

Durant la période 2000-2004, la moyenne annuelle de catastrophes a augmenté de plus de 55\% par rapport aux années 1995-1999, entrainant également une augmentation de plus de $33 \%$ des personnes touchées (aide immédiate, évacuation des blessés ou des morts). D'après les estimations de La fédération internationale de la Croix-Rouge et du Croissant-Rouge (FISCR) de 2005, environ 213 millions de personnes sont touchées chaque année, entre 1999 et 2003, par ces catastrophes; entrainant ainsi une augmentation de la moyenne annuelle de plus de 707 catastrophes.

en 2011, on constate une baisse du nombre de personnes touchées par des catastrophes comparativement à la période 2000-2010. Cependant, les dommages économiques causés par ces dernières en 2011 (363 989869 USD) représentaient en moyenne plus de quatre fois ceux constatés sur la période 2000-2010 (USD 95.982.686).

II n'existe pas de définition unanimement admise en ce qui concerne le concept les opérations humanitaires. Par ailleurs, il comprend tous les processus concourant à fournir et à distribuer de l'aide (nourriture, médicaments, etc.) aux bénéficiaires afin de réduire la souffrance humaine et la mort. Pour des catastrophes de grande ampleur, la participation de la communauté internationale est nécessaire car elle canalise souvent des fonds d'urgence via des organisations humanitaires afin d'aider les pays concernées.

Les missions essentielles des organisations humanitaires sont généralement définies soient comme des opérations de secours, des programmes de développement, soient comme les deux.

En ce qui concerne les opérations de secours, elles sont habituellement exécutées dans des catastrophes d'urgence telles que la famine, le tremblement de terre et l'inondation, qui créent des demandes pour ces types d'opérations. Bien que de telles catastrophes nécessitent généralement des réponses et services d'urgence ponctuels, dans de nombreux cas, les organisations humanitaires continuent de 
desservir les zones touchées pendant de nombreuses années durant. En plus de ces services d'urgence, de nombreux projets sont mis en place dans le but d'améliorer la qualité de vie des pays pauvres ; ces derniers, appelés programmes de développement, comprennent des programmes de santé, d'alimentation, d'hygiène et social. Contrairement aux opérations de secours qui entrainent une augmentation imprévue de la demande, les programmes de développement quant à eux montrent une demande plus stable et prévisible.

Indépendamment de leur mandat, les organisations humanitaires investissent chaque année des milliards de dollars dans la couverture financière de leurs opérations. Par exemple en 2011, les dépenses totales du Programme Alimentaire Mondial (World Food Program) ont excédées 3,8 milliards de dollars. En outre, les coûts opérationnels des organisations humanitaires ont augmentés : les dépenses totales d'Oxfom UK ont par exemple augmenté, passant de $£ 115,1$ millions en 2003 à £ 286,4 millions en 2013. Malgré leur ampleur, ces efforts ne sont guère utiles que si les ressources sont déployées pour atteindre les bénéficiaires ciblés. La distribution et le transport capillaire jouent un rôle important dans les processus de traitement des commandes. L'élément clé de transport, ici la gestion de flotte de véhicules, est l'objectif principal de cette thèse.

\section{Motivation:}

La gestion de la flotte constitue une préoccupation majeure pour les organisations humanitaires internationales. Deux raisons justifient cela : l'ampleur des coûts de transport liés aux opérations humanitaires (qui occupent le second rang après les frais de personnel) et la place centrale qu'occupe le transport dans les processus de traitement des commandes. Ceci a amené les organisations humanitaires internationales à mieux évaluer leur gestion de flotte. Certains défis propres à la logistique humanitaire représenteraient des situations extrêmes dans la chaîne d'approvisionnement commerciale. II est donc raisonnable, sur le plan théorique et pratique, de se focaliser sur la logistique humanitaire.

Les missions des organisations humanitaires sont supposées accroître la pertinence mais également une prise de conscience de la possibilité d'apporter des améliorations dans ce domaine. Cependant, on note une absence des modèles théoriques solides pour guider leurs actions. La motivation de cette thèse réside dans l'absence de bases conceptuelles et méthodologique dans le domaine. 


\section{Gestion de la flotte dans les opérations humanitaires:}

Gestion de flotte se compose d'une gamme de fonctions, telles que le la taille de la flotte, la maintenance et les politiques d'utilisation. Les grandes organisations humanitaires internationales ont généralement quatre niveaux d'organisation: le sièges social, les bureaux régionaux, les bureaux nationaux (ou délégations nationales) et les bureaux de projet (ou sous-délégations). Habituellement les sièges sociaux ont établis dans les pays développés et les bureaux régionaux dans les régions géographiques comme l'Asie, le Moyen-Orient, l'Afrique et l'Amérique et ils sont en charge de la coordination des opérations. Les délégations nationales contrôlent les opérations humanitaires au niveau national et ils coopèrent avec les autorités locales et d'autres organisations humanitaires. Enfin, les sous-délégations sont en charge des projets et de traiter directement avec les opérations, en effet ils sont responsables de la distribution capillaire.

Pour gérer leur flotte, les organisations humanitaires suivent généralement une approche décentralisée, un modèle hybride ou centralisée. Dans un modèle décentralisé, les décisions sont prises au niveau du projet (sous-délégation) au sein du pays d'opérations. Par exemple CARE International et Médecins Sans Frontières (MSF-International) suivent ce modèle. Dans un modèle hybride, les décisions sont partagées entre les délégations nationales et le siège. La Fédération Internationale des Sociétés de la Croix-Rouge et du Croissant-Rouge, le Programme Alimentaire Mondial et Vision du Monde sont des exemples d'organisations humanitaires qui utilisent le modèle hybride. Dans un modèle centralisé, toutes les décisions sont prises au niveau du siège. Par exemple Le Comité international de la Croix-Rouge applique ce modèle. D'ailleurs, sur la base des données réelles, environ $80 \%$ de la flotte en fédération internationale des Sociétés de la Croix-Rouge et du Croissant-Rouge et le Programme Alimentaire Mondial est acheté suivant le modèle centralisé.

Dans de nombreux cas, le transport est une partie interne des opérations humanitaires et les organisations humanitaires ne peuvent généralement pas l'attribuer à un tiers. Par exemple, un médecin ne peut pas visiter les bénéficiaires dans les zones reculées, en Afghanistan, si elle ne possède pas de véhicule. Les Véhicules, dans les programmes de développement humanitaire, sont utilisés pour coordonner et exécuter la distribution capillaire du programme, notamment: 
- Le transport des articles de secours

- Le transport du personnel qui coordonnent ou la prestation de services aux bénéficiaires

- Le transport du personnel et des matériaux qui sont liés aux projets, par exemple la construction d'écoles et d'hôpitaux

De plus, le transport est l'un des dépenses le plus importante dans les opérations humanitaires. Une enquête récente montre que les coûts de la flotte sont la préoccupation principale de $67 \%$ des grandes organisations humanitaires internationales. Vicente Escrebano, le directeur de Supply Chain d'Agence des Nations Unies pour les réfugiés, a indiqué que pour la plupart des organisations humanitaires l'investissement actif sur la flotte ou liées aux transports sont le plus important, une flotte bien gérée peut se traduire par au moins $20-30 \%$ économies sur les coûts de fonctionnement.

Enfin, la gestion de flotte et le transport a des conséquences sur la visibilité des organisations humanitaires. II est supposé que la visibilité influe sur les dons (dons publics en particulier) dont les organisations humanitaires reçoivent. c'est la raison pour laquelle les organisations humanitaires préfèrent fortement d'utiliser uniquement leurs propres véhicules pour gagner le plus de visibilité auprès des médias. Par conséquent, ils ne partagent pas les véhicules avec d'autres organisations.

Vu le rôle clé de la gestion de flotte, les organisations humanitaires se sont récemment efforcés pour améliorer la gestion de leur flotte. Par exemple, la Fédération internationale des Sociétés de la Croix-Rouge et du Croissant-Rouge, qui opère dans 187 pays, ont conçu et mis en œuvre des nouvelles règles sur la façon de gérer et d'utiliser ses véhicules. Le Comité international de la CroixRouge, qui opère dans 80 pays, a amélioré son système centralisé de gestion de flotte à l'ide de logiciel 'Fleetwave' qui augmente la qualité des données et les capacités d'analyse au niveau du siège. Une autre grande organisation humanitaire internationale qui intervient dans 75 pays est le Programme Alimentaire Mondial, il a mis en place le système de positionnement mondial pour suivre l'utilisation et la performance de tous les véhicules individuels. Malgré les efforts de quelques-unes de grandes organisations humanitaires internationales, la plupart d'entre eux ne sont toujours pas gérés leurs flottes d'une manière efficace. 


\section{Les défis:}

Les organisations humanitaires et leurs homologues commerciaux peuvent apprendre les uns des autres. Cependant, les humanitaires ne peuvent pas copier les solutions qui viennent du secteur commercial en raison des défis attachés aux opérations humanitaires. Ces défis sont généralement classés par le type de la catastrophe, la phase du cycle de la vie en cas de catastrophe, le contexte géographique (par exemple, les routes et les infrastructures) et les conditions courantes (par exemple, la sécurité). Néanmoins, nous résumons les principaux défis liés à la gestion de flotte dans les programmes de développement:

- Médiocrité des infrastructures: les opérations humanitaires se sont souvent effectuées dans les zones où La médiocrité des infrastructures et le manque de voies de communication mènent aux lieux de demande. Par exemple, plus de $60 \%$ de la population de 15 pays d'Afrique sub-saharienne n'ont pas d'accès direct aux routes toutes les saisons.

- Niveau du conflit: les problèmes posés par les zones de conflits concernent les organisations humanitaires sur leur façon de répartir des véhicules pour les missions. Par exemple, dans certaines zones humanitaires si un véhicule tombe en panne au cours d'une mission de secours, cela pourrait être en danger. par conséquence, ils attribuent des véhicules plus récents pour les missions sur le terrain et des véhicules plus anciens à des tâches administratives dans les zones urbaines. Les problèmes de sécurité et les infrastructures médiocres rendent les modes d'utilisation des véhicules au sein des programmes de développement très différents de ceux des chaînes d'approvisionnement commerciales. Le mode d'utilisation du véhicule est explicitement pris en compte dans notre étude.

- Manque de communication et de coordination: le manque de la vision globale et de la coordination au sein des organisations humanitaires qui mènent à des frais supplémentaires ou baisse de performance. L'impact économique de cette question sera dévoilé dans notre étude.

- Limites financières: les contraintes budgétaires et les dons qui sont fréquemment assignés rajoutent ainsi des limites supplémentaires à l'achat de nouveaux véhicules. Par exemple, le programme alimentaire mondial pourrait seulement couvrir environ 25\% de ses objectifs attendus en 2011. 
- Délai d'achat trop long: travailler dans les régions où les infrastructures sont anormales (par exemple, les routes non revêtues) se rétrécit les options en ce qui concerne l'acquisition de véhicules propres. Les véhicules doivent être fiables et spécialement équipés aux missions de secours. Ces véhicules ne sont pas facilement disponibles sur les marchés locaux des pays pauvres où les programmes de développement sont exécutés. Par conséquence, les humanitaires doivent commander directement auprès des fabricants, une approche qui peut apporter des avantages de coûts pour les organisations humanitaires. en même temps, il augmente le délai d'achat au maximum de six mois, car les fabricants sont obligés créer des cycles de production supplémentaires.

- Manque des données réelles: manque des données est un problème extrêmement sérieux dans les opérations humanitaires. En raison de contraintes financières et le manque de personnel formé, les organisations humanitaires ne sont pas en mesure de développer leur infrastructure de system d'information et recueillir régulièrement les données opérationnelles. C'est pourquoi, dans des nombreuses situations, ils devraient prendre des décisions (par exemple, les décisions de la flotte de dimensionnement) qui ne sont pas qualitativement, bien entendu, optimales.

Sace aux défis susmentionnés, cette thèse propose des solutions pour améliorer la gestion de la flotte humanitaire afin de minimiser les coûts d'exploitation tout en maximisant la performance de la flotte des organisations humanitaires.

\section{Problématique de la recherche et contribution:}

Les questions de recherche en gestion de la flotte humanitaire peuvent être classées en deux groupes principaux qui sont chacun liés à des décisions spécifiques dont les gestionnaires de flotte doivent effectuer:

- Au niveau macro-économique et liée à l'acquisition de véhicules

- Au niveau micro et liés à l'utilisation des véhicules

Le premier groupe comprend des questions comme la taille optimale de la flotte, les modèles d'achat efficaces, la sélection des fournisseurs et le mécanisme de contrat. Le deuxième groupe concerne des questions telles que la politique du remplacement individuel, Le problème de tournées de véhicules et l'ordonnancement, la fiabilité des véhicules et leur entretien, et l'attribution de mission des véhicules et leur utilisation. Pour ce qui est de coûts, les deux groupes 
sont tous aussi importants. II est évident que 50\% des coûts de la flotte entiers pourraient minimiser grâce à une politique d'acquisition de véhicules optimale tandis que le reste des coûts de la flotte sont liées à l'utilisation des véhicules sur le terrain.

Dans la présente étude, deux questions principales sont adressées. En se concentrant sur un modèle centralisé de gestion de flotte, nous définissons d'abord une politique d'achat optimal qui minimise les coûts d'achat. Nous considérons un modèle de gestion de la flotte centralisée pour les raisons suivants: (1) la littérature montre que le modèle centralisé est plus rentable, donc une réduction supplémentaire des coûts serait utile, (2) dans ce modèle, les décisions sont prises d'une façon centralisée dont le siège dispose de suffisamment de pouvoir sur les décisions de la taille de la flotte et, enfin, (3) nous avons l'accès aux bases de données CICR qui suit un modèle centralisé. Des données réelles fournies par cette organisation rendent nos résultats plus approprié et pratique pour ce type de gestion de flotte.

L'objectif de la première partie (chapitres 2 et 3 ) est de concevoir une politique d'achat optimal qui minimise les coûts d'achat des organisations humanitaires au fil du temps. Notre modèle proposé contiens deux avantages importants: (1) contre la littérature, notre modèle n'est pas sensible aux données (c'est-à-dire, elle minimise les coûts même si les données détaillées ne soient pas disponibles) (2) nous considérons l'impact de la politique du remplacement des véhicules individuels sur la taille de la flotte à chaque fois. Cela n'a pas sollicité l'intérêt des chercheurs dans le domaine de gestion de flotte. Le résultat de cette partie a été présenté comme un article scientifique accepté pour publication dans la revue Production and Operations Management.

La deuxième question abordée dans cette étude concerne la gestion de flotte de véhicules sur le terrain. Nous examinons la politique d'utilisation des véhicules sur le terrain (sous-délégation) afin de comprendre (1) la manière dont les véhicules ont été gérés sur le terrain et, (2) la façon de les mieux gérer afin de minimiser La dépréciation physique des véhicules tout en maximisant leur utilisation. Nos résultats présentés comme un article scientifique, montrent que la gestion de flotte bien conçue pourrait augmenter l'utilisation des véhicules tout en réduisant considérablement les coûts associés. Par exemple, notre résultat montre que le CICR ne peut pas réduire ses coûts de flotte au-dessus de 6 millions de 
dollars. Cette étude est le premier travail empirique dans ce domaine qui mettrait en lumière la gestion de la flotte humanitaire sur le terrain, c'est à dire, il dépeint l'irrationalité existant dans le domaine de la gestion de flotte de véhicules sur le terrain. Par conséquent, cette étude donnerait des meilleures idées sur les futurs travaux de recherche dans ce domaine.

\section{chapitres 2 et 3 :}

Les décisions relatives à la taille de la flotte sont particulièrement difficiles pour les organisations humanitaires en raison des environnements inhabituels dans lesquels ils devraient opérer. Les problèmes de sécurité dans les zones de conflit affectent la répartition des véhicules aux missions. Dans certaines régions, si un véhicule tombait en panne les opérateurs humanitaires craindraient le danger, donc il est supposé que seuls les nouveaux véhicules pourraient utiliser pour les déplacements sur le terrain tandis que les anciens véhicules devraient se charger des tâches administratives dans les zones plus prudentes. Les organisations humanitaires sont également confrontées aux longs délais d'achats. Vu les situations dans lesquelles les organisations humanitaires interviennent, ils ont besoin de véhicules spécialement aménagés qui doivent être commandés directement auprès des fabricants. De plus, l'entretien est aussi un défi: dans les pays en développement, les concessionnaires automobiles peuvent être faibles, les possibilités d'externalisation sont limités, et c'est difficile de trouver les pièces d'échanges. Enfin, la mauvaise coordination et le manque de l'infrastructure d'un system d'information suffisant entraînent des coûts supplémentaires et pourrait diminuer encore les performances.

Outre les conditions de travail, le processus d'achat insolite d'une organisation humanitaire entrainerait les difficultés supplémentaires pour les décideurs. Au niveau du Siège, les planificateurs au niveau central sont responsables de prendre les décisions de taille de la flotte au nome des délégations nationales. Pourtant, le suivi des opérations est cher, donc le siége a rarement la demande détaillée et les coûts nécessaires pour optimiser les décisions. Donc la taille des flottes sont souvent établis qualitativement à l'aide de simple algorithme heuristique adapté aux circonstances. Donc les planificateurs au niveau ont tout intérêt à partir des outils simples et parcimonieux afin de guider l'achat de véhicules et les décisions d'allocation des outils qui utilisent les informations stylisée de la demande globale 
pour inférer la structure générale des politiques optimales. Bien sûr, la validité des politiques qui sont façonnées par ces outils devraient être comparés avec les politiques détaillées calculable à partir des modèles détaillés lorsque des données sont disponibles.

Nous cherchons à identifier les meilleures politiques d'achat de véhicules pour les organisations humanitaires engagées dans des programmes de développement ainsi que tirer des aperçus généraux sur les caractéristiques de ces politiques sous diverses conditions opérationnelles.

L'accent est mis sur les programmes de développement car, malgré leurs importantes dans les activités d'organisation humanitaire, ils ont reçu moins d'attention par rapport aux opérations de secours.

Nous envisageons une approche inductive en deux étapes. Lors de la première étape expliquée dans le chapitre 2 , nous étudions les opérations du CICR dans trois pays représentatifs (Soudan, l'Afghanistan et l'Éthiopie) pour lesquels des données détaillées sont disponibles. Nous avons analysé les opérations du CICR dans ces pays sur des données entre 2000 et 2007. Ces dernières sont idéales pour une recherche sur le terrain car chacun de ces pays est très représentatif de leurs opérations.de plus, Ce sont les pays où le CICR avait ses plus grandes flottes. En outre, chaque pays est représentatif d'un environnement d'exploitation typique en ce qui concerne le climat, la géographie, les infrastructures, et la mission. Toutes les délégations ont été équipées de $4 \times 4$ Land Cruiser Toyota qui est le plus utilisé pour les missions humanitaires.

Compte tenu de ces données, nous avons effectué une analyse empirique pour estimer le coût du véhicule et les paramètres de capacité. Ensuite, un modèle de programmation linéaire (LP) a été appliqué afin de calculer la taille optimale de la flotte dans chaque pays, puis cette taille a été comparée avec la politique mise en œuvre par le CICR.

Notre modèle proposé optimise la taille de la flotte du véhicules au niveau des délégations nationales, où les décideurs peuvent avoir accès à des données détaillées sur leurs véhicules et de la demande estimée. L'objectif est d'identifier le nombre de véhicules à un âge donné et pendant une période déterminée qui minimise le coût total induits par la flotte au fil du temps. Notre modèle proposé 
comprend trois principaux coûts dans la fonction objectif qui est en accord avec des études précédentes considérant le même problématique pour les flottes commerciales: coût d'achat, frais d'entretien, et de la valeur résiduelle des véhicules à la fin de leur vie opérationnelle (c'est une occasion parce que le coût SH peut récupérer une partie de cette valeur par la revente des véhicules localement à un prix). Nous ne considérons pas explicitement les coûts de carburant dans notre modèle, car la consommation de carburant varie beaucoup moins que les coûts de maintenance en fonction de l'âge des véhicules. Toutes les fonctions de coût sont actualisées en utilisant un taux d'intérêt annuel et tous les budgets et les flux de trésorerie sont donnés en termes réels. Étant donné que toutes nos variables de coûts dépendent du pays, le modèle est résolu d'une manière efficace au niveau des délégations nationales.

L'ensemble de contraintes contient la limitation budgétaire, la contrainte des ventes, la contrainte de niveau de service et le débit équilibre. La contrainte de vente interdire de revendre un véhicule du CICR au cours des 36 premiers mois de sa vie. La contrainte de niveau de service garantit que l'utilisation prévue de la flotte (c'est à dire la distance maximale que les véhicules de la flotte peuvent se déplacer dans une période donnée en fonction de son environnement d'exploitation) est suffisante pour satisfaire la demande de chaque période. Les équations de bilan garantissent la cohérence des stocks de véhicules d'une période à l'autre.

Le modèle LP a été exécuté séparément pour l'Afghanistan, le Soudan et l'Éthiopie. Avec ce modèle, nous cherchons à établir une politique optimale de «référence» qui pourrait être utilisée dans le but de donner des aperçus pour un modèle de contrôle plus général. Donc, il a été exécuté sur la durée entière où nous disposions des données. Les résultats montrent que la politique recommandé par notre modèle LP réduit les variations de la demande et de la taille de la flotte. Pour confirmer cette hypothèse, nous avons mené une série de tests $F$ afin de vérifier si l'utilisation optimale de la flotte montre une variation plus faible que celui de la demande d'une manière significative. Notre analyse au niveau de la délégation confirme que l'utilisation optimale de la flotte est moins variable que la demande, qui est dû également à des contraintes propres aux organisations humanitaires et trouve rarement dans d'autres environnements opérationnels. 
Le modèle LP génère une politique détaillé sur les achats des véhicules et donne des indications intéressantes. Cependant, ces résultats sont seulement valables pour la réalisation particulière de la fonction de demande observés dans nos trois pays sur la période de 2000-2007. Les décideurs au niveau du siège social voudraient relancer le modèle LP afin de tirer des politiques optimales plus général pour des différents scénarios de demande, mais cela prend beaucoup de temps et à la fois sensible aux données, il est donc moins utiles dans le contexte humanitaire où les données ne sont pas facilement disponibles. Nous avons interrogés les responsables du CICR, ils ont confirmé que seules quelques délégations du CICR recueillent des données détaillées sur les opérationnels et généralement ils utilisent des règles ad hoc pour prendre des décisions d'achat de véhicules car l'interaction entre les scénarios de demande et les politiques de gestion de flotte ne sont pas bien compris.

Nous proposons une approche alternative qui est plus pratique afin d'orienter les décisions du siège social: un modèle stylisé qui s'appuie sur les résultats de la LP pour décrire la structure des politiques optimales non seulement dans le cas particulier mais encore sous les différents scénarios de demande. La gouvernance ainsi que les politiques d'achat et d'entretien d'une sous-délégation au niveau central sont imposées par le siège du CICR, c'est pourquoi ils font face à toutes les contraintes qui contribuent à l'utilisation étant moins variable que la demande. Ce fait nous permet de généraliser les résultats de notre modèle de LP et de les utiliser pour construire le modèle du siège. Nous utilisons ce modèle de quadratique afin de caractériser la structure générale de la politique optimale dans le cadre de différents scénarios de demande ainsi que des contraintes opérationnelles. Ce modèle peut être utilisé pour diffèrent but : analyser les propriétés générales de la politique optimale, effectuer des contrôles de validité sur les heuristiques actuellement utilisées par les organisations humanitaires, exécuter des analyses de sensibilité afin de bien comprendre l'impact des changements de paramètres d'entrées sur la politique optimale.

Notre modèle établit des liens entre la dynamique du budget, la dynamique d'utilisation prévue, et les contextes de relation opérationnelle qui n'ont pas été examinés dans la littérature. Nous démontrons que les résultats du modèle de contrôle sont conformes à celles du modèle de LP dans le contexte analysés précis; 
nous discutons également l'applicabilité du modèle quadratique en matière de planification stratégique de l'actif.

Nous avons distingué deux hypothèses pour élaborer le modèle du siège. Premièrement, On suppose que (basé sur les résultats du modèle LP) la variabilité élevé de la taille de la flotte n'est pas optimale. Nous avons donc construit un modèle de contrôle quadratique qui explique la variabilité en pénalisant le taux auquel la taille de la flotte augmente ou diminue au fil du temps. Deuxièmement, on assume que l'efficacité des opérations doit correspondre à l'offre et à la demande à un niveau déterminé par la direction. Notre modèle permet au décideur de choisir ce niveau. Donc, il pénalise moyenne temporelle de surpeuplement et souspeuplement des coûts ainsi que les décisions d'achat qui augmentent la variabilité taille de la flotte au cours de la période de planification. Notez que notre modèle ne pénalise pas la taille de la flotte à la demande décalage à un moment précis, mais plutôt l'inadéquation moyenne dans le temps. En plus de capturer plus précisément la dynamique révélée par le modèle LP, le modèle quadratique est plus facile à utiliser et donc plus efficace.

Le modèle est construit QC optimiser la taille de la flotte à un niveau agrégé, et travaille avec des données qui ne sont qu'approximatifs, car toutes ces raisons, nous utilisons le nombre moyen de véhicules (au lieu de l'utilisation prévue) pour représenter la demande. Observez que la demande moyenne par période en nombre de véhicules peut être facilement déterminée en divisant la demande totale (en kilomètres) par la distance moyenne qu'un véhicule est entraîné par période. Entrées du modèle sont les exigences de la demande et des contraintes opérationnelles, sa sortie est une trajectoire temps taille de la flotte qui remplit ces conditions, tout en minimisant la variation de taille de la flotte. En outre, le modèle permet au décideur de décider combien d'une pénalité à imposer des coûts de stockage et de la variabilité taille de la flotte.

Notre analyse présente plusieurs idées intéressantes. Le modèle de programmation linéaire suggère que, contrairement aux politiques adoptées par la plupart des $\mathrm{SH}$, la taille optimale de la flotte reste relativement stable (selon le scénario de demande spécifique observée dans les trois pays échantillonnés) alors que la demande fluctue,. Le modèle de contrôle quadratique permet d'améliorer notre 
compréhension de la structure générale de la politique optimale et illustre comment cette structure varie selon les caractéristiques de la demande, les niveaux de service souhaités, ainsi que les seuils minimum et maximum pour le remplacement de véhicules.

Nous constatons que, si les organisations humanitaires sont limitées par le taux auquel les niveaux de la taille de la flotte peuvent être changés, alors la politique optimale est d'uniformiser la taille de la flotte en lissant les exigences de la demande. Pourtant, si les organisations humanitaires peuvent remplacer les véhicules fréquemment, face à surpopulation importante et le sous-peuplement et les coûts relativement sans contrainte par les budgets d'approvisionnement, alors la politique optimale consiste à suivre une stratégie dite 'chasse', qui a une structure plus complexe. Parce que le contexte humanitaire satisfait rarement les dernières conditions, nos résultats indiquent également qu'une stratégie de level serait optimale pour la plupart des missions humanitaires. L'analyse présentée ici peut également être utilisé pour identifier les cas dans lesquels les organisations humanitaires peuvent redevenir plus simples, les stratégies d'approvisionnement intuitives ne nécessitant pas de traitement intensif de données de solutions. Par exemple: si les budgets sont serrés, alors à chaque période il suffit d'acheter autant de véhicules que le budget le permet jusqu'à la demande de pointe est finalement rencontré. En outre, nous montrons que la baisse des budgets nécessaires pour les missions dont la fréquence d'oscillation de la demande dépasse la fréquence d'achat de véhicules.

Cette partie de la thèse contribue à la littérature sur la gestion de la flotte humanitaire par ces différents points : (a) prise en compte des contraintes qui sont spécifiques à des opérations humanitaires au niveau sous-délégation, (b) intégration des contraintes (par exemple, les restrictions budgétaires) qui sont liés à l'acquisition de véhicules, et (c) la construction d'un modèle qui préserve la dynamique imposées par ces contraintes et contribue ainsi à nous décrire comment ces dynamiques interagissent avec paramètres de la demande afin de déterminer laquelle des décisions de gestion de flotte sont optimales au niveau agrégé.

Nos conclusions doivent être considérées à la lumière de certaines limitations qui suggèrent des possibilités intéressantes pour de recherches futures. Tout d'abord, 
les modèles sont développés dans le cadre d'une flottille composée de véhicules homogènes. Le cas des flottes hétérogènes peuvent être traités soit par décomposition du problème ou de l'exécution des modèles séparément pour les catégories de modèles différents ou en ajoutant le modèle des indicateurs spécifiques (ce qui serait évidemment augmenter la complexité). Deuxièmement, nous avons supposé que les exigences de la demande sont connues avant la mission et ne changent pas au cours de la mission; clairement, cette hypothèse n'est pas toujours valable. Dans le modèle LP, nous avons supposé aussi que la demande est exogène et indépendante de la taille de la flotte, mais quand les organisations humanitaires augmentent leur taille de flotte, ils peuvent décider d'exécuter des missions plus simples parce qu'ils le peuvent. Pour intégrer ce facteur nous pourrons corriger l'endogénéité par une technique d'estimation en deux étapes et puis ré-exécutez le modèle LP en utilisant les données corrigées. Troisièmement, nous avons supposé qu'un budget constant est disponible dans chaque période. C'est peut-être vrai pour les grandes organisations humanitaires un accès à des ressources financières importantes, mais ce n'est pas vrai pour les petits. Des recherches futures pourraient ainsi examiner les relations entre les politiques d'achat des ressources et de la structure financière des organisations humanitaires et de leurs politiques de gestion de flotte. Enfin, les paramètres du modèle de société en commandite ont été estimés en utilisant les données d'une organisation spécifique. Bien que le CICR est une organisation vaste et assez représentatif humanitaire, la validité de nos résultats devraient être également testées dans d'autres contextes empiriques.

\section{Chapitre 4:}

Le chapitre 4 est consacré à notre second article qui est une étude empirique. Dans ce chapitre, nous analysons la gestion de flotte sur le terrain pour comprendre comment les véhicules sont gérés dans la pratique et comment ils peuvent être gérés correctement. La prestation de services humanitaires aux bénéficiaires, aussi connu comme la distribution last mile (LMD), est l'une des opérations les plus critiques pour les organisations humanitaires. Comme LMD est organisé par des sous-délégations (c.-à-unités d'exploitation situées sur le terrain et géographiquement proche des gens mal), sa performance dépend fortement des conditions locales. Le transport joue un rôle essentiel dans ce contexte. Cependant, les difficultés d'accès physique sont dues à la nature des terrains, des conflits 
locaux, longues distances et de mauvaises infrastructures créent des défis particuliers pour LMD dans les opérations humanitaires.

Pour optimiser les performances de la flotte et maximiser la couverture de la demande, les organisations humanitaires mettent en œuvre des politiques visant à accroître l'utilisation des véhicules et de réduire leur dépréciation physique. Dans cette partie, nous vérifions tout d'abord si les délégations suivent les politiques recommandées par le siège social. Ensuite, nous examinons l'impact des différentes composantes de la politique d'utilisation d'un véhicule sur son utilisation et la dépréciation physique. En fin, nous déterminons s'il existe un compromis entre l'utilisation et la dévalorisation, ou si les organisations humanitaires peuvent améliorer les deux simultanément.

Une politique de gestion de la flotte est basée sur trois décisions majeures. ces dernière affectent le compromis entre l'utilisation et la perte de la valeur résiduelle, notamment: (1) comment attribuer les véhicules aux différents types de missions, (2) comment modifier l'utilisation d'un véhicule sur son durée de vie (par exemple, la façon d'identifier la tendance d'un véhicule d'utilisation optimale) et (3) quand est-ce qu'il faut remplacer un véhicule d'occasion par un nouveau. En utilisant des données fournies par le CICR, nous construisons et examinons plusieurs modèles économétriques pour analyser ces décisions.

Le fait d'attribuer des véhicules aux missions a un véritable impact sur la performance desdites missions de même que sur les frais de gestion d'une flotte. La demande de transport au niveau des sous-délégations se divise en deux groupes: les missions de fortes ampleurs (visites sur le terrain par exemple) et les missions de faibles ampleurs (visites de la ville par exemple). La première catégorie de missions implique de longs trajets, généralement dans des zones à accès limité. La seconde catégorie quant à elle concerne les distances de trajets plus courts pour effectuer habituellement des tâches administratives au sein des villes. Compte tenu de l'impact potentiel de pannes de véhicules (dans certaines régions, les opérateurs humanitaires pourraient être en danger si un véhicule tombait en panne). Pour des voyages sur le terrain, CICR recommande que seuls les nouveaux véhicules "spécialement équipés" soient concernés, contrairement aux véhicules normaux utiles à des fins administratives dans des zones plus sûres. Selon le pays où les opérations sont menées, les véhicules destinés aux missions à 
forte ampleur sont censés être utilisés pour une durée pouvant atteindre deux ans ou pour une distance parcourue estimée à $60000 \mathrm{~km}$. Quant aux véhicules affectés aux missions de faible ampleur, ils le sont jusqu'à la fin de leur vie opérationnelle.

La deuxième décision concerne le mode d'utilisation des véhicules, c'est à dire, l'intensité avec laquelle un véhicule est utilisé pendant les différentes périodes de sa vie opérationnelle. La tendance d'utilisation d'un véhicule permet de dire si un véhicule est utilisé d'une manière plus intensive au début ou à la fin de sa vie opérationnelle. Un véhicule affiche une tendance d'utilisation à la baisse si sa distance parcourue mensuelle diminue avec son âge. Suivant les recommandations du siège social du CICR, il est conseillé d'utiliser un véhicule de manière plus intensive au début de son cycle de vie opérationnelle et moins quand il prend de l'âge ; il s'agit-là d'une tendance à l'utilisation décroissante. En plus de son impact sur l'utilisation des véhicules, une tendance d'utilisation à la baisse est recommandée pour des raisons de sécurité. Pour les organisations humanitaires la probabilité qu'un véhicule ayant un kilométrage total élevé (par exemple, plus de $60.000 \mathrm{~km}$ ) échoue lors d'une mission sur le terrain est forte, mettant ainsi en danger la vie de leurs travailleurs. Enfin, les véhicules d'occasion sont vendus sur le marché local. Actuellement, le standard en ce qui concerne la politique de remplacement des organisations humanitaires (par exemple le CICR, la Fédération internationale et le HCR) nécessite le remplacement des véhicules au bout de 5 ans ou $150.000 \mathrm{~km}$, selon la première éventualité.

À I'heure actuelle, les politiques recommandées sont basées sur l'estimation de certaines organisations humanitaires. Ces estimations font référence à l'impact présumé de différentes décisions opérationnelles sur l'utilisation d'un véhicule ainsi que sur sa valeur résiduelle. Toutefois, à notre connaissance, on note une carence d'études empiriques rigoureuses permettant de quantifier ces impacts et de faire la lumière sur les mécanismes qui les animent.

Nous examinons d'abord s'il existe une justification dans l'attribution des véhicules aux missions. Ensuite, nous examinons l'impact du type de mission sur les véhicules d'amortissement physique. Troisièmement, nous considérons l'impact des différents modèles d'utilisation sur l'utilisation des véhicules et la valeur résiduelle. Enfin, nous analysons l'efficacité de la politique de série du véhicule de 
remplacement proposé par la plupart des organisations humanitaires. Nous abordons ces questions de manière empirique, en analysant les opérations de gestion de flotte d'une grande organisation humanitaire, le CICR, dans quatre pays représentatifs de 2000 à 2010 .

Dans ce chapitre, nous examinons en outre les relations endogènes entre les différents éléments d'une politique de gestion de flotte. Le traitement de ces éléments séparément peut conduire à une sous-estimation/surestimation de leur impact sur la performance de la flotte et inciter les organisations humanitaires à mettre en œuvre des politiques sous-optimales. Par exemple, les véhicules utilisés dans des missions à forte ampleurs devraient être généralement attribué à des missions plus exigeantes (missions sur le terrain notamment) qui peuvent détruire des véhicules plus rapidement. Par conséquent, nous supposons qu'une estimation naïve de l'impact du type de mission sur la valeur résiduelle ne serait pas exacte en ce sens que les véhicules ne sont pas affectés au hasard. L'analyse de ces dépendances montre que notre modèle produit des estimations sans biais, conduisant ainsi à la mise en œuvre des politiques optimales.

La contribution de ce chapitre à la littérature est double. Tout d'abord, l'utilisation des véhicules et les coûts d'amortissement sont soit ignorés soit pris en charge dans les papiers de modélisation. Bien qu'il n'existe aucune étude indiquant comment contrôler ces variables, basée sur des observations de gestion de flotte humanitaire dans la pratique, ce chapitre fournit des estimations robustes des différentes variables qui influencent l'utilisation d'un véhicule et amortissement. Par conséquent, les résultats de ce chapitre peuvent être utilisés dans les travaux de modélisation supplémentaires dans ce domaine. Ensuite, même si la littérature humanitaire se concentre principalement sur la façon de fournir des ressources et des actifs aux sous-délégations, on note une carence notoire d'études sur la manière d'utiliser les actifs (véhicules) de façon à maximiser l'utilisation des équipements et de réduire l'amortissement. Nous pensons que certains de nos résultats ne sont pas seulement limités à la zone humanitaire, mais peuvent être également utile pour le secteur commercial.

La première série d'hypothèses concerne l'allocation type de véhicule, la mission et l'impact du type de mission sur la valeur résiduelle du véhicule. II existe deux types 
de Land Cruisers dans le domaine; normaux et des véhicules spécialement équipés. Par véhicules normaux, il s'agit des Land Cruisers ordinaires équipés de dispositifs électroniques, contrairement aux véhicules spécialement équipés qui comportent de forte suspension, des puissants pare-chocs et des appareils électroniques. Sur terrain dur, ces véhicules sont plus résistants et plus sécurisant en cas d'accident. Ces véhicules sont en outre plus chers que les véhicules normaux. Actuellement, les organisations humanitaires recommandent aux sousdélégations d'allouer tous les véhicules récemment achetés et « spécialement équipés » aux missions de grande importance, puis aux missions faible importance en fonction de leur âge ou du kilométrage total. Toutefois, les véhicules normaux achetés sont destinés aux missions utilitaires de faible ampleur. Nos données montrent que les véhicules sont affectés soit aux missions de faible ou de grande importance, au début de leur vie opérationnelle, et ils ne sont jamais passés à un autre type de mission. Comme les missions de faible ampleur sont mises en œuvre dans les conditions géographiques difficiles, et le plus souvent dans les zones à faible infrastructure, il est raisonnable de supposer que les délégations attribuent les véhicules spécialement équipés aux missions de grande ampleur et de ne jamais changer leur type de mission.

Le second vague d'hypothèses examine l'impact de la deuxième composante de la politique d'utilisation du véhicule, tendance utilisation du véhicule, sur l'utilisation des véhicules et de l'amortissement. Comme mentionné précédemment, la tendance est l'utilisation du véhicule soit en baisse soit en hausse. Un véhicule utilisé plus intensivement au début de sa vie opérationnelle, une fois qu'elle vieillit, affiche une tendance d'utilisation à la baisse. A l'inverse, on note des véhicules dont la tendance d'utilisation est croissante. La deuxième recommandation faite par les organisations humanitaires, d'utiliser des véhicules qui suivent une tendance d'usage à la baisse, est mis en œuvre sur certains véhicules.

Intuitivement, une meilleure utilisation des véhicules devrait être atteinte au détriment de l'amortissement plus élevé des véhicules, ce qui devrait également impliquer une faible valeur résiduelle. Cette idée est également confirmée dans la littérature. Par conséquent, il doit y avoir un compromis entre l'utilisation du véhicule et sa valeur résiduelle. Le troisième ensemble d'hypothèses considère l'existence de ce compromis. 
Nous avons adopté différentes méthodes économétriques pour obtenir les résultats les plus efficaces et impartiales. Nos résultats génèrent des idées intéressantes et de contester la politique d'utilisation en cours. Nous démontrons que la politique d'utilisation du véhicule recommandé par le CICR n'est pas correctement suivie par ses sous-délégations. Contrairement aux hypothèses de départ, les résultats montrent qu'il n'y a pas de raison d'être dans l'attribution des véhicules de types de mission.

En outre, nos résultats montrent que la tendance d'utilisation d'un véhicule n'a pas un impact significatif sur la valeur du véhicule résiduelle. une tendance d'utilisation à la baisse recommandée par les organisations humanitaires n'ont pas d'impact positif sur l'utilisation des véhicules et ne permet non plus d'améliorer la sécurité des humanitaires. Nous concluons à l'existence d'une politique optimale d'utilisation du véhicule. Celle-ci devrait être universellement appliquées à tous les véhicules quel que soit leur type de mission.

Nous démontrons enfin que, en moyenne, un taux d'utilisation dévalorisation de compromis n'existe pas et qu'une politique bien conçue de gestion de flotte conduit à une meilleure utilisation des véhicules et à la dépréciation physique inférieure. Nos résultats montrent qu'un compromis entre utilisation-valeur résiduelle peut exister uniquement pour les véhicules qui sont conservés plus longtemps, quel que soit leur odomètre cumulatif. Cependant, nous suggérons que les organisations humanitaires ne peuvent se détacher de ce compromis, en identifiant certaines politiques spécifiques d'utilisation.

Enfin, nos résultats montrent que la politique de remplacement des véhicules mis en œuvre par la plupart des organisations humanitaires n'est pas efficace et doit être revue. Contrairement à la littérature, nous constatons que la perte de la valeur résiduelle d'un véhicule est fonction de son âge. Cela implique que les organisations humanitaires devraient revoir leurs politiques actuelles en matière de remplacement des véhicules.

\section{Conclusion}


Les résultats de cette recherche sont pertinents pour les chercheurs et les organisations humanitaires. Une meilleure compréhension de l'état des opérations humanitaires est nécessaire afin d'identifier les futures recherches sur le sujet et guider les directeurs d'organisations humanitaires dans leur processus de développement. Ce projet de recherche peut être considéré comme l'une des premières tentatives pour expliquer et explorer la gestion de flotte humanitaire. En tant que tel, il vise à fournir une base pour de futures recherches dans ce domaine en fournissant une riche description de la gestion de la flotte humanitaire sur le terrain.

Cette recherche contribue à l'étude scientifique de la gestion de flotte de deux manières. Premièrement, elle établit la gestion de flotte humanitaire comme un sujet distinct de l'OM de recherche digne d'étude et d'analyse. Deuxièmement, alors que les organisations humanitaires peuvent apprendre de leurs homologues commerciaux quand il s'agit de gérer les opérations courantes, le secteur commercial est capable d'apprendre de l'expérience des organisations humanitaires quand il s'agit de la nécessité d'effectuer dans des conditions anormales d'exploitation. Aussi, son importance se trouve dans l'identification des lacunes dans la compréhension d'un phénomène. Enfin, nous mettons en exergue des problématiques constituant des champs de recherches futures. 


\section{1}

\section{Introduction and Overview}

\subsection{BACKGROUND}

According to the International Disaster Database, only in 2011, natural and man-made disasters directly affected over 210 million of the world's population with economic damage estimated to be more than 360 billion USD [1]. Table 1.1.1 summarizes the impact of disasters on the world population.

There is no globally accepted definition of humanitarian operations. However, it consists of all processes that provide and distribute aid (e.g., food and medicine) to beneficiaries to minimize human suffering and death. Large-scale disasters usually require contribution of the international community. To help the affected country, the international community often channels emergency funds through humanitarian organizations [53]. The core mandate of Humanitarian Organizations 
Table 1.1.1: Impact of Disasters on World's Population 2000-2011

\begin{tabular}{lcccccc}
\hline & 2000 & 2001 & 2002 & 2003 & 2004 & 2005 \\
\hline No. of people affected & $174,283,959$ & $109,027,279$ & $659,332,560$ & $255,791,984$ & $162,189,400$ & $160,787,033$ \\
Economic damages USD & $46,456,153$ & $27,064,439$ & $62,096,559$ & $69,810,350$ & $137,483,178$ & $214,622,533$ \\
\hline & 2006 & 2007 & 2008 & 2009 & 2010 & 2011 \\
\hline No. of people affected & $126,478,731$ & $213,826,413$ & $222,865,222$ & $199,194,163$ & $254,714,471$ & $211,509,291$ \\
Economic damages USD & $34,105,925$ & $75,289,257$ & $190,548,247$ & $48,174,323$ & $150,158,590$ & $363,989,869$ \\
\hline
\end{tabular}

(HOs) is usually defined as relief operations, development programs or both. Relief operations usually are executed in emergency situations when disasters such as famine, earthquakes and floods create the demand for these operations. While such disasters usually require quick response and emergency services, in many cases, HOs continue to serve affected areas for years. These projects, in addition to those designed to enhance the quality of living standards in poor countries, are called development programs [64]. Examples of such programs include health, food, sanitation and social programs. Consequently, against the relief operations that generate an unforeseen increase in the demand, demand in development programs is more stable and predictable [48].

Regardless of their mandate, every year, humanitarian organizations invest billions of dollars for the coverage of their operations [11]. For example, in 2011 alone, the total expenditures of the World Food Program (WFP) exceeded US $\$ 3.8$ billion. HOs' operational costs have been increasing too. As an example, the total expenditures of Oxfom UK soared from $£ 115.1$ million in 2003 to $£ 286.4$ million in 2012 . Yet, despite their magnitude, these efforts are of little use unless the resources deployed reach the right beneficiaries. Last mile distribution and transportation play a significant role in order fulfillment processes. The key element of transportation is vehicle fleet management that is the focus of this thesis.

Fleet management consists of a range of functions, such as fleet sizing, maintenance and utilization policies. There are internal and external factors that affect humanitarian fleet management [49]. Internal factors consist of mandate, background and organizational structure. As mentioned, the core mandate of HOs is usually defined as relief operations, development programs or both. Organizational background shows the past of a humanitarian organization in age and geographic 
coverage aspects. Organizational levels and how decisions are made within the firm indicate organizational structure. Large international HOs typically have four organizational levels: Headquarters, Regional Offices, National Offices (or National Delegations) and Project Offices (or Subdelegations) [49]. Usually the Headquarters (HQ) are established in developed countries and Regional Offices in geographic regions like Asia, Middle East, Africa and America and are in charge of coordinating operations. National Delegations control humanitarian operations at the national level and cooperate with local governments and other humanitarian organizations. Finally, Subdelegations are in charge of the projects and deal directly with operations i.e. they are responsible for the last mile distribution.

To manage their fleet, HOs usually follow a decentralized, hybrid or centralized model. In a decentralized model, decisions regarding how to manage a fleet are made at project level (Subdelegation) in the country of operations. For example CARE International and Medecins Sans Frontieres (MSF-International) follow this model. In a hybrid model, decisions regarding the fleet are shared between the National Delegations and the Headquarters. International Federation of Red Cross and Red Crescent Societies (IFRC), United Nations World Food Program (WFP) and World Vision International (WVI) are examples of HOs that use the hybrid model. In a centralized model, all decisions regarding the fleets are made at the Headquarters level. For instance the International Committee of the Red Cross (ICRC) follows this model. Also, based on real data, approximately $80 \%$ of the fleet in IFRC and WFP is procured following the centralized model [12]. Figure 1.1.1 illustrates a centralized model in which all decisions are made at the Headquarters Fleet Management Unit. All solid lines in the figure show 'request signals' while dashed lines indicate 'response signals'.

\subsection{Motivation}

It is important to learn about the context in which HOs operate and how they best manage their operations, at least for two reasons: (1) effectiveness of humanitarian operations can save lives and, (2) HOs encounter serious financial limitations and therefore, must perform as efficient as possi- 


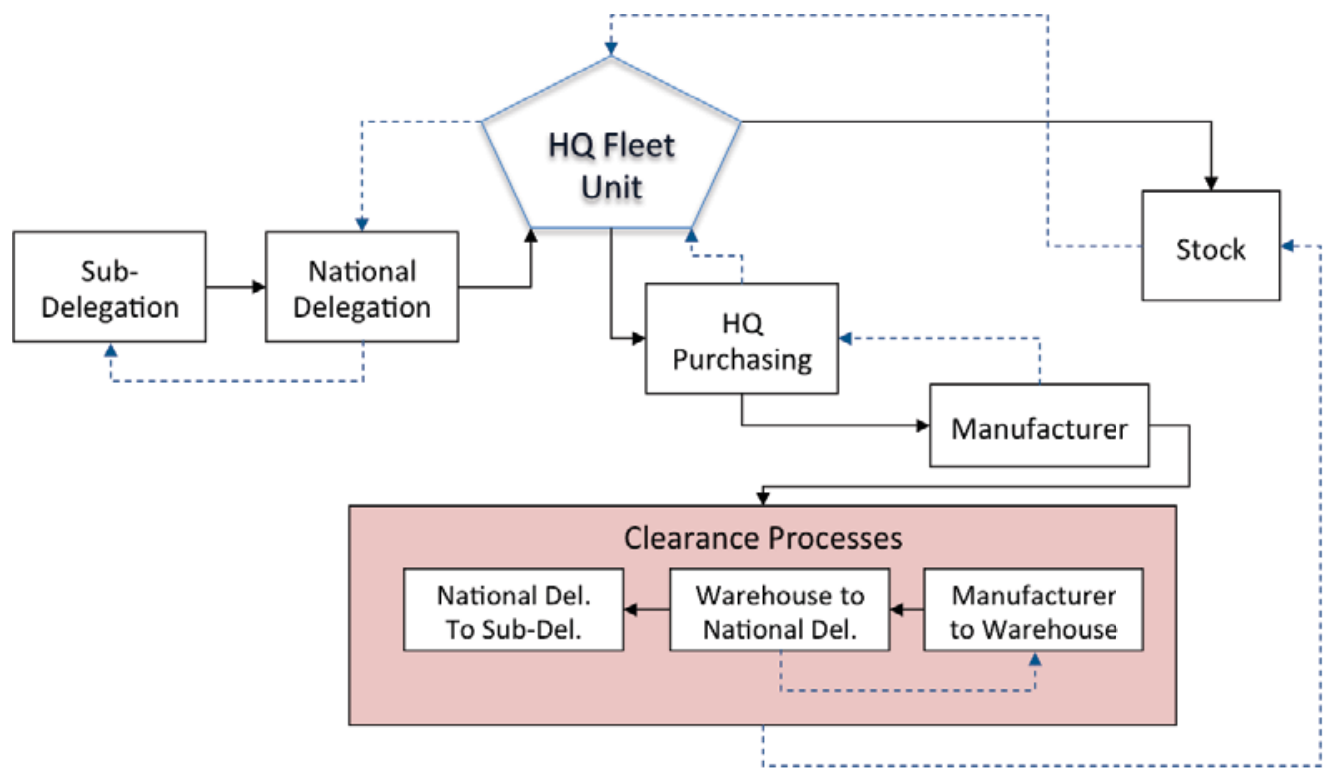

Figure 1.1.1: Centralized fleet management.

ble. Nevertheless, research on humanitarian operations is nascent $[45,53]$. The motivation behind this research study was the serious lack of any basis in terms of conceptual and methodological apparatus in this area.

In many situations, transportation is an internal part of humanitarian operations and HOs usually cannot assign it to a third party [45]. For example, a doctor cannot visit the beneficiaries in remote areas e.g. in Afghanistan, if she does not have a vehicle. Vehicles, in humanitarian development programs, are used to coordinate and execute last mile distribution of program delivery for example:

- the transportation of relief items.

- the transportation of staff coordinating or delivering services to beneficiaries.

- the transportation of staff and materials related to projects e.g. building schools and hospitals. 
In addition, transportation is one of the largest expenditures in humanitarian operations [49]. A recent survey shows that fleet costs are the main concern of $67 \%$ of large international $\mathrm{HOs}$ [2]. Vicente Escrebano, the Head of the Supply Chain of United Nation High Commissioner for Refugees (UNHCR), indicated that the largest asset investments for most humanitarian organizations are fleet or transport related; a fleet, that is managed well, can result in at least $20-30 \%$ cost savings on running costs alone ${ }^{1}$.

Finally, fleet management and transportation affect the visibility of humanitarian organizations. It is assumed that visibility influences the donations (particularly public donations) that HOs receive. For this reason, HOs strongly prefer to use only their own vehicles to gain the most visibility from media. Therefore, they do not share vehicles with other organizations.

Recognizing the pivotal role of fleet management, HOs have recently made efforts to improve their fleet management. For example, International Federation of Red Cross and Red Crescent Societies (IFRC), operating in 187 countries, have designed and implemented new standards on how to manage and utilize its fleet vehicles. The International Committee of the Red Cross (ICRC), operating in 80 countries, has enhanced its centralized fleet management system through 'Fleetwave software' that increases data quality and analytical capabilities at the Headquarters level. Another large international HO operating in 75 countries, World Food Program (WFP), has installed Global Positioning System (GPS) to track the utilization and performance of all individual vehicles. Despite these recent efforts in some of the large international humanitarian organizations, most of HOs still run their fleets inefficiently and ineffectively.

Humanitarian Organizations and their commercial counterparts can learn from each other. However, humanitarians cannot copy solutions that come from the commercial sector due to the challenges attached to humanitarian operations. These challenges are usually defined by the type of disaster, the phase of disaster life cycle [36], geographical context (e.g., roads and infrastructure) and prevalent conditions (e.g., safety) [8]. Nevertheless, we summarize the main challenges attached to fleet management in development programs as follows:

\footnotetext{
${ }^{1}$ Fleet Forum, 2012, Geneva, Switzerland.
} 
- Poor infrastructure: humanitarian operations that are run in areas with poor infrastructure $[25,28,35,62]$ and lack of reliable transportation routes that lead to demand locations. For example, over $60 \%$ of the population of 15 countries in sub-Saharan Africa do not access to all-season roads [6].

- Level of conflict: problems created in conflict zones [64] concern HOs about how to allocate vehicles to missions. For instance, in some areas humanitarians might be in danger if a vehicle fails during a relief mission. As a result, they assign only newer vehicles to field missions and allocate older vehicles to administrative tasks in urban areas [60]. Security problems and poor infrastructure make vehicle usage patterns in development programs very different from those in commercial supply chains. Vehicle usage pattern is explicitly considered in our study.

- Lack of communication and coordination: Lack of holistic perspective and coordination processes within HOs leading to extra cost or lower performance [49]. The economic impact of this issue will be disclosed in our study.

- Financial limitations: budget constraints and donations that are frequently earmarked [7, 20] thereby adding extra limitations to the procurement of new vehicles. For example, World Food Program could roughly cover only $25 \%$ of its expected goals in 2011.

- Long procurement lead-times: working in regions with abnormal infrastructures (e.g., unpaved roads) narrows options with regard to procuring proper vehicles. Vehicles must be reliable and specifically equipped for relief mission purposes and are not readily available on the local market of poor countries where development programs are run. As a consequence, HOs must order directly from manufacturers, an approach which can bring cost advantages to $\mathrm{HOs}^{2}$. At the same time, it increases procurement lead-time up to six months because manufacturers must create extra production runs [49].

- Lack of data: lack of data is a serious problem in humanitarian operations. Due to financial

\footnotetext{
${ }^{2}$ Manufacturers usually sell vehicles to HOs at a lower price than that available on the local market. Moreover, large HOs like the ICRC normally benefit from a duty free status and do not pay registration taxes in the countries of operation. As described in [49], registration costs can be more than $100 \%$ of the purchasing cost of the vehicle in certain cases.
} 
limitations and lack of trained staff, HOs are not able to develop their IT infrastructure and collect operational data regularly. Consequently, in many situations, they have to make decisions (e.g. fleet sizing decisions) qualitatively that are not, of course, optimal decisions.

Considering the aforementioned challenges, the present dissertation suggests solutions to improve humanitarian fleet management through minimizing the operational costs while maximizing the HOs' fleet performance.

\subsection{Research Objectives and Questions}

Research questions in humanitarian fleet management can be categorized into two main groups that each are related to specific decisions that fleet managers must make:

1. At macro level and related to vehicle procurement

2. At micro level and related to vehicle usage

The first group contains questions such as optimal fleet sizing, efficient and effective procurement models, supplier selection and contract mechanism. The second group relates to questions such as individual vehicle replacement policy, vehicle routing and scheduling problems, vehicle reliability and maintenance, and vehicle-mission assignment and utilization. In terms of costs, both groups are equally important. Pedraza Martinez et al. [49] explain that $50 \%$ of the whole fleet costs can be minimized through an optimal vehicle procurement policy while the rest of the fleet costs are related to vehicle usage at the field.

In this thesis, two questions are addressed. Focusing on a centralized fleet management model, we first define an optimal procurement policy that minimizes procurement costs. We consider a centralized fleet management model because: (1) the literature shows that a centralized model is the most cost efficient model [12] hence a further cost reduction would be valuable, $(2)$ in this model, decisions are made centrally and the HQ has enough power on fleet sizing decisions and finally, (3) we access to the ICRC's dataset that follows a centralized model. Real data provided by 
this organization has made our results more suitable and practical for this type of fleet management.

The aim of the first section is to design an optimal procurement policy that minimizes HOs' procurement costs over time. The objective of our primary model is to minimize procurement costs including maintenance costs, purchasing and residual value. Based on the results of our first model, the second model aims to minimize the costs through minimizing the variation of inventory level (i.e. vehicle). Two significant advantages of our model is that: (1) against the literature, our model is not data intensive (i.e., it minimizes the costs when detail data is not available) and, (2) we consider the impact of individual vehicle replacement policy on fleet sizing at each time instance. This has not been considered in the fleet management literature. Our result has been reported as an academic article that has been accepted for publication.

The second question addressed in this thesis relates to field vehicle fleet management. We consider vehicle utilization policy at the field (Sub-delegation) level to understand ( 1 ) how vehicles are managed in the field and, (2) how they can be best managed to minimize vehicles' physical depreciation while maximizing their utilization. Our results, reported as an academic paper, show that a well-conceived fleet management can increase vehicle utilization while minimizing the related costs significantly. For example, our result show that only ICRC can reduce its fleet costs over US\$ 6 million. This study is the first empirical work in this area. Therefore, its main contribution is to shed light on the dark side of humanitarian fleet management in the field, e.g., it depicts the irrationality existing in the field vehicle fleet management. Therefore, this paper provides a better picture for future research works.

\subsection{Relevance and Contribution of Research}

The results of this research are relevant to researchers and humanitarian organizations. An understanding of the state of humanitarian operations is necessary to identify future research on the subject as well as guiding humanitarian organizations in their development path. This research project can be considered as one of the first attempts to explain and explore humanitarian fleet management. As such, it aims to provide the basis for future research in this area by providing a 
rich description of humanitarian fleet management at the field level.

This research contributes to the scientific study of fleet management in two ways. First, it establishes humanitarian fleet management as a distinct topic of OM research worthy of study and analysis. Second, while HOs can learn from their commercial counterparts when it comes to managing routine operations, the commercial sector is able to learn from HOs' experience when it comes to the need to perform in abnormal operational conditions. Also, it is useful in identifying gaps in our understanding of a phenomenon. Finally, we illustrate uncovered areas that are valuable questions for future research.

\subsection{Structure of The Thesis}

This thesis is structured based on two academic papers. Chapters 2 and 3 are dedicated to our first paper related to procurement policy. In Chapter 2, we propose a model that optimizes fleet size when detailed data is available. Chapter 3 was developed based on the results of Chapter 2. In this Chapter we propose a closed form solution that minimizes procurement costs in the absence of detailed data. Chapter 4 is dedicated to our second paper that is an empirical study. In this Chapter, we analyze fleet management at the field level to understand how vehicles are managed in practice and how they can be managed properly. Finally, Chapter 5 concludes the dissertation and suggests potential research works that are worthy to conduct in the future. Since the thesis is based on the two papers, a comprehensive literature review for each has been presented individually. 
Notice: The Introduction and Literature Review is written

for both Chapters 2 and 3 but it is presented only in this

Chapter.

\section{2 \\ Optimal Fleet Sizing}

\subsection{ABSTRACT}

Transportation is critical to order fulfillment in the operations of humanitarian organizations (HOs) and a major source of expenditure. Acquiring, maintaining, using, and disposing of vehicles are key components of this activity and a challenge for HOs. Chapters 2 and 3 aim to identify optimal vehicle procurement policies for organizations engaged in humanitarian operations and to derive general insights on the characteristics of these policies. Toward that end, we follow an inductive approach. In this Chapter, we study the operations of the International Committee of the Red Cross (ICRC) in three representative countries: Sudan, Afghanistan, and Ethiopia. Using a linear programming model primed with field data provided by the ICRC, we calculate the optimal vehicle fleet size and compare it with the policies actually implemented. 


\subsection{INTRODUCTION}

International humanitarian organizations operate worldwide to run relief operations and development programs. Relief operations address emergency situations created by such disasters as famine, earthquakes, and floods, all of which require immediate response on a short-term basis. In contrast, development programs aim to provide long-term support and to improve living standards in poor countries. Such programs may run for years after a disaster, and they are the second main activity of HOs [64].

Transportation plays a pivotal role in both relief operations and development programs. It is a vital element of the demand fulfillment process [64] and, after personnel, the second-greatest $\mathrm{HO}$ operating expense [18]. Much of the transportation-related costs are associated with fleet management - that is, the acquisition, maintenance, use, and disposal of vehicles. It is not surprising that international HOs have begun to pay more attention to this issue, given the expected cost savings and performance improvements associated with optimized fleet management processes.

Decisions on fleet size are especially challenging for humanitarian organizations because of the unusual environments in which they must operate [48]. Security problems, poor infrastructure, and lack of reliable routes make vehicle usage patterns in $\mathrm{HO}$ contexts much different from those in commercial supply chains $[28,35,62]$. Security problems in conflict zones [64] affect the allocation of vehicles to missions. In some areas, humanitarian operators may be in danger if a vehicle breaks down; hence only new vehicles can be used for field trips while older vehicles must be used for administrative purposes in safer zones [60]. Earmarked donations $[7,20]$ hamper the procurement process because they make it difficult for HOs to adjust their budgets in response to changing operational requirements. Humanitarian organizations also face long procurement lead times. Operating in areas with poor infrastructure they need specially equipped vehicles that must be ordered directly from manufacturers. Maintenance, too, is a challenge: in developing countries, auto dealers may not be trustworthy, outsourcing options are limited, and obtaining spare parts can be difficult. Finally, poor coordination and the lack of an adequate information technology (IT) infrastructure creates extra costs and may lower performance even further [49]. 
In addition to the operational constraints just described, the peculiar decision-making process of humanitarian organizations creates additional challenges. Most HOs have a three-level structure: headquarters (HQ), which is usually established in a developed country, is responsible for strategic planning and budgeting decisions; national delegations coordinate activities within a country and are usually established in that country's capital city; and sub-delegations are operational units, spread over many locations in the country, that run projects in the field. Although vehicles are deployed at the local level, fleet planning decisions are made by HQ at the aggregate level. In a centralized procurement procedure, such as the one used by the International Committee of the Red Cross (ICRC), sub-delegations send requests to the national delegation, which in turn uses sub-delegation data to derive an estimate of total demand that is submitted to HQ. Headquarters then uses these national estimates to decide how many vehicles should be purchased and shipped to delegations worldwide. However, owing to the lack of adequate IT infrastructure and poor communication between different organization layers, HQ seldom has complete and accurate information upon which to make decisions.

Given these idiosyncratic characteristics, standard fleet management practices derived in commercial supply chains are unlikely to be easily applicable to humanitarian organizations. Furthermore, an HO's unusual procurement process creates certain problems for decision makers. At the HQlevel, central planners are responsible for making fleet size decisions on behalf of national delegations (and, by extension, their sub-delegations). Yet monitoring is expensive [48], so HQ seldom has the detailed demand and cost data needed to optimize decisions. Hence fleet sizes are often established qualitatively by using simple, ad hoc heuristics. Central planners would therefore benefit from simple and parsimonious tools to guide vehicle procurement and allocation decisions - tools that use stylized aggregate demand information to infer the general structure of optimal policies. Of course, the validity of policies shaped by these tools should be compared with the detailed policies computable from detailed models when data are available.

Despite the relevance of fleet management from both an academic and a managerial perspective, the literature on aggregate-level fleet sizing in development programs is sparse. This paper (Chapters 2 and 3 ) aims to fill that void. We seek to identify optimal vehicle procurement policies for humanitarian organizations engaged in development programs and also to derive general 
insights on the characteristics of these policies under various operational conditions. The focus is on development programs because-despite representing a significant part of an HO's activities-they have received less attention than relief operations. We take an inductive approach in two steps. In the first step, explained in this Chapter, we study ICRC operations in three representative countries (Sudan, Afghanistan, and Ethiopia) for which detailed data are available; given these data, we empirically estimate vehicle cost and capacity parameters. We next apply a linear programming (LP) model to calculate the optimal fleet size in each of these countries and then compare this size with the ICRC's implemented policy. The second step, described in the next Chapter, consists of drawing upon the results of this LP model to develop a stylized quadratic control (QC) model that, while preserving the properties of the LP solution, is more parsimonious and has data requirements compatible with the data typically available at $\mathrm{HO}$ headquarters. We use this quadratic control model to characterize the optimal policy's general structure under different demand scenarios and different operational constraints. We demonstrate that, in the specific context analyzed, the results of the control model are consistent with those of the LP model; we also discuss the quadratic model's applicability to strategic asset planning.

Our analysis yields several interesting insights. The linear programming model suggests that, in sharp contrast to the policies adopted by most HOs, the optimal fleet size remains relatively stable (under the specific demand scenario observed in the three sample countries) even when demand fluctuates. The quadratic control model increases our understanding of the optimal policy's general structure and illustrates how that structure varies with demand characteristics, desired service levels, and the minimum and maximum thresholds for vehicle replacement.

The rest of this Chapter is organized as follows. In Section 2.3 we position our research with respect to the extant literature. Section 2.4 describes our research setting. Finally, section 2.5 describes the linear programming model and its application to ICRC operations in Sudan, Ethiopia, and Afghanistan. 


\subsection{LiterATURE REVIEW}

The humanitarian operations literature has studied fleet management in the context of both relief operations and development programs, where the focus varies to reflect the different transportation requirements of the two undertakings [49]. In relief operations, vehicles are used for disaster assessment, search and rescue, or emergency aid distribution; they are allocated to tasks based on emergency priorities. In development programs, vehicles are used for delivering aid on a regular basis and for administrative purposes. Because such tasks are seldom urgent, vehicle allocation can be planned in advance to incorporate efficiency goals.

These differences between relief and development programs influence not only their operational objectives with regard to fleet management but also the related academic research. With relief operations, the main goal is to maximize responsiveness and demand coverage; with development programs, in contrast, optimizing use and reducing costs are the main priorities. Scholars studying fleet management for relief operations have dealt mostly with problems of victim evacuation and aid distribution, usually with the objective of minimizing response time. The victim evacuation literature has considered the problem from such various angles as optimal routing [29], optimal shelter locations [54], scheduling helicopters [10], and pre-positioning assets [52]; this literature has also examined a number of trade-offs, including the cost of evacuation versus the cost of false alarms [50], travel distance versus clearance time [61], and safe area capacity versus traveling distance $[51]$.

Research on aid distribution has focused on optimizing the delivery of aid to beneficiaries while maintaining the general objectives to minimize travel time between demand points and maximize demand coverage. Scholars have focused on a variety of issues, which include the dispatching of commodities $[9,69]$, routing vehicles $[8,15]$, planning distribution [66], scheduling cargo [17], and optimizing facility location [32].

Fleet management has received comparatively less attention in development programs than in relief operations [5], even though the former make up a substantial part of any HO's operations. In development programs, scholars have dedicated attention primarily to other themes: identifying 
efficient organizational structures, the effects of earmarked budgets [12], vehicle reliability [45], or incentive mechanisms to guarantee accurate data sharing between delegations and HQ [48].

In a development program there are two primary objectives of fleet management: optimizing vehicle routing, so as to maximize demand coverage; and optimizing fleet sizing, so as to guarantee fleet availability and cost efficiency [49]. However, only the first of these objectives has been adequately studied. For the most part, research on vehicle routing and demand coverage in development programs has followed the same lines as studies addressing similar problems for relief operations $[31]$.

The few studies that deal with vehicle procurement and replacement in development programs have done so at the micro level. In the literature, "micro-level replacement policy" refers to the replacement of each vehicle on an individual basis; a "macro-level replacement policy" determines the optimal fleet size at the aggregate level over time [65] . [47] use dynamic programming to identify the optimal odometer threshold after which individual vehicles should be replaced to minimize operational costs. They show that the ICRC should adopt a threshold of 100,000 kilometers-far below the $150,000-\mathrm{km}$ replacement threshold recommended by the vehicle manufacturer and set by ICRC headquarters.

Studies at the micro level are useful to local managers in sub-delegations, who handle a limited number of vehicles and have the time to manage each of them individually. However, such studies are less applicable at the headquarters level, where central planners can decide on fleet sizes only at the aggregate level and are constrained by the lack of detailed data. Other constraints may also limit the applicability of micro-level replacement policies for HQ. For example, a replacement schedule based on considering each vehicle individually may turn out to be infeasible because of budget limitations. For all these reasons, macro-level studies would clearly be a useful tool for central planners seeking guidance on fleet procurement decisions. Yet we are not aware of any paper that addresses fleet size at the macro level for development programs.

The literature on commercial supply chains has treated the problem of fleet sizing too. It is useful to consider these studies, despite their different operational context, and to assess the extent 
to which their models can be applied to humanitarian development programs - especially with respect to demand uncertainty. This literature has predominantly taken a deterministic approach to the treatment of fleet sizing problems [42]. A representative example of these models is the work of Vemuganti et al. [65], who determine the optimal vehicle replacement schedule by optimizing operating and maintenance costs, vehicle purchase prices, and residual values. We build on it both to develop our LP model's structure and to identify relevant costs.

Among the studies that have incorporated uncertainty is the work of Song and Earl [59]; they address the problems of empty vehicle repositioning and fleet sizing in a two-depot service system after accounting for uncertainty in both vehicle arrival time and vehicle repositioning time but not in demand. Klincewicz et al. [34] treat demand uncertainty by considering variations in the number and location of demand points; they also examine the trade-off between using in-house capacity versus outside carriers to meet demand. Du and Hall [19] consider a fleet optimization problem in a hub-and-spoke network with demand uncertainty and constraints on service level; they use an $(S, s)$ policy to determine the optimal truck inventory level at the network's various nodes for a given and fixed fleet size (thus the focus is on vehicle allocation and not on fleet sizing). List et al. [42] examine a problem that is conceptually similar to ours. They use robust optimization techniques to solve a fleet sizing problem with uncertainty in both demand and vehicle productivity, thereby capturing the trade-off between fleet capacity and service level.

Although these models have the clear merit of treating uncertainty, there are several reasons why they are not easily applicable to the problem under study here. The first reason is data limitations. Stochastic models require knowledge of both the mean and the variance of the demand process. Although such information is usually available for commercial operations, in the humanitarian sector it is nearly impossible to find reliable data on variability. When limited access to information is a recurring problem, data-intensive models cannot be easily used for strategic asset planning purposes. Note also that these models do not address the exact same problem studied in this paper. In some cases, they consider solutions that are not easily implementable in the humanitarian context [34] or analyze operational contexts different from ours [19]. In other cases, they address sources of uncertainty that are not a primary concern for development programs [59]. More importantly, they do not account for certain identifying characteristics of humanitarian operations, such as age- 
dependent vehicle usage patterns and procurement and reselling constraints. And even for models that might incorporate such constraints, computational complexity would be magnified [42].

In light of these limitations, our paper takes a deterministic approach and a macro-level perspective to the analysis of fleet sizing problems in development programs. We develop a linear programming model and a stylized quadratic control model, both of which minimize total costs over time (subject to the typical operational constraints of a large $\mathrm{HO}$ ). Our deterministic approach is motivated by other reasons as well. We focus on a relatively novel problem in the humanitarian operations literature and so, before modeling demand scenarios that are more complex, it is helpful first to examine the fundamental mechanisms - and the trade-offs - affecting the performance of fleet management. Simple models are both easier to use and more suitable for garnering useful general insights. Moreover, the potential error due to neglecting demand uncertainty is small in this case; development programs are defined well in advance and have less variability than do other humanitarian endeavors and also some commercial operations [48].

This paper (Chapters 2 and 3 ) contributes to the literature on humanitarian logistics in development programs by focusing on fleet procurement decisions at the macro (i.e., aggregate) level. It complements and extends - along several dimensions — the work of [47], who study vehicle replacement policies from a micro-level perspective. These authors model the optimal replacement of a single vehicle. We consider the problem from a macro-level perspective and develop an aggregate fleet sizing model; this model allows us to determine how many vehicles are needed over a given period of time under a particular demand curve and subject to certain budget constraints. Whereas Pedraza Martinez and Van Wassenhove [47] focus on the frequency of individual vehicle replacement, we focus on changes in fleet size at the aggregate level. Their result establish that vehicles should be replaced sooner than stipulated by ICRC headquarters and sooner also than the actual practices of sub-delegations. Our results indicate that the ICRC should not change the total number of vehicles too abruptly.

One advantage of adopting this macro-level perspective is that doing so enables our consideration of such constraints as meeting demand and not exceeding monthly budgets, constraints that do not apply at the individual vehicle level yet are important at the fleet level. Note also that, unlike 
many studies in this area, we posit a model that describes the general structure of optimal policies - in other words, irrespective of the empirical context in which they are implemented.

Although we build upon Vemuganti et al. [65] to develop our LP model and to identify relevant fleet management costs, our work differs from most research on commercial fleet management in that it accounts for two identifying characteristics of humanitarian operations. First, although the vehicle usage pattern in commercial fleets does not vary with age (e.g., a five-year-old vehicle is supposed to operate no less than a recently purchased one), in humanitarian supply chains a vehicle's usage typically decreases with age. We take this phenomenon explicitly into account and use empirical methods to estimate the rate of this decrease. Second, macro-level models from the commercial sector typically ignore the role of replacement thresholds for individual vehicles; our models take this role explicitly into account as well.

In sum, our paper contributes to the literature on humanitarian fleet management by (a) considering constraints that are specific to humanitarian operations at the sub-delegation level, (b) incorporating constraints (e.g., budget limitations) related to vehicle procurement, and (c) constructing a model that preserves the dynamics imposed by these constraints and thereby helps us describe how those dynamics interact with demand parameters to determine which fleet management decisions are optimal at the aggregate level.

\subsection{Research SetTing}

In order to ground the study, we analyzed the operations of the International Committee of the Red Cross between 2000 and 2007 in three representative countries: Ethiopia, Sudan, and Afghanistan. We received two data sets from ICRC headquarters in Geneva as part of the collaboration between the INSEAD Humanitarian Research Group and the ICRC Fleet Management Unit. This information was complemented by several interviews with representatives of the ICRC and other HOs that attended the 2011 International Fleet Forum in Geneva.

Over the period of our analysis, ICRC had established 29 sub-delegations in the countries we 
selected. The ICRC suggested that the three countries make for an ideal research field because each is highly representative of their operations. These are also the countries in which the ICRC had its largest fleets (on average, 265 vehicles in Sudan, 187 in Afghanistan, and 139 in Ethiopia). Furthermore, each country is representative of a typical operating environment with regard to climate, geography, infrastructure, and mission. All sub-delegations were equipped with the most frequently used vehicle for humanitarian missions, the $4 \times 4$ Toyota Land Cruiser. This light-duty vehicle is used to transport both staff and freight (up to a weight limit) and is well suited for working in the difficult environmental conditions that ICRC operators typically face.

Similarly to what we observed at other HOs, the ICRC's vehicle procurement process is centralized. Sub-delegations periodically provide estimates of their demand for transportation services to their national delegation, which aggregates the information and submits requests to HQ. Headquarters then uses these estimates in determining how many vehicles to purchase from the manufacturer and how they should be allocated to sub-delegations.

Like other HOs, the ICRC is tied (with this vehicle's manufacturer) to a commercial agreement that dictates specific constraints related to procurement. For example, the ICRC purchases vehicles at below-market prices, but it is not allowed to resell any vehicle before it is three years old. The manufacturer may also impose minimum and maximum purchasing quantities. Combined with budget limitations, such requirements further constrain an HO’s procurement process.

The most important characteristics of the ICRC fleets in our three sample countries are described in Table 2.4.1 and Table 2.4.2, which summarize the two data sets we received. The first, an unbalanced panel data set with monthly observations, covers all the vehicles used by the ICRC in Sudan, Afghanistan, and Ethiopia for the period 2000-2007. For each vehicle and time period (month), this data set reports the country of operation, the vehicle's identification code, the distance traveled, the vehicle's age, and the sub-delegation that used the vehicle. This data set is an extension of the one used in [47]; it differs in that (i) it covers a longer time period and (ii) it has been cleared of potential outliers with unrealistic odometer readings. Descriptive statistics are reported in Table 2.4 .1 . 
Table 2.4.1: ICRC fleets 2000-2007: average distance travelled

\begin{tabular}{|c|c|c|c|c|c|c|}
\hline Country & & Mean & Median & Std. Dev. & Min. & Max. \\
\hline Afghanistan & Obs $=89$ & & & & & \\
\hline Age & (months) & 35.483 & 35 & 17.146 & 1 & 89 \\
\hline Average Distance Travelled & (kms) & $1,167.764$ & 1,029 & 957.045 & $\mathrm{o}$ & 9,800 \\
\hline Ethiopia & $\mathrm{Obs}=116$ & & & & & \\
\hline Age & (months) & 35.080 & 32 & 21.924 & 1 & 113 \\
\hline Average Distance Travelled & $(\mathrm{kms})$ & $2,113.694$ & 1,870 & $1,528.494$ & o & 9,997 \\
\hline Sudan & $\mathrm{Obs}=106$ & & & & & \\
\hline Age & (months) & 21.203 & 20 & 12.177 & 1 & 63 \\
\hline Average Distance Travelled & $(\mathrm{kms})$ & $1,181.823$ & 858 & $1,282.368$ & $\mathrm{o}$ & 9,903 \\
\hline
\end{tabular}

The second data set that we received is a cross-sectional one covering the ICRC fleets for the same countries and time period. This data set includes information on the country of operation, vehicle identification code, vehicle age when it was used for the first time and when it was sold, the subdelegation that used the vehicle, and its residual value. Descriptive statistics for this second data set are given in Table 2.4.2, where "CHF" denotes "Swiss francs".

Table 2.4.2: ICRC fleets 2000-2007: vehicle age and residual value

\begin{tabular}{llccccc}
\hline Country & & Mean & Median & Std. Dev. & Min. & Max. \\
\hline Afghanistan & Obs=187, 101 active & & & & & \\
Active & Age (years) & 4.59 & 5 & 1.75 & 1 & 8 \\
Sold & Age (years) & 7.70 & 8 & 1.95 & 4 & 12 \\
& Residual value (CHF) & 7,197 & 6,510 & 2,809 & 1,287 & 13,536 \\
\hline Ethiopia & Obs=139, 95 active & & & & & \\
Active & Age (years) & 4.61 & 5 & 2.41 & 1 & 14 \\
Sold & Age (years) & 7.75 & 8 & 1.92 & 2 & 14 \\
& Residual value (CHF) & 16,555 & 16,486 & 6,305 & 6,349 & 27,612 \\
\hline Sudan & Obs=265, 189 active & & & & & \\
Active & Age (years) & 3.47 & 3 & 1.41 & 1 & 10 \\
Sold & Age (years) & 7.12 & 8 & 2.82 & 1 & 12 \\
& Residual value (CHF) & 12,470 & 11,000 & 7,305 & 3,030 & 45,139 \\
\hline
\end{tabular}

Because some of the parameters we estimate for the LP model are time independent, we converted the first data set (which had a panel data structure) into a cross-sectional format so that it 
could be merged with the second data set. The conversion proceeded by computing the averages (over time) of all the time-dependent variables. The new, combined database was then used to estimate the model parameters (see Section 4.2).

In the section that follows we use the data on ICRC operations during 2000-2007 in Sudan, Afghanistan, and Ethiopia in order to identify the optimal fleet management policies that should have been used in these countries over the period analyzed. Toward that end, we build a linear programming model that minimizes total costs subject to the ICRC operational constraints.

\subsection{Linear Programming Model for Vehicle Fleet Sizing}

\subsubsection{Notation ANd Model Formulation}

The purpose of this section is to construct an LP model that optimizes vehicle fleet sizing at the national delegation level, where decision makers may have access to detailed data on their vehicles and estimated demand. In Section 4.2 we describe how this model's parameters were estimated from field data. Then, in Section 4.3, we present and discuss the results by comparing the optimal fleet size and the optimal cost as calculated by our LP model with the actual fleet size and the actual cost (i.e., the fleet size and cost resulting from the ICRC's implemented policy). Notation is summarized in Table 2.5.1.

Equations (2.1) - (2.7) describe the objective function and the model constraints. The decision maker's objective is to identify the number of vehicles of age $a$ in period $t$ (i.e., $x_{a, t}$ ) that minimizes the total cost associated with fleet management from $t=\mathrm{o}$ to $t=T$, subject to some operational constraints. Cost functions are discounted using an annual interest rate of $i$, and all budgets and cash flows are given in real (not nominal) terms. In any period $t$, the optimal fleet size $x_{a, t}$ is determined by choosing the number of new vehicles to be purchased, $u_{t}$, and the number of vehicles of age $a$ that should be sold, $s_{a, t}$. Note that the vehicle purchase price $p$ is independent of age whereas both the residual value, $r_{a}$, and the maintenance cost, $h_{a}$, are a function of vehicle $a$. Because vehicle allocation decisions are revised monthly, each period in the model is a month. For notational 
Table 2.5.1: Model Notation

\begin{tabular}{|l|l|l|}
\hline Group & Symbol & Description \\
\hline \hline \multirow{4}{*}{ Indices } & $t$ & Time period, in months, $t=0,1,2, \ldots, T$ \\
\cline { 2 - 3 } & $a$ & Age of vehicles, in months, $a=0,1,2, \ldots, A$ \\
\hline \hline \multirow{5}{*}{ Parameters } & $h_{a}$ & Maintenance and miscellaneous costs of a vehicle with age $a$ \\
\cline { 2 - 3 } & $r_{a}$ & Residual value of a vehicle with age $a$ \\
\cline { 2 - 3 } & $p$ & Purchasing price of a vehicle \\
\cline { 2 - 3 } & $d_{a}$ & Planned usage of a vehicle with age $a$ \\
\cline { 2 - 3 } & $B_{t}$ & Available budget for period $t$ \\
\cline { 2 - 3 } & $i$ & Annual interest rate \\
\cline { 2 - 3 } & $D_{t}$ & Demand in period $t$ (in kilometers) \\
\cline { 2 - 3 } & $x_{a \circ}$ & Number of vehicles with age $a$ at the beginning of planning horizon \\
\hline \hline \multirow{5}{*}{ Variables } & $x_{a t}$ & Number of vehicles with age $a$ in period $t$ \\
\cline { 2 - 3 } & $s_{a t}$ & Number of sold vehicles with age $a$ in period $t$ \\
\cline { 2 - 3 } & $u_{t}$ & Number of purchased vehicles in period $t$ \\
\hline
\end{tabular}

convenience, we consider the first decision as being made at $t=0$.

In accordance with previous studies that have addressed the same problem for commercial fleets [65], our model includes three major costs in the objective function (1): purchasing cost, maintenance costs, and the residual value of vehicles at the end of their operational lives (this is an opportunity cost because HOs can recover some of that value by reselling the vehicles locally at a price $r_{a}$ ). We do not explicitly consider fuel costs because fuel efficiency varies with vehicle age much less than maintenance costs. Since all our cost variables are country dependent, the model is effectively solved at the national delegation level.

Objective function: $\quad \min C=\frac{1}{(1+i)^{t}}\left(\sum_{t=0}^{T} \sum_{a=0}^{A}\left(x_{a, t} h_{a}\right)-\sum_{t=0}^{T} \sum_{a=36}^{A}\left(s_{a, t} r_{a}\right)+\sum_{t=0}^{T} u_{t} p\right)$ 
subject to the following constraints.

$$
\begin{aligned}
& \text { Sales constraint: } \quad \forall t>0, \sum_{a=0}^{35} s_{a, t}=0 . \\
& \text { Service level: } \quad \forall t>0, \sum_{a=0}^{A} x_{a, t} d_{a} \geq D_{t} . \\
& \text { Budget limitation: } \quad \forall t, \sum_{a=0}^{A}\left(x_{a, t} h_{a}\right)+u_{t} p \leq B_{t} . \\
& \text { Initial fleet size: } t=0, x_{a, t}=x_{a, 0} .
\end{aligned}
$$

Equations (2)-(8) reflect the ICRC's actual operational constraints. The sales constraint (2.2) accounts for the prohibition against ICRC reselling a vehicle in the first 36 months of its life. The service level constraint (2.3) guarantees that the fleet planned usage (i.e., the maximum distance that vehicles in the fleet can travel in a given amount of time and in a given operating environment) is sufficient to meet estimated demand, $D_{t}$, in each period. Note that $d_{a}$ is the planned usage (in kilometers) of a vehicle of age $a$. Constraint (2.4) captures the limited budgets of ICRC delegations for purchasing new vehicles and maintaining their fleets; note that the revenue generated by reselling vehicles is not included in the budget constraint because it is not re-injected into the fleet management budget of the national delegation (instead, it is channeled back to ICRC headquarters). Constraints (2.5) and (2.6) are balance equations that guarantee the consistency of the vehicle stock from one period to the next. Finally, constraint (2.7) guarantees that the numbers of vehicles purchased, sold, or held in the fleet are nonnegative in each period.

Although the purchase price $p$ is constant, both the vehicle maintenance $\operatorname{cost} h_{a}$ and the residual value $r_{a}$ depend on vehicle age $a$ (note that $a$ represents the age of a vehicle at the beginning of each period). The logic of the model is thus quite intuitive: in any period, if the cumulative maintenance cost of a vehicle is greater than the difference between the purchase price and the vehicle's residual value (i.e., if $p-r_{a}<h_{a}$ ), then the vehicle is replaced; otherwise, it remains in the fleet for (at 
least) one more period.

\subsubsection{Parameter Estimation}

Unlike most papers on disaster management, which use synthetic data $[5,47]$, we use field data to estimate the model parameters empirically. The proprietary data set obtained from the ICRC was used to calculate two variables directly: the planned usage of individual vehicles (i.e., the maximum distance a vehicle can travel in a given time period in a given environment) and the total transportation demand during each period. The planned usage of individual vehicles was then used to compute total fleet planned usage and to estimate maintenance costs and the residual value of individual vehicles.

\section{Fleet Planned Usage}

A distinguishing characteristic of humanitarian fleets is that a vehicle's planned usage $d_{a}$ varies with its age. In commercial fleets, the maximum distance a vehicle can travel in a given period is independent of its age or total odometer. In the humanitarian sector, however, poor infrastructure and safety considerations affect how vehicles are used. For safety reasons, vehicles are not assigned to risky field missions after a specified age $\bar{a}$ (typically 24 months); vehicles older than $\bar{a}$ are used only for safer and shorter trips in urban areas [60]. So in a given period, the maximum distance a fleet can cover depends not only on the number of vehicles in the fleet but also on average fleet age. The influence of these factors is illustrated in Figure 2.5.1, which plots average vehicle usage (kilometers traveled) against vehicle age.

This policy of switching the use (mission type) of vehicles after a critical age threshold implies that the planned usage of a vehicle, $d_{a}$, is best approximated by a two-step function:

$$
d_{a}= \begin{cases}b_{\circ}^{-}+b_{1}^{-} a & \text { if } a \leq \bar{a} \\ b_{\circ}^{+}+b_{1}^{+} a & \text { if } a>\bar{a}\end{cases}
$$


Figure 2.5.1: Vehicle Usage As a Function of Vehicle Age in Afghanistan, Sudan, and Ethiopia

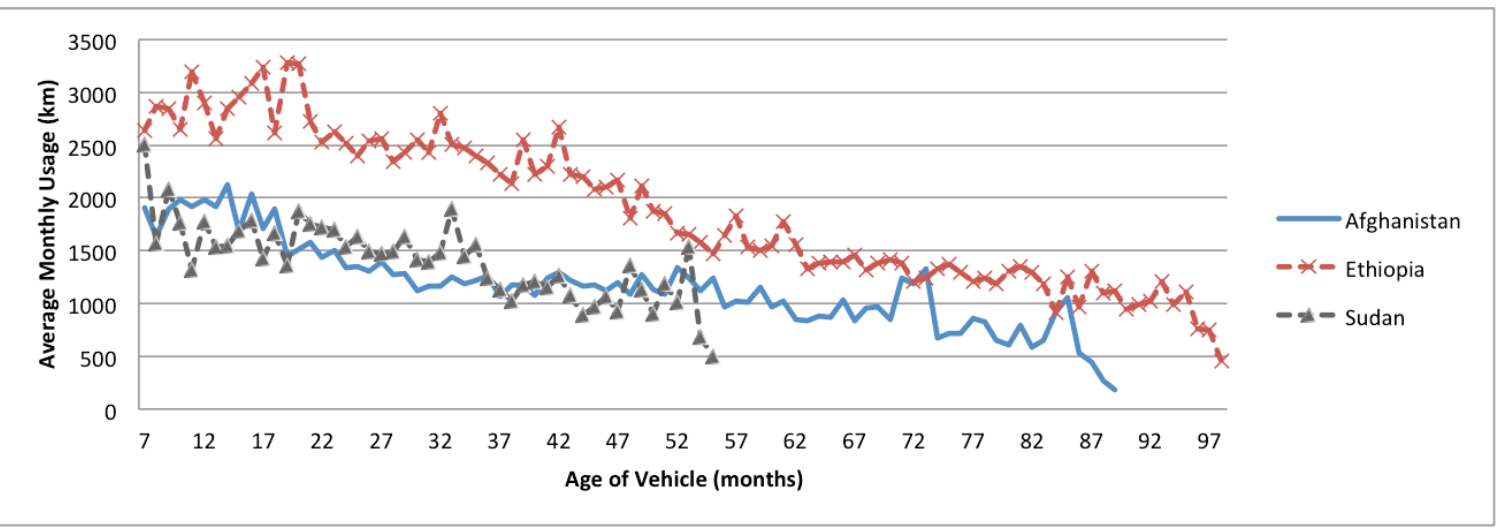

Although ICRC recommends switching mission types after 24 months, in practice the critical age threshold $\bar{a}$ depends on the country of operations (in safer areas, for instance, vehicles can be used longer for field missions; [47]). Calculating the fleet planned usage requires that we estimate the coefficients $b_{1}^{-}$and $b_{1}^{+}$empirically and then determine the age threshold $\bar{a}$ at which switching takes place. For this purpose we used two different approaches: a cross-sectional analysis and a panel data analysis.

In the cross-sectional approach we first estimated equation (2.8) for each country separately using the cross-sectional database. The models were estimated for age thresholds $\bar{a}$ below and above the ICRC policy of $\bar{a}=24$. For each run, we used a Chow test to check for equality between the coefficients $b_{1}^{-}$and $b_{1}^{+}$(i.e., the slopes of the curve before and after the hypothesized critical age threshold). We retained the value of $\bar{a}$ with the highest significance level in the Chow test-in other words, the value of $\bar{a}$ for which the estimates of $b_{1}^{-}$and $b_{1}^{+}$were most significantly different.

The results of this procedure are presented in Table 2.5.2. The null hypothesis of equality between coefficients is rejected for all three countries. One consequence is that assessing the dependence of $d_{a}$ on $a$ through the general model $d_{a}=b_{\circ}+b_{1} a$ while using the same estimated coefficient $\hat{b}_{1}$ for all $a \in[\mathrm{o}, A]$ would yield less accurate results. Moreover, although the coefficient 
estimate $\hat{b}_{1}^{+}$is strongly significant, $\hat{b}_{1}^{-}$is insignificant for all three countries. In the age interval $[o, \bar{a}]$, planned usage does not depend on vehicle age; but after the age threshold $\bar{a}$, planned usage decreases sharply with age. The estimated age thresholds were 18 months for Afghanistan and 23 months for both Sudan and Ethiopia.

Table 2.5.2: Individual Vehicle's Planned Usage: Cross-Sectional Analysis

\begin{tabular}{|c|c|c|c|c|c|c|c|c|c|c|}
\hline \multirow{2}{*}{$\begin{array}{l}\text { Country of } \\
\text { operations }\end{array}$} & \multirow{2}{*}{ Knot } & \multicolumn{3}{|c|}{ Chow test results } & \multicolumn{5}{|c|}{ Age interval regressions } & \multirow{2}{*}{$\begin{array}{l}\text { Planned usage } \\
\left(d_{a}\right)\end{array}$} \\
\hline & & Fcrit. & $F$ & Null hy. & $\hat{b}_{\circ}^{-}, \hat{b}_{\circ}^{+}$ & $\hat{b}_{1}^{-}, \hat{b}_{1}^{+}$ & $p$-value & $t$ & Adj. $R^{2}$ & \\
\hline Afgh & $\begin{array}{l}a \leq 18 \\
a>18\end{array}$ & 3.11 & $17 \cdot 37$ & Rej. & 1676.98 & $\begin{array}{c}2.26 \\
-11.57\end{array}$ & $\begin{array}{l}0.86 \\
0.00\end{array}$ & $\begin{array}{c}0.18 \\
-12.56\end{array}$ & $\begin{array}{c}-0.10 \\
0.69\end{array}$ & $\begin{array}{c}2124.77 \\
1676.98-11.57 a\end{array}$ \\
\hline Ethiopia & $\begin{array}{l}a \leq 23 \\
a>23\end{array}$ & 3.10 & 4.77 & Rej. & $\begin{array}{c}- \\
3180.19\end{array}$ & $\begin{array}{c}2.44 \\
-24.76\end{array}$ & $\begin{array}{l}0.86 \\
0.00\end{array}$ & $\begin{array}{c}0.18 \\
-27.39\end{array}$ & $\begin{array}{c}-0.06 \\
0.91\end{array}$ & $\begin{array}{c}3281.15 \\
3180.19-24.76 a\end{array}$ \\
\hline Sudan & $\begin{array}{l}a \leq 23 \\
a>23\end{array}$ & 3.20 & 21.34 & Rej. & $\begin{array}{c}- \\
2175.62\end{array}$ & $\begin{array}{l}-17.14 \\
-23.51\end{array}$ & $\begin{array}{l}0.23 \\
0.00\end{array}$ & $\begin{array}{l}-1.26 \\
-5.89\end{array}$ & $\begin{array}{l}0.03 \\
0.52\end{array}$ & $\begin{array}{c}2509.65 \\
2175.62-23.51 a\end{array}$ \\
\hline
\end{tabular}

We next used these results to calculate vehicle planned usage as follows. In the interval $(\bar{a}, A]$, we calculated usage via $d_{a}=\hat{b}_{\circ}+\hat{b}_{1}^{+} a$ (where $\hat{b}_{\circ}$ and $\hat{b}_{1}^{+}$are, respectively, the estimated values of $b_{\circ}$ and $b_{1}^{+}$from the regression described previously). In the interval $[\mathrm{o}, \bar{a}]$, where $d_{a}$ is independent of $a$, we followed the approach of Lapre et al. [39] and calculated $d_{a}$ as the maximum monthly distance traveled in the interval $[o, \bar{a}]$. That is, we assumed that if a vehicle was able to cover a given distance in any time period before $\bar{a}$ then it would be able to travel the same distance again in any other time period before $\bar{a}$. The last column of Table 2.5.2 shows the estimated vehicle planned usage in Sudan, Afghanistan, and Ethiopia for the different time intervals of interest.

To validate these results, we re-estimated the relationship between planned usage and vehicle age using a panel data approach with sub-delegation fixed effects; this method allows for different intercepts, but it constrains the slopes to be the same across all vehicles operating in the same sub-delegation. An advantage of the panel data approach is that it does not aggregate observations pertaining to different vehicles with the same age $a$. Yet, it may also reduce the accuracy and explanatory power of the estimates because in our data set there are no observations for some ages. A series of Chow tests confirmed the presence of an age threshold $\bar{a}$ at which the vehicle usage changes and thus the appropriateness of choosing a two-step function to estimate $d_{a}$. Results displayed in 
Table 2.5.3 reveal that the estimates of $\bar{a}$ are only slightly different from those in the cross-sectional analysis but indicate an even sharper change in the slope of the curve at the critical age threshold.

Table 2.5.3: Individual Vehicle's Planned Usage: Panel Data Analysis with Subdelegation Fixed Effects

\begin{tabular}{|c|c|c|c|c|c|c|c|c|}
\hline \multirow{2}{*}{$\begin{array}{l}\text { Country of } \\
\text { operations }\end{array}$} & \multirow{2}{*}{ Groups } & \multirow{2}{*}{ Knot } & \multicolumn{2}{|c|}{ Chow test results } & \multicolumn{3}{|c|}{ Age interval regressions } & \multirow{2}{*}{$\begin{array}{l}\text { Planned Usage } \\
\left(d_{a}\right)\end{array}$} \\
\hline & & & $F$ & Null hy. & $\hat{b}_{\circ}^{-}, \hat{b}_{\circ}^{+}$ & $\hat{b}_{1}^{-}, \hat{b}_{1}^{+}$ & Within $R^{2}$ & \\
\hline Afghanistan & 8 & $\begin{array}{l}a \leq 19 \\
a>19\end{array}$ & $F(2,4628)=28.88^{* * *}$ & Rej. & $\begin{array}{l}1408.65^{* * *} \\
1313.22^{* * *}\end{array}$ & $\begin{array}{c}12.51 \\
-6.19^{* * *}\end{array}$ & $\begin{array}{l}0.02 \\
0.01\end{array}$ & $\begin{array}{c}7209 \\
1313.22-6.19 a\end{array}$ \\
\hline Ethiopia & 11 & $\begin{array}{l}a \leq 25 \\
a>25\end{array}$ & $F(2,4052)=21.97^{* * *}$ & Rej. & $\begin{array}{l}2345.76^{* * *} \\
3145.37^{* * *}\end{array}$ & $\begin{array}{c}9.89 \\
-26.24^{* * *}\end{array}$ & $\begin{array}{l}0.01 \\
0.11\end{array}$ & $\begin{array}{c}9997 \\
3145.37-26.24 a\end{array}$ \\
\hline Sudan & 11 & $\begin{array}{l}a \leq 23 \\
a>23\end{array}$ & $F(2,1732)=3.90^{* * *}$ & Rej. & $\begin{array}{l}1112.84^{* * *} \\
1657.53^{* * *}\end{array}$ & $\begin{array}{c}2.84 \\
-13.15^{* * *}\end{array}$ & $\begin{array}{l}0.00 \\
0.01\end{array}$ & $\begin{array}{c}9903 \\
1657.53-13.15 a\end{array}$ \\
\hline
\end{tabular}

\section{DEMAND}

Several observations suggest that, in development programs, the demand for transportation services is relatively stable and predictable [48]. First, most of the demand fluctuations in these programs are not random; that is, they are due to such assignable causes as the $\mathrm{HO}$ increasing or decreasing its level of activity in a country. These fluctuations are not difficult to predict because HOs neither enter nor exit a country overnight, and the time interval in our analysis is significantly shorter than the planning cycles of most development programs. Second, even if it cannot be completely ignored, unpredictable demand variation in development programs is inherently lower than in relief operations because of the type of activities undertaken (development programs involve long-term health, food, and sanitation initiatives). This length and the repeated nature of development programs allow fleet managers to generate relatively accurate forecasts. Third, even if some inherent variability is observed at the daily or weekly level, its magnitude is greatly attenuated at the monthly level because of pooling effects and because some journeys can easily be backlogged, given the noncritical nature of most development operations.

Sub-delegations do not record actual demand for transportation services in each period, so we used a proxy to estimate this parameter. The total distance traveled by the whole fleet over a given 
time period was used as a reasonable approximation for aggregated demand. The data confirmed our initial observation that demand is relatively stable in development programs as it displays low coefficients of variations. Although total distance traveled is a convenient proxy for aggregated demand, using it may create endogeneity problems due to the correlation between fleet size and number of journeys completed. We conducted additional tests to assess the magnitude of the potential error induced by our proxy, but we found no evidence of endogenity.

First, if the average distance traveled depended on fleet size, then the data describing that distance would be censored. That is, there would be some time periods during which the average distance traveled would be less than the true (unobservable) demand owing to fleet size constraints. For the generic sub-delegation $j$, the data on distance traveled would therefore be generated by the process $D_{j t}=\min \left\{\hat{D}_{j t} ; \sum_{a} x_{j a t} d_{a}\right\}$; here, for each sub-delegation $j$ and period $t, D_{j t}$ is the cumulative distance (in kilometers) traveled by all vehicles in the fleet, $\hat{D}_{j t}$ is the true unobservable demand (also in kilometers), $x_{j a t}$ is the number of vehicles of age $a$, and $d_{a}$ is the planned usage of a vehicle of age $a$.

To assess the potential error caused by observing $D_{j t}$ instead of $\hat{D}_{j t}$, we estimated the regression $D_{j t}=a+b x_{j t}$ using first a panel data model with fixed effects and then a Tobit model with an upper bound on $D_{j t}$ to correct for censoring, where $x_{j t}=\sum_{a} x_{j a t}$ is the fleet size of delegation $j$ in period $t$. Finally, we compared the coefficients obtained via the two estimation methods. Since that comparison revealed no significant differences among the sub-delegations examined, there was no evidence of data censoring nor hence of endogeneity.

Second, if the number of journeys were constrained by fleet size then, at any given time, an $\mathrm{HO}$ would reduce its fleet only if the true unobserved demand fell below the level that could be met with the current fleet. If this were the case then the estimate of coefficient $b$ in the regression $\Delta D_{j t}^{-}=a+b \sum_{a=0}^{A} \Delta x_{j a t}^{-}$would be positive and significant, where $\Delta D_{j t}^{-}$and $\Delta x_{j a t}^{-}$denote negative changes from $t$ ? 1 to $t$ in (respectively) the average distance traveled and the fleet size. However, the estimate of $b$ was not statistically significant in any of the model regressions, indicating once again no evidence of endogeneity bias. We therefore estimate demand through actual supply and demonstrate that this is a good proxy. 


\section{Cost Functions And Budget}

The three cost items in the objective function-purchasing cost, maintenance costs, and residual value of used vehicles-were estimated as follows. Purchasing cost includes the actual purchase price, equipment costs, and vehicle shipment costs; data on these items were obtained through interviews with the ICRC fleet manager. Over the period of our analysis, Toyota charged a fixed and constant price of $\mathrm{CHF} 28$,000 for each vehicle purchased by ICRC.

Maintenance costs include both preventive maintenance costs and miscellaneous costs. A method to estimate the former in humanitarian fleets was developed by Pedraza Martinez and Van Wassenhove [47], who show that maintenance costs are a function a vehicle's odometer reading. Since these authors estimate those costs empirically in the same research setting as the one of this paper (their data set is a subsample of ours), we can use their results. Table 2.5.4 summarizes the applicable formulas. Note that $I_{k}$ is an indicator function for the cost items; it is set equal to 1 if the odometer's reading indicates that it is time to change a part $k$ (and set to o otherwise). The term $I_{\text {bat }}$ is likewise an indicator function for battery replacement, which depends not on the odometer's reading but rather on the vehicle's age. The cost $c_{k}$ is the replacement cost of item $k, \Theta(a)$ is the odometer reading in a vehicle of age $a$, and $l$ is a constant to be determined empirically. Finally, $\gamma_{\circ}$ and $\gamma_{1}$ are the ordinary least-squares regression coefficients used to estimate the residual value of used vehicles. The parameters of the cost functions for an average vehicle of age $a$ were thus calculated using the formulas given in Table 2.5.2 and then used to run our linear programming model.

Table 2.5.4: Cost functions from: Pedraza Martinez and Van Wassenhove [47]

\begin{tabular}{|l|c|}
\hline Cost function & Estimation method \\
\hline \hline Preventive maintenance & $\sum_{i=1}^{13} c_{i} I_{i}+c_{14} I_{b a t}$ \\
\hline Miscellaneous & $l\left(\frac{\Theta(a)}{75000}\right)$ if $\Theta(a) \leq 150000$ \\
& $l\left(1+\frac{\Theta(a)}{150000}\right)$ if $\Theta(a)>150000$ \\
\hline Residual value & $\gamma_{0}+\gamma_{1} \ln (\Theta)$ \\
\hline
\end{tabular}

The ICRC did not disclose data on its actual budgets, so we used an alternative approach to estimating the parameter $B_{t}$. The managers we interviewed suggested that the best way to estimate 
budget figures is to consider the actual fleet cost (which is a conservative estimate of $B_{t}$ ). Hence nominal monthly budgets were simply estimated by dividing the total fleet cost for a given time period by the number of months in that period.

\subsubsection{Results of The LP Model}

The LP model was run for Afghanistan, Sudan, and Ethiopia separately. With this model we seek to obtain a 'reference' optimal policy that could be used to generate insights for the more general control model; therefore, it was run for the entire time span over which we had data (i.e., the parameter $T$ was set equal to the last month in which we had usable observations). The results are plotted in Figure 2.5.2 and Figure 2.5.3, which compare (respectively) optimal with actual usage and optimal with actual fleet size.

Figure 2.5.2: Optimal Capacity vs. Demand (in kilometers)

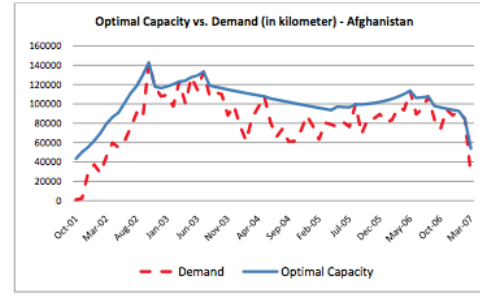

(a) Afghanistan

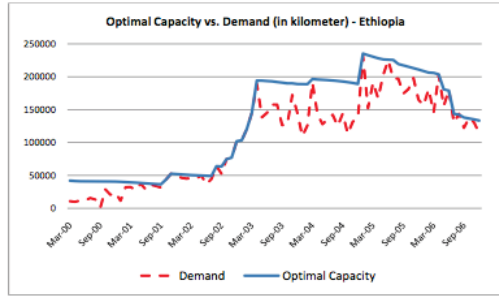

(b) Ethiopia

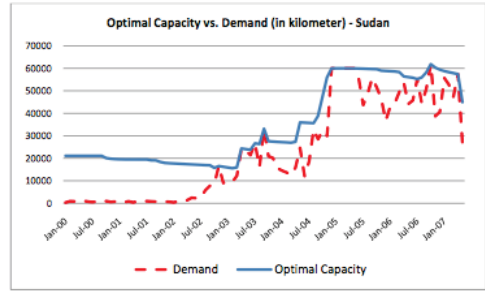

(c) Sudan

Figure 2.5.3 suggests that the policy recommended by our LP model smooths out demand variations and keeps fleet size fluctuations to a minimum. To confirm this hypothesis, we ran a series of F-tests to check whether optimal fleet usage exhibits significantly lower variation than does demand. These tests, whose results are reported in Table 2.5.5, reject the null hypothesis of equality of variances for all three countries in our analysis. Our analysis at the delegation level confirms that optimal fleet usage is less variable than demand, owing also to constraints that are unique to humanitarian organizations and rarely found in other operational environments. 
Figure 2.5.3: Optimal vs. Actual fleet sizes

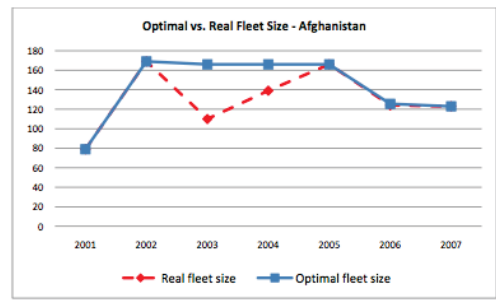

(a) Afghanistan

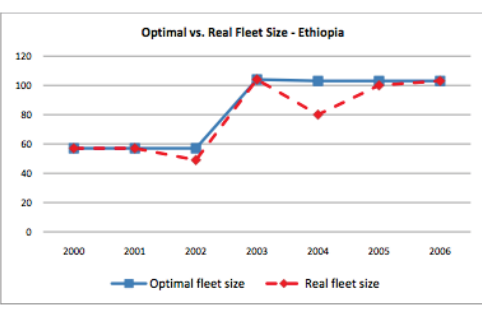

(b) Ethiopia

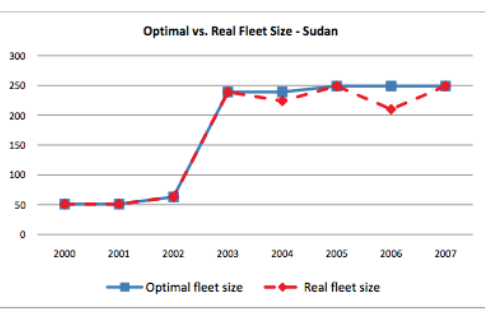

(c) Sudan

Table 2.5.5: Differences between Optimal and Actual Policies

\begin{tabular}{lccc}
\hline & Afghanistan & Sudan & Ethiopia \\
\hline Obs. & 66 & 89 & 85 \\
$d f$ & $(65,65)$ & $(88,88)$ & $(84,84)$ \\
$F$ & $2.10^{* * *}$ & $1.56^{* *}$ & $1.49^{* *}$ \\
\hline \multicolumn{3}{r}{ Note. ${ }^{* *}$ denotes significance at the .05 level, ${ }^{* * *}$ at the .01 level. }
\end{tabular}

To obtain further insights into the differences between the optimal and the actual policy, we compared the cost of the optimal policy identified by the LP model to the cost of the policy actually implemented for all three countries; see Table 2.5.6. Over the period of our analysis, using the optimal policy would have reduced costs by $7.9 \%$ in Afghanistan, by $19.2 \%$ in Sudan, and by $26.2 \%$ in Ethiopia-a cumulative cost savings exceeding CHF 3.7 million.

Table 2.5.6: Optimal versus Actual Costs (CHF)

\begin{tabular}{lccc}
\hline & Afghanistan & Sudan & Ethiopia \\
\hline Optimal cost & $4,887,979$ & $8,326,354$ & $2,821,489$ \\
Actual cost & $5,307,315$ & $10,283,425$ & $3,824,276$ \\
\hline
\end{tabular}

There might be several reasons why ICRC did not implement the optimal policy over the period of our analysis. The most intuitive reason is that it did not even try to determine an optimal policy and instead merely implemented the simplest ad hoc heuristic available (e.g., increase/decrease fleet size when demand increases/decreases). A second reason pertains to the impact of an optimal policy on media coverage. Adopting a 'level' strategy that does not follow every demand oscillation 
implies that, during some periods, some vehicles in the fleet are underutilized or idle. Since HOs rely on donations and since donations are directly influenced by media visibility and press reports, an $\mathrm{HO}$ may be concerned that idle fleet vehicles may be (erroneously) associated with wasting resources and thus receive negative press coverage - even when such idleness results from a policy that is cost optimal in the long run. Third, budgeting cycles and earmarked donations may require deviations from the optimal policy. When resources abound, an HO may well seek to increase its fleet size if it anticipates future periods of resource scarcity. An HO may also be forced to adjust fleet size-even if not optimal—when donations are earmarked for specific activities.

Based on the LP results, we develop another model, explained in the next Chapter, that preserves the properties of LP results while does not need detail data. 


\section{3 \\ Optimal Procurement Policy}

\section{$3.1 \quad$ AbStract}

This Chapter is based on the results of Chapter 2. Drawing from results of the linear programming model, we develop a stylized quadratic control model and use it to characterize the general structure of the optimal policy under different demand scenarios and operational constraints. After demonstrating that the results of the control model are consistent with those of the linear programming model in the specific context analyzed, we discuss the optimal policies and the applicability of the former as a practical tool for strategic asset planning. 


\subsection{Quadratic Control Model for Determining Optimal Policies un- Der General Demand Scenarios}

\subsubsection{Model Rationale}

The LP model generates a detailed vehicle procurement policy and yields some interesting insights. However, these results are valid only for the particular realization of the demand function observed in our three sample countries from 2000 to 2007 . In order to derive optimal policies for different demand scenarios, decision makers at the HQ level would want to rerun the LP model for those scenarios; however this is both time consuming and data intensive-and thus less useful in the humanitarian context, where data are not readily available. The ICRC managers we interviewed have confirmed that only a few ICRC delegations collect detailed operational data, and that they use ad hoc rules to make vehicle procurement decisions because the interaction between demand scenarios and fleet management policies are not well understood.

We offer an alternative and more practical approach to guiding HQ decisions: a stylized model that draws on the results of the LP to describe the structure of optimal policies not only in the specific case considered but also under different and more general demand scenarios. Because the governance as well as the procurement and maintenance policies of any sub-delegation are imposed centrally by ICRC headquarters, they all face constraints that contribute to usage being less variable than demand. This fact allows us to generalize the results derived from our LP model and to use them to construct the QC model. This model can be used to analyze the optimal policy's general properties, to conduct validity checks on the heuristics currently used by HOs, and to run sensitivity analyses that elucidate the impact of changes in input parameters on the optimal policy. Our model establishes links among budget dynamics, planned usage dynamics, and the operational context-relations that have not been examined in the literature.

We make two assumptions to develop the QC model. The first (based on results of the LP model) is that high fleet size variability is not optimal. We therefore construct a quadratic control (QC) model that accounts - through the term $u^{2}(t)$, as explained in what follows-for such variability by penalizing the rate at which fleet size increases or decreases over time. The second 
assumption is that efficient operations ought to match supply and demand with the level specified by management. Our model allows the decision maker to choose this level (through the parameter $q$ ). Thus, the model penalizes time-averaged overstocking and under-stocking costs as well as procurement decisions that increase fleet size variability over the planning horizon. Note that our model does not penalize the fleet size-demand mismatch at a specific time but rather the average mismatch over time. In addition to capturing more accurately the dynamics revealed by the LP model, the quadratic model is easier to use and hence more efficient.

This model is constructed to optimize fleet size at an aggregate level, and works with data that are only approximate; for these reasons, we use the average number of vehicles (instead of the planned usage) to represent demand. Observe that the average demand per period in number of vehicles can be easily determined by dividing the total demand (in kilometers) by the average distance that a vehicle is driven per period. The model's inputs are demand requirements and operational constraints; its output is a fleet size time trajectory that satisfies those conditions while minimizing fleet size variation. In addition, the model allows the decision maker to decide how much of a penalty to impose for stocking costs and fleet size variability. In Section 5.2 we introduce the model. In Section 5.3 we use it to analyze the structure of optimal policies for three general demand cases. In Section 5.4 we compare the optimal policy based on the QC model for a specific realization of demand with its counterpart based on the LP model.

\subsubsection{Model Formulation}

Equations (3.1) - (3.5) describe the objective function of the QC model and its constraints. Just as in the LP model, $x(t)$ is a state variable representing the number of vehicles available in period $t$ and $u(t)$ is the control variable accounting for the number of vehicles either purchased or sold in period $t$. Unlike in the LP model, however, in the QC model $u(t)$ can be either positive (when vehicles are purchased) or negative (when they are sold). The rate at which fleet size changes is $\dot{x}(t)$ and it is the summation of the control variable $u(t)$ and the number of old vehicles (per period) that should be replaced owing to safety or maintenance concerns. This number is given by $x(t) / \tau$, where $\tau$ is the average time before a vehicle is replaced. We remark that the need to replace vehicles from 
time to time is another source of variability in fleet size. According to [47], the individual replacement policy should be set as a function of a vehicle's odometer reading; hence $\tau$ depends on the number of kilometers a vehicle is driven before it needs to be replaced. We estimate this number as $\frac{\text { optimal replacement odometer }}{\text { average monthly usage }}$. For example, if vehicles are optimally replaced at an odometer reading of $100,000 \mathrm{~km}$ and if vehicles average $2,000 \mathrm{~km}$ per month, then $\tau$ is 50 months. $M$ is a constant that reflects maximum purchasing and selling quantities, whereas $\delta$ represent the least proportion of demand to be covered. Finally, $D(t)$ is the demand in period $t$ (in number of vehicles).

$$
\text { Objective function: } \quad \min _{u(t)} J=\frac{1}{2} \int_{0}^{T}\left(q[x(t)-D(t)]^{2}+r[u(t)]^{2}\right) \mathrm{d} t
$$

subject to the following expressions.

$$
\begin{aligned}
\text { State equation: } & \dot{x}(t)=u(t)-\frac{x(t)}{\tau} . \\
\text { Demand fulfillment constraint: } & x(t) \geq \delta D(t) . \\
\text { Purchasing/selling constraint: } & -M \leq u(t) \leq M . \\
\text { Boundary condition: } & x(\mathrm{o})=\mathrm{o} .
\end{aligned}
$$

The term $r[u(t)]^{2}$ is used to penalize fleet size variation, and the term $q[x(t)-D(t)]^{2}$ is used to penalize the mismatch between fleet size and demand. Here, $q$ and $r$ are, respectively, the penalty cost due to fleet size-demand mismatches and the penalty cost due to purchasing or selling vehicles. Thus, if the ratio $q / r$ is high then the model forces fleet size to match demand; but if $q / r$ is low, the model focuses on minimizing fleet size variation and allows for a greater mismatch between fleet size and demand. The value of $q$ could be set by specifying a value for the cost of the average mismatch between fleet size and demand for a given time period. This parameter is a proxy for customer service and can be estimated empirically. A sub-delegation that does not have enough vehicles to cover demand could incur costs associated with wasting perishable food products or drugs that cannot be delivered to beneficiaries and with reduced future donations because of negative press stemming from poor field performance. In order both to simplify notation and to limit solution complexity, we assume that overstocking and under-stocking are equally expensive. (This is a tenable assumption for development programs, but in relief operations under-stocking can be 
significantly more costly: it may result in a mission being canceled and, ultimately, in lives being lost.) The parameters $\tau$ and $\delta$ can also be used to account for differences between programs. For instance, health programs may require both shorter replacement intervals and higher service levels than do food programs.

Several scenarios can be represented by altering the parameters $q$ and $r$, whose values can be set based on past experience. Constraint $(3.2)$ is the state equation representing the fleet size variation in each period. The term $u(t)$ is the decision variable, which indicates how many vehicles should be added to (or removed from) the fleet; $x(t) / \tau$ is the number of vehicles that must be replaced in period $t$. Note that for a given number of missions, $x(t) / \tau$ is greater in countries that are (geographically) larger. This is because their vehicles must cover more ground in a given period to accomplish the same missions. Note also that, since HOs cannot purchase partial vehicles, $u(t)$ is rounded to the nearest integer when the model is used in practice. Constraint (3.3) guarantees that, in any period, a portion $\delta$ of demand will be satisfied. The parameter $\delta$ is positive, and it can take values greater than 1 (this allows for cases in which some vehicles are used as a safety stock). Constraint (3.4) captures a limit that may be placed on the number of vehicles bought or sold each period. As in the LP case, this constraint reflects annual order quotas imposed by vehicle manufacturers as a condition of offering discounts. The selling constraint reflects transaction costs, which arise because it is not economical for an $\mathrm{HO}$ to organize the resale of just a few used vehicles. To simplify notation, the maximum selling and purchasing levels are assumed to be equal. Finally, constraint $(3.5)$ is the boundary condition. Without loss of generality, we assume that the initial number of vehicles is zero.

\subsubsection{Analysis of Demand Scenarios}

In this section we use the quadratic control model just developed to study the structure of optimal policies under three different demand scenarios: (i) a general demand function that consists of an increasing (or decreasing) term and of a term that varies around a constant; (ii) a demand function that consists only of an increasing (or decreasing) term; and (iii) a demand function that consists only of a term that varies around a constant. As it is discussed in Chapter 2, demand does not vary 
too much in development programs. However, we consider the three demand functions to present a comprehensive discussion. These functions reflect well the structure of the real demand observed in the three countries that we analyze in this study. Between 2000 and 2007 , for example, demand in Sudan can be subdivided into three distinct patterns: constant from $t=0$ to $t=22$ (i.e., from 2000 to 2002), linearly increasing from $t=23$ to $t=33$ (2002-2003), and oscillating around a constant mean from $t=34$ to $t=84(2003-2007)$.

\section{General Demand Function}

We consider the general nonmonotonic demand function

$$
D(t)=a t+\beta \sin (\omega t)
$$

which represents the most general case. The first term in (3.6) represents the increasing (or decreasing) trend; the second term represents the demand oscillation. The parameter $\omega$ is the frequency of the demand oscillation, and $\beta$ is its magnitude. For development programs (unlike relief operations), we can assume that $\beta$ is constant because typically the demand for humanitarian services in these programs is strongly correlated with the size of the population in the affected area, which is relatively constant over time in the short to medium run. The term at captures a common situation. The ICRC often starts operating in a country with a few small projects and then expands its operations over time; demand then follows an upward trend and varies with time. A symmetrical situation occurs (now with $a<0$ ) as the ICRC withdraws from a country.

Whereas relief operations encounter a lot of unpredictable variability, the demand variability in development programs is fairly cyclical. It can therefore be accurately and conveniently approximated by a sinusoidal function, which reflects well the seasonality of some demand drivers. For instance, organizations running food programs typically face demand peaks during or right after drought periods, which are seasonal events. Likewise, the demand for health programs increases in tropical regions after floods, which are also seasonal events. Our interviews with executive managers in large HOs (including the ICRC, the World Food Program, and World Vision International) confirmed that demand variation exists but that its magnitude $\beta$ is usually a small percentage of 
the total demand. The model's demand parameters can also be used to accommodate differences among different program types - for example, the demand for food programs may oscillate more frequently but at a lower amplitude than does the demand for health programs.

Our first proposition follows from solving the QC model for the demand function (3.6).

\section{Proposition 1:}

For the demand function $a t+\beta \sin (\omega t)$, let $x(t)$ and $u(t)$ be the unconstrained solution of problem (3.1) given by

$$
\begin{aligned}
& x(t)=\frac{a q t \tau^{2}}{q \tau^{2}+r}+\frac{\beta q \sin (\omega t)}{q+r\left(1 / \tau^{2}+\omega^{2}\right)}, \\
& u(t)=\frac{q \tau^{2} \alpha}{r+q \tau^{2}}+\frac{q \tau \alpha t}{r+q \tau^{2}}+\frac{\tau \beta(\alpha \omega \cos (\omega t)+q \sin (\omega t))}{r+\tau^{2}\left(r \omega^{2}+q\right)} .
\end{aligned}
$$

Then, in each period, the optimal solution will be as given by one of the following cases:

(a) If $x(t) \geq \delta D(t)$ and $-M \leq u(t) \leq M$ (i.e., if none of the constraints (3.3) and (3.4) is binding), then the optimal solution is $u^{*}(t)=u(t)$.

(b) If $x(t) \geq \delta D(t)$ and $u(t)>M$ or $u(t)<-M$ (i.e., if constraint (3.3) is not binding but constraint (3.4) is binding), then the optimal solution is $u(t)^{*}=M$ or $u(t)^{*}=-M$.

(c) If $x(t)<\delta D(t)$ and $-M \leq u(t) \leq M$ (i.e., if constraint (3.3) is binding but constraint (3.4) is not), then the optimal solution is $u(t)^{*}=\delta(\dot{D}(t)+D(t) / \tau)$.

(d) If $x(t)<\delta D(t)$ and $u(t)>M$ (i.e., if both constraints (3.3) and (3.4)are binding), then $u(t)^{*}$ is the minimum of the the solutions of cases $(b)$ and $(c)$.

Observe that the optimal policy is time dependent. Only one of the optimal solutions of Proposition 1 holds for any given period, but during that period any one solution can be optimal at different times. The results of this proposition also hold when there is an inventory of vehicles at time $t=o$. In that case, $u(t)$ should be set to $o$ in any period $t$ before the initial fleet size reaches $D(t)$-after which, (3.8) is followed. 
When neither (3.3) nor (3.4) is a binding constraint, the procurement policy $u^{*}(t)$ given by (3.8) consists of a constant term, a linearly increasing term, and a third term that oscillates with the same frequency as (but with a different phase from) the demand. Purchasing/selling decisions take place before demand increases or decreases: the numerator $\tau b(a \omega \cos (\omega t)+q \sin (\omega t))$ of the third term increases before the demand term $b \sin (\omega t)$ increases. It is trivial to show that, as the ratio $\beta / \tau \omega$ decreases, the third term of (3.8) decreases and approaches zero. Unlike relief operations, development programs do not expect to experience a high $\beta / \omega$ ratio and so, as Proposition 1 shows, the dynamics of fleet size variation depend mostly on the vehicle replacement frequency $1 / \tau$.

Depending on the parameter values, either one (or both) of constraints (3.3) and (3.4) may be binding. If (3.3) is binding and (3.4) is not, then the optimal policy is $u(t)=\delta(\dot{D}(t)+D(t) / \tau)$. If both constraints are binding, then the optimal policy is to increase fleet size quickly by setting $u(t)=M$ until there are enough vehicles to cover the demand. This result is in line with what we observe from the LP model. In that model, as the budget constraint (2.4) narrows, the model calls for purchasing as many vehicles in each period as are allowed (by the available budget) until the fleet size can accommodate demand. It is interesting that, depending on the parameter values, the optimal fleet size strategy changes from one that levels fleet size by smoothing out demand requirements to one that "chases" demand [58]. A combination of these strategies is required when the procurement rate $u(t)$ is constrained and demand requirements are high.

The results of Proposition 1 can be summarized as follows: Depending on the portion of demand coverage and procurement constraints, there are three main regions occupied by the procurement policy for the demand function at $+\beta \sin (\omega t)$. In the first region, the procurement policy is given by $(3.8) ; a$ portion of the demand is procured at $t=0$, after which the procurement policy has oscillatory characteristics similar to those of demand. In the second region, the procurement policy is to match demand. In the third region, an early buildup of fleet size (to meet future demand requirements) is optimal.

In order to examine the link between budget requirements and operational environment, we consider the effects of $\omega$ and $\tau$ on the budget required for the demand function (3.6). Given that budget requirements may vary as a function of time and mission characteristics, we consider the upper bound of those requirements associated with completing a mission. Let $h$ denote the cost 
of holding vehicles (maintenance and miscellaneous costs) and $p$ the cost of purchasing a vehicle. Then the following equation describes the maximum budget available in any period:

$$
\bar{B}=\max _{t \in[0, T]}(h x(t)+p u(t))
$$

Our next proposition examines the effects of $\tau$ and $\omega$ on the upper limit of the budget, $\bar{B}$.

\section{Proposition 2:}

Let $\omega_{R}=1 / \tau$ denote the frequency of vehicle replacement. If constraints (3.3) and (3.4) are not binding, then the upper limit of the budget requirements to complete a mission are affected by the frequency of demand oscillation as follows:

$$
\frac{d \bar{B}}{d \omega} \begin{cases}<0 & \text { if } \frac{\omega}{\omega_{R}}>\frac{\sqrt{r\left(h^{2} r \tau^{2}+p^{2}\left(q \tau^{2}+r\right)\right)}-h r \tau}{p r \tau^{2}} \\ >0 & \text { if } \frac{\omega}{\omega_{R}}<\frac{\sqrt{r\left(h^{2} r \tau^{2}+p^{2}\left(q \tau^{2}+r\right)\right)}-h r \tau}{p r \tau^{2}}\end{cases}
$$

This proposition states that completing missions for which $\omega / \omega_{R}$ is high requires a budget with a lower upper bound. The intuition is as follows. Recall from Proposition 1 that the optimal policy oscillates with the same frequency as the demand but with a different phase. In other words, the procurement of vehicles meant to replace old vehicles occurs during the same period in which new vehicles are procured to prepare for the next demand peak. This dynamic allows us to minimize the mismatch between fleet size and demand, as fleet size is augmented in a single period to compensate for both the increase in demand and the vehicle replacement. Increasing procurement levels in one period to compensate for both vehicle replacement and future demand reduces the timeaveraged variability $u^{2}(t)$ of purchasing/selling decisions and consequently the fleet size-demand mismatch. Hence overall costs decrease as well. This outcome may not prevail, however, if vehicles need to be replaced often and demand increases much later in the future. In that case, frequent purchasing/selling decisions are necessary to compensate for vehicle replacement. That being said, it may not be economical to purchase more vehicles (to satisfy future demand) and thereby incur high holding costs.

Proposition 2 reveals a link between budget requirements and such operational characteristics 
as demand oscillation and vehicle replacement policies. It also suggests that the upper budget limit in missions for which the frequency of demand peaks is greater than the frequency of vehicle replacement is lower than that limit in missions for which this inequality is reversed.

\section{INCREASING OR DeCREASING DEMAND}

We now consider a simpler version of the demand function (3.6) in which we concentrate only on the increasing (decreasing) term at. This case is representative when both the magnitude $\beta$ and frequency $\omega$ of demand oscillation are small, as usually occurs when the ICRC must continuously expand its actions in a country. We then have the following proposition.

\section{Proposition 3:}

For the demand function at, the optimal fleet size is

$$
x^{*}(t)=\frac{a q \tau^{2}}{q \tau^{2}+r} t
$$

and the optimal control is

$$
u^{*}(t)=\frac{a q \tau^{2}}{q \tau^{2}+r}\left(1+\frac{t}{\tau}\right) .
$$

This proposition yields some useful intuition. Observe that equation $(3.11)$ implies $q \tau^{2} /\left(q \tau^{2}+\right.$ $r) \leq 1$; this term approaches unity as the vehicle replacement interval $\tau$ increases. Therefore, constraint $(3.3)$ is always binding when $\delta>1$-that is, when demand must always be satisfied. Also, note that constraint $(3.3)$ will either bind for the whole demand interval $[0, T]$ (when $\delta>$ $\left.q \tau^{2} /\left(q \tau^{2}+r\right)\right)$ or it will not bind at all. This explains why the optimal policy is not time dependent.

For a linearly increasing demand function, if constraint $(3.3)$ is not binding then the only demand that should be satisfied is the portion $q \tau^{2} /\left(q \tau^{2}+r\right)$, which increases in $\tau$. To see this, note that $q \tau^{2} /\left(q \tau^{2}+r\right) \rightarrow 1$ as $\tau \rightarrow \infty$. Thus, optimal fleet size is closer to demand in regions with shorter travel distances and hence with high $\tau$ (in Haiti, e.g.) than in regions with longer travel distances to cover and hence with low $\tau$ (in Sudan, e.g.). In regions with shorter-distance missions and hence less frequent vehicle replacement, following demand more closely is a less expensive policy than it 
would be in regions with longer-distance missions and hence more frequent vehicle replacement.

For an increasing demand function $D(t)=a t$, we use $u(t)$ to represent the increase in fleet size during period $t$. Taking the derivative of (3.9) with respect to both $q$ and $r$, we find that

$$
\begin{aligned}
& \frac{d \bar{B}}{d q}=\frac{a r \tau(t(h \tau+p)+p \tau)}{\left(q \tau^{2}+r\right)^{2}}>0, \\
& \frac{d \bar{B}}{d r}=-\frac{a q \tau(t(h \tau+p)+p \tau)}{\left.q \tau^{2}+r\right)^{2}}<0 .
\end{aligned}
$$

These equalities imply that, for a linear demand function, the budget increases when the penalty for supply-demand mismatch is high. This relation is plotted in Figure 3.2.1, which confirms the LP model results: an increase in the penalty $r$ (for fleet size variation) leads to a lower budget allocation; whereas an increase in the penalty $q$ (for fleet size-demand mismatch) leads to a higher budget allocation.

Figure 3.2.1: Budget Allocation in period $t$ (with respect to $r$ and $q$ )

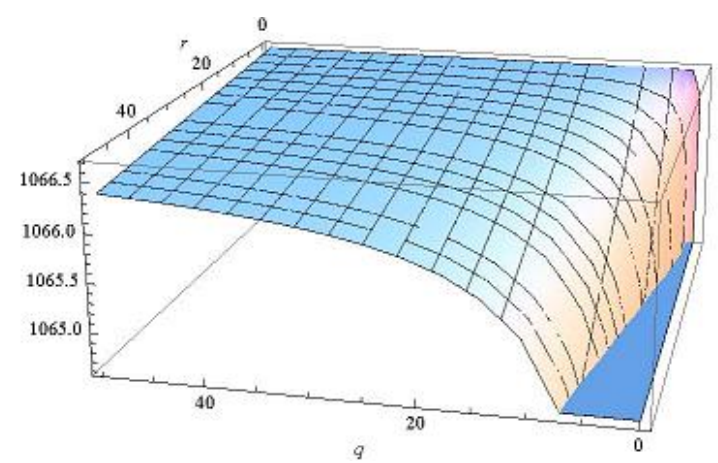

Another notable interaction is that between the individual replacement policy $\tau$ and the fleet budget constraint. Although the optimal individual replacement policy aims to minimize each vehicle's operational costs, system constraints may render this policy unfeasible in some situations. Despite the exogenous reasons (e.g., maintenance policies) driving these decisions, it remains possible for decision makers to modify them without affecting fleet quality. For the demand function 
at, the budget is affected by $\tau$ as follows:

$$
\frac{d \bar{B}}{d \tau} \begin{cases}>0 & \text { if } \tau<\mathcal{F} \\ <0 & \text { if } \tau>\mathcal{F}\end{cases}
$$

here

$$
\mathcal{F}:=\frac{\sqrt{r\left(T^{2}\left(h^{2} r+p^{2} q\right)+2 h p r T+p^{2} r\right)}+h r T+p r}{p q T} .
$$

Thus, as $\tau$ increases, the budget increases up to a threshold but then decreases afterwards. The reason is that, when $\tau$ is small, a higher portion of the fleet per unit time is replaced and so additional new vehicles are needed to satisfy the demand. The resulting increased costs are due to the increased variability of $u(t)$, which (as shown with regard to the LP model) is expensive. Even so, with higher values of $\tau$, this variability cost is increasingly outweighed by the benefit of replacing vehicles at a lower rate.

\section{Demand Fluctuating around a Constant Mean}

We now consider a demand function that varies around a constant:

$$
D(t)=a+\beta \sin (\omega t)
$$

\section{Proposition 4:}

When the constraints (3.3) and (3.4) are not binding, for the demand function $\alpha+\beta \sin (\omega t)$, the optimal fleet size is

$$
x^{*}(t)=\frac{a q \tau^{2}}{r+q \tau^{2}}+\frac{\beta q \sin (\omega t)}{q+r \omega^{2}+\frac{r}{\tau^{2}}}
$$

and the optimal control is

$$
u^{*}(t)=\frac{a q \tau}{r+q \tau^{2}}+\frac{\beta q \tau[\sin (\omega t)+\tau \omega \cos (\omega t)]}{q \tau^{2}+r \omega^{2} \tau^{2}+r} .
$$

Similarly to the results of Proposition 1, here we have four cases for the optimal solutions de- 
pending on whether (3.3) and/or (3.4) are binding. However, we forgo discussing these cases because doing so does not enhance our intuition of the problem beyond that obtained via Proposition 1 . The main difference is that, for the unconstrained case, Proposition 4 has no counterpart to the linearly increasing term in equation (3.8).

We emphasize that our model suggests a level strategy when the $\mathrm{HO}$ is restricted in the rate at which it can increase or decrease the fleet size. Restrictions of this kind are common in HOs and result from operational restrictions and bureaucratic reasons such as budget limitations, difficulties in shipping vehicles to different countries, the manufacturer's capacity restrictions, and the often vague timelines of humanitarian projects. Given that these constraints are fairly common in HOs, our model suggests that a level fleet size strategy is usually optimal in the humanitarian sector.

\subsubsection{Comparison of LP- ANd QC-Based Policies}

The quadratic control model just described can be applied by decision makers at the HQlevel to identify optimal policies for aggregated fleet sizing. Because demand is relatively stable in development programs, past demand data can be used to estimate the parameters $\alpha, \beta, \omega$ in the demand function (3.6) and to generate aggregate forecasts for future periods. The parameters $q$ and $r$ can likewise be set based on past experience-or "reverse engineered" by applying the model to previous optimal policies obtained via the linear programming model. Finally, once the specific function for the optimal policy has been determined, optimal vehicle sizes and optimal purchasing/selling quantities can be determined for each period of interest by computing numerical values for the state function $x(t)$ and for the control function $u(t)$ in those periods.

We shall illustrate the practical application of the QC model—and assess its validity—by comparing the optimal policy it generates for a specific demand scenario against the optimal policy generated by the LP model for the same scenario. In order to maximize the generalizability of this analysis, we address the case of Sudan because that country's demand function is the most complex and the most general among those available from our data set. 
To estimate the parameters of the demand function (3.6), we used the ICRC data described in Section 3. As outlined in Section 5.3, the demand function in Sudan consisted of three distinct patterns. From $t=0$ to $t=22$ it was constant, with an initial value of 50 vehicles (i.e., $a=50$ without oscillation). From $t=23$ to $t=33$, demand increased linearly with $a=15.2$. Finally, from $t=34$ to $t=84$ it oscillated around a constant $a$ at frequency $\omega \approx 0.26$. Therefore the demand is estimated by setting $a=15.2$ for periods $23-33$ and $a=250$ for the last interval (approximated as $\left.D_{t}=250+20 \sin 0.26 t\right)$. We calculated $\tau=\frac{100,000}{1,181.8} \approx 84$, where $100,000 \mathrm{~km}$ is the optimal vehicle replacement threshold [47] and $1,181.8 \mathrm{~km}$ is the average planned usage of vehicles in Sudan (see Table 2.4.1). Both $r$ and $q$ are set at HQ depending on different conditions; we hypothesized a rather large $r=250$ compared to $q=2$. In other words, we assumed that the per-period cost of each vehicle above (or below) the average demand is significantly higher than the costs associated with attempting to match demand.

The QC model generates the following policy. From $t=0$ to $t=22$ the model retains the initial stock. From $t=23$ to $t=33$, Proposition 3 holds: new vehicles are purchased in accordance with equation ( 3.12$)$, and the optimal fleet size at any time during this period is given by equation (3.1 1). Finally, Proposition 4 holds from $t=34$ to $t=84$; for this period, the model calls for purchasing new vehicles per equation (3.18) and the optimal fleet size is given by equation (3.17).

We used the policy just summarized to calculate the number of fleet vehicles specified by equations $(3.11)$ and (3.12) at discrete intervals $t=0,1, \ldots, T$. We then compared these values to those generated by the LP model and calculated the absolute value of the relative difference. The comparison indicates that the differences QC vs. LP (6.2\%), QC vs. Demand (4.1\%) and LP vs. Demand (5.4\%) are limited. The comparison also illustrated in Figure 3.2.2 indicates that the policies generated by the two models have a similar structure. However, the LP model typically generates a solution that exceeds demand whereas the QC model keeps the fleet size closer to demand. 
Figure 3.2.2: Optimal QC Policy versus Optimal LP Policy: Sudan

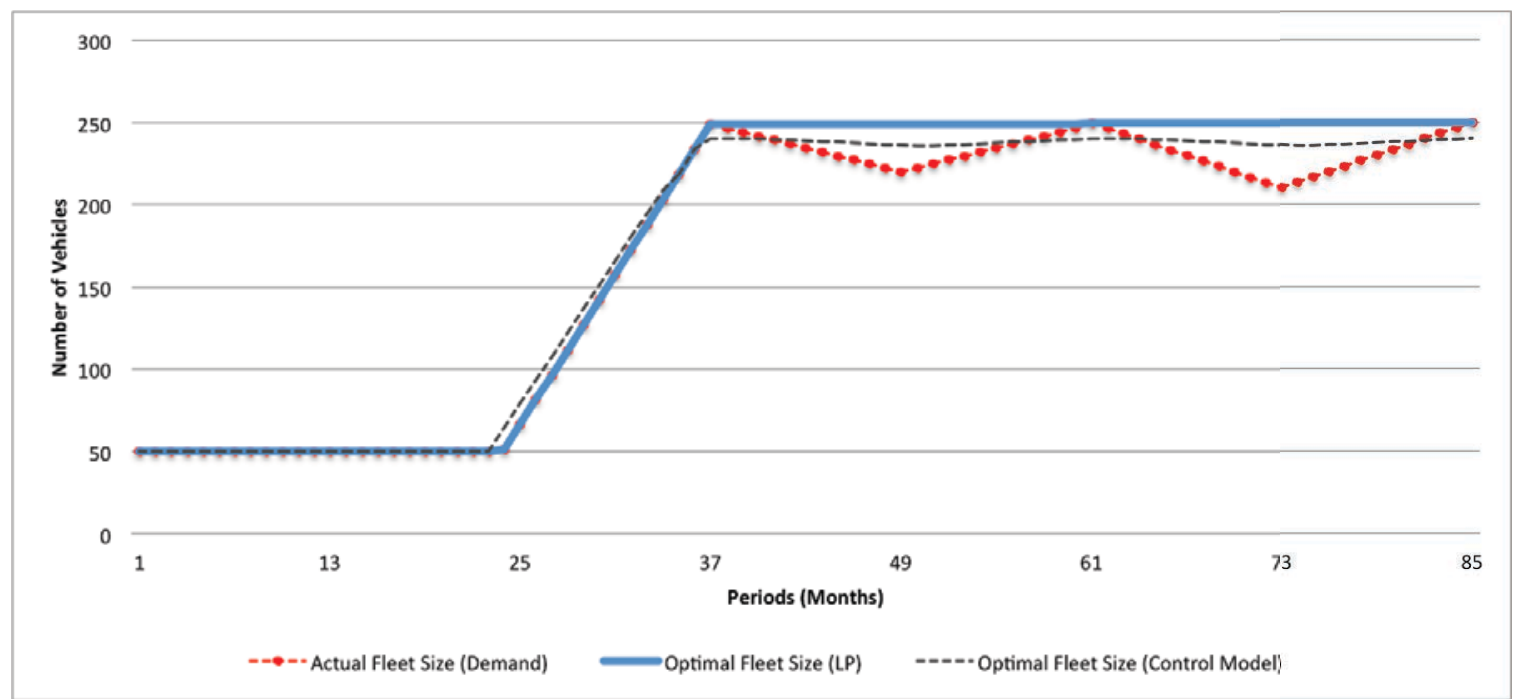

\subsection{Conclusions, Limitations, and Future Research}

In this paper we examine the properties of optimal humanitarian fleet procurement policies for development programs. After studying the operations of a large international organization (the ICRC) in three countries, we develop and apply a linear programming model to calculate the optimal fleet size in each country. In a second step, we draw on these LP results to build a stylized quadratic control model that, while preserving the properties of the LP solution, is more parsimonious and has data requirements that are better matched with the data to which HO headquarters typically has access. We use the model not only to characterize the general structure of the optimal policy under different demand scenarios but also to obtain additional intuition on the major tradeoffs faced by HOs in their fleet management decisions. After demonstrating that the QC model's results are consistent with those of the LP model, we discuss the former's applicability as a practical tool for strategic asset planning.

We find that, if HOs are constrained by the rate at which fleet size levels can be changed, then the optimal policy is to level fleet size by smoothing out demand requirements. Yet if HOs can replace vehicles frequently, face substantial overstocking and understocking costs and are relatively unconstrained by procurement budgets, then the optimal policy is to follow a so-called chase strat- 
egy, which has a more complex structure. Because the humanitarian context seldom satisfies the latter conditions, our results also indicate that a level strategy would be optimal for most humanitarian missions. The analysis presented here can also be used to identify cases in which HOs can revert to simpler, intuitive procurement strategies that do not require data-intensive solutions. For instance: if budgets are tight, then in each period simply purchase as many vehicles as the budget allows until peak demand is eventually met. In addition, we show that lower budgets are required for missions in which the demand oscillation frequency exceeds the vehicle procurement frequency.

Our findings should be viewed in light of some limitations that suggest interesting opportunities for future research. First, the models are developed in the context of a fleet consisting of homogeneous vehicles. The case of heterogenous fleets could be treated either by decomposing the problem and running the models separately for different model categories or by adding model-specific indicators (which would obviously increase complexity). Second, we have assumed that demand requirements are known before the mission and do not change during the mission; clearly, this assumption may not always hold. In the LP model we assumed also that demand is exogenous and independent of fleet size, but when HOs increase their fleet size they may decide to run more missions simply because they can. To incorporate this factor one could correct for endogeneity via a two-stage estimation technique and then rerun the LP model using the corrected data. Third, we assumed that a constant budget is available in each period. That might be true for large HOs with access to substantial financial resources, but it is not true for small ones. Future research could well examine the relationships among the resource procurement policies and financial structure of HOs and their fleet management policies. Finally, the LP model parameters were estimated using data from a specific organization. Although the ICRC is a large and fairly representative HO, the validity of our results should be tested also in other empirical contexts. 


\section{4 \\ Fleet management policies in humanitarian operations: an empirical investigation}

\subsection{INTRODUCTION}

Humanitarian Organizations (HOs) assist populations affected by natural or man-made disasters and contribute to the development of poor countries. Their mandate encompasses both relief operations and development programs. Relief operations are short term programs aimed at providing rapid response to, usually, emergency situations. Development programs, such as health, food, and sanitation programs, are longer term activities aimed at enhancing living standards in poor countries.

In both programs, HOs face critical operational challenges. Although they invest billions of dollars every year [11], their budgets are often insufficient to meet all their beneficiaries' needs. For 
example, whereas in 2011 alone, the total expenditures of the World Food Program exceeded US\$ 3.8 billion, they allowed this organization to achieve only about a quarter of its stated goals. Over the past decade, HOs' operational costs have been increasing too. A case in point is Oxfom UK, whose total expenditures soared from $£ 115.1$ million in 2003 to $£ 235.8$ million in 2009. Yet, despite their magnitude, the resources allocated are of little use unless they reach their target beneficiaries.

The delivery of humanitarian services to beneficiaries, also known as Last Mile Distribution (LMD) [8], is one of the most critical operations for HOs. As LMD is organized by sub-delegations (i.e. operating units located in the field and geographically close to underserved people), its performance is heavily dependent on local conditions. Transportation plays a pivotal role in this context [6]. However, difficulties in physical access due to the nature of terrain, local conflicts, long distances and poor infrastructure create specific challenges to LMD in humanitarian operations.

It is hardly surprising that in the last few years LMD has generated a lot of interest in the OM research community. Because of its cost, complexity and potential impact on beneficiaries [67], questions such as how to optimally allocate resources among sub-delegations [7], how to optimize service distribution and vehicle routing [38] or how to maximize vehicle performance in LMD [45], have been studied in depth.

Fleet management decisions for humanitarian LMD involve two general areas: procurement (i.e. determining fleet size and optimal replacement schedules) and fleet management at the field level (i.e. optimizing the usage of vehicles after they have been purchased). Procurement problems have recently begun to attract the interest of OM scholars [21]. Conversely, despite contributing to about $50 \%$ of total fleet costs [49], fleet management decisions at the field level have received comparatively less attention than fleet sizing problems, mostly because of the difficulty of gathering reliable data from sub delegations. As a result, the impact of many operational decisions on the performance of humanitarian fleet operations remains largely under examined and not empirically validated.

The importance of field vehicle fleet management is significant on operational performance and costs. Vicente Escribano, the Head of the Supply Management Services of United Nation High 
Commissioner for Refugees (UNHCR), said: 'Purchasing a new $4 \times 4$ Toyota Land Cruiser from the manufacturer would save us around \$US 3,ooo. However, if we manage a Land Cruiser properly, we can save more than $\$ U S 20,000$ for each vehicle over [on average] its five years of operational life. This means \$US 220 million saving over a period of 10 years for our 5,500 Land Cruisers' ${ }^{1}$. It therefore is obvious why $67 \%$ of large international HOs prioritized fleet costs as their main concern in fleet management [2].

Vehicles, in humanitarian development programs, are used to coordinate and to execute last mile distribution of program delivery for example [49]:

- to transport of relief items.

- to transport of staff coordinating or delivering services to beneficiaries.

- to transport of staff and materials related to projects e.g. building schools and hospitals.

Economists attempt to relate 'depreciation' to an explicit, i.e. well-known and measurable, index of 'utilization' [13]. Likewise, a particularly serious challenge in LMD is how to implement fleet management policies that maximize the utilization of vehicles during their operational life cycle, while simultaneously limiting their depreciation. The trade-off between these objectives is clear. On one hand, HOs have an obvious interest in utilizing their vehicles as much as possible to maximize demand coverage and the number of missions they perform. On the other hand, as HOs are allowed to resell vehicles at the end of their operational life, over-utilization may reduce their recovery value and consequently reduce the budget available for future operations.

HOs typically recommend specific policies based on the expected benefits in maximizing mission success, vehicle utilization and residual value, under the assumption that trade-offs between these objectives would prevent their simultaneous achievement. Yet, there is no empirical evidence either that the recommended policies are actually implemented or that the expected benefits are eventually realized. Without any loss of generality, these trade-offs can be illustrated by referring

\footnotetext{
${ }^{1}$ Fleet Forum, Geneva, Switzerland, April 2012.
} 
to the practices of one of the largest HOs, the International Committee of the Red Cross (ICRC).

A fleet management policy consists of three significant decisions that affect the trade-off between utilization and the loss of residual value, namely: (1) how to assign vehicles to different types of missions, (2) how to modify a vehicle's utilization over its operational life (i.e., how to identify a vehicle's optimal usage trend) and, (3) when to replace a used vehicle with a new one.

Allocating vehicles to missions has a clear impact on the performance of missions and the costs of managing a fleet. Demand for transportation at sub-delegations is divided into two groups: heavyduty missions (i.e. field trips) and light-duty missions (i.e. city trips). Heavy-duty missions involve long distance journeys, typically in limited access areas. Light-duty missions are shorter distances journeys usually done to perform administration tasks within cities. Given the potential impact of vehicle breakdowns (in some areas, humanitarian operators may be in danger if a vehicle breaks down) ICRC recommends that only new 'specially-equipped' vehicles be assigned to field trips, while it recommends to use normal or older vehicles for administrative purposes in safer zones. Depending on the country of operations, vehicles are recommended to be used for heavy-duty missions for up to two years [60] or, as a rule of thumb, 60,000 km [30] and then assigned to lightduty missions until the end of their operational life.

The second decision concerns the vehicles usage pattern, i.e., how intensively a vehicle is used during the different periods of its operational life [27]. The usage trend of a vehicle defines whether a vehicle is used more intensively at the beginning or at the end of its operational life. A vehicle is said to display a decreasing (non-decreasing) usage trend if its monthly distance traveled decreases (does not vary) with its age. ICRC Headquarters recommend using a vehicle intensively at the beginning of its operational life cycle and less when it gets older, i.e. a decreasing usage trend. Beside its impact on vehicle utilization, a decreasing usage trend is recommended due to the safety reasons. HOs believe it is more likely that a vehicle with high total mileage (e.g. more than 60,000 $\mathrm{km}$ ) fails during a field mission and puts humanitarian workers in danger. Finally, used vehicles are sold at the local market. Currently, the Standard Replacement Policy for most HOs (e.g. ICRC, IFRC $^{2}$ and UNHCR) requires the replacement of vehicles after 5 years or $150,000 \mathrm{Km}$, whichever

\footnotetext{
${ }^{2}$ The International Federation of Red Cross and Red Crescent Societies
} 
occurs first.

Understanding and quantifying the specific impact of these decisions on fleet performance is key to help HOs design better fleet management policies. Currently, the recommended policies are based on an HO's estimate of the presumed impact of its different operational decisions on a vehicle's utilization and residual value. However, to our knowledge, there is a lack of rigorous empirical studies that quantify these impacts and shed light on the mechanisms driving them. Furthermore, in this study, we consider the endogenous relationships between the different elements of a fleet management policy. Treating these elements separately may lead to under- or over estimating their impact on fleet performance and induce HOs to implement suboptimal policies. For instance, vehicles used in heavy-duty missions should be typically assigned to more demanding missions (i.e. field missions) that may wear out vehicles sooner. Therefore, we assume a naif estimation of the impact of mission type on residual value would not be accurate because vehicles are not assigned to missions randomly. Analyzing these dependencies, we illustrate that our model produces unbiased estimates that lead to the implementation of optimal policies.

The aim of this chapter is to shed light on the mechanisms affecting the performance of fleet management in humanitarian LMD. Specifically the chapter aims to examine how a vehicle's usage policy affects fleet utilization and the loss of a vehicle's residual value, to determine whether trade-offs exist between utilization and loss of residual value, and to identify why and where these trade-offs originates. We first examine whether there is a rationale in assigning vehicles to missions. Then, we analyze the impact of mission type on vehicles physical depreciation. Third, we consider the impact of different usage patterns on vehicle utilization and residual value. And finally, we analyze whether the standard vehicle replacement policy proposed by most HOs is effective or not. We address these questions empirically, by analyzing the fleet management operations of a large $\mathrm{HO}$, the ICRC, in four representative countries from 2000 to 2010.

Results generate some interesting insights and challenge the current usage policy. First, we demonstrate that the vehicle usage policy recommended by the ICRC is not properly followed by its sub-delegations. Second, a vehicle's usage trend does not have a significant impact on vehicle residual value. Also, a decreasing usage trend recommended by HOs neither has positive impact 
on vehicle utilization nor improves humanitarians safety. Third, our results show that a utilizationresidual value trade-off may exist only for vehicles that are kept longer, regardless of their cumulative odometer. However, we suggest that HOs can break away from the utilization-residual value trade-off, by identifying some specific usage policies. Finally, in contrast of literature, we find that loss of residual value of a vehicle is a function of its age. This implies that HOs should revise their current vehicle replacement policies.

Unfortunately, lack of data in humanitarian context has limited researchers to have a clear picture of humanitarian operations at the field level. This empirical study sheds some more light on the dark side of these operations. This study demonstrates incentive misalignment and lack of communication, exist between different levels in humanitarian organization, lead to extra costs. This picture provides a basis for the future research required to be done in this area.

The rest of the chapter is organized as follows: In $\$ 2$ we review the relevant literature on LMD in relief operations and development programs. $\$_{3}$ develops testable hypotheses. $\$_{4}$ describes the methodology - including the data, the operationalization of variables and the econometric model employed. $\$ 5$ presents and discusses the results of the analysis. $\$ 6$ presents some managerial insights and finally, $\$_{7}$ concludes the chapter and suggests avenues for further research.

\subsection{Literature REVIEW}

In the last few years, humanitarian logistics - especially LMD, have generated a lot of interest in the research community especially since the Indian Ocean Tsunami in 2004 [37]. Most of the literature in humanitarian operations has been dedicated to relief operations [43], while the literature on development programs is nascent, but steadily growing. [5], in a comprehensive literature survey, report that the methodologies deployed in majority of research articles in humanitarian areas use a modeling approach whereas empirical research is scant. The serious lack of empirical studies in this field has also been reported in other recent literature survey articles $[43,56]$. While modeling papers usually provide normative prescriptions, empirical studies usually test the effectiveness of prescriptions or the actual behaviors. Therefore to enrich academic literature of a specific area, 
both research types are required.

Researchers have analyzed LMD in both relief operations and development programs at the strategic level e.g. facility location problems $[7,10]$, the tactical level e.g. delivery and distribution questions $[8,45,63]$ and the operational level e.g. emergency response and operations scheduling $[31,55]$.

[3 1] is an example of fleet sizing problem in LMD of relief operations. They describe a locationallocation model to minimize the number of ambulances required to provide a specified service level, here defined as the fraction of calls reached within a fixed time period.

Considering development programs, [49], in a case-based article, describe large HOs' last mile vehicle supply chain. Comparing it with its commercial counterparts, they study agility, adaptability and alignment in the HOs' supply chain. [12] study fleet management at HOs' dual mandate of relief and development programs. Using system dynamics, they consider the relationship between fleet management structures (i.e., centralized, hybrid and decentralized) and HOs' mandate to determine the structure that would maximize HOs' fleet procurement performance. They demonstrate that strategic decisions to implement more (less) relief operations determines what type of fleet management structure should be implemented.

Fleet sizing question, at a macro-level, is considered in Eftekhar et al. [2 1 ] and at a micro-level is studied in [47]. Eftekhar et al. [2 1] propose an optimal fleet vehicle procurement policy after taking into account the specific constraints of humanitarian operations. Connecting an empirical study to an analytical model, they study how to, in the absence of detailed data, efficiently build fleet capacity over time for different demand requirements. [47] consider a vehicle replacement policy. They apply dynamic programing to determine the optimal vehicle replacement threshold, and estimate empirically the required cost functions, including maintenance costs, purchasing price and salvage values of used vehicles. Also, Pedraza Martinez et al. [48] develop a model to align incentives in a humanitarian setting. They consider a case where sub-delegations do not hide information from the Headquarters to increase fleet size. 
As the goal of this chapter is to study the impact of vehicle usage patterns on vehicle's utilization and depreciation, we need to clarify the meaning of these constructs. Concepts such as vehicle utilization and usage pattern does not exist in humanitarian literature. Therefore, we borrow these concepts from articles considering fleet management problems in commercial supply chains. Most of this work is model-based and, similar to the case of humanitarian fleets, empirical research in this area is also scant. Empirical studies on vehicle utilization and fleet management usually focus on maintenance planning [14], energy and fuel consumption $[16,27]$, and vehicle ownership [44]. In these studies, vehicle utilization is defined as total miles/kilometers driven [24, 27] or miles/kilometers driven in a defined period of time e.g., annual kilometers driven [16]. In these references, 'vehicle usage' and 'vehicle utilization' are either used interchangeably or are defined closely.

Household vehicle choice behavior based on different parameters like fuel consumption, operating costs and vehicle utilization have been considered in economic research studies. For example, [44] empirically analyze household vehicle ownership and utilization decisions through a dataset that contains information about the households behavior before, during and after an energy shock. To estimate vehicle utilization, they consider economic aspects of usage (i.e., operating costs), the driving habits, the household characteristics (e.g., income, age of household head, number of workers, urban or non-urban residence), and regional residence. Considering the household demographic, vehicle characteristics and the characteristics of the household s stock of vehicles, [26] estimates annual miles. [3] and [4] estimate the distribution of values of old vehicles that would be scraped. The average age of vehicles in their dataset is 17 years.

[22] analyze whether the benefits from owning a vehicle, which is approximated by its annual miles driven, explain the price declines that are observed over a vehicle $s$ life. They show that the effect of vehicle age on annual miles and market value depends on household characteristics and the composition of the vehicle stock owned. The index of annual miles is assumed to explain the observed drop in used car prices over a vehicle s working life. To estimate the household vehicle annual miles decisions, they consider the car portfolios (the number and the age distribution of the vehicles) and household demographic characteristics. 
Our study is different with the literature focuses on household vehicles in several ways: (1) Our model specification differs significantly from other models. For example, unlike [26] and [22], we use different independent variables to estimate vehicle residual value and its utilization. (2) We consider vehicles that are used in different types of operations (e.g. in more difficult conditions). We therefore control for some other variables like vehicle's equipment, its condition and the environmental conditions. (3) Given we consider vehicle usage for an organization, we consider different models following different set of assumptions. For instance, to have unbiased estimates, we run a Seeming Unrelated Regression to control the impact of demand variation on individual vehicle usage variation.

The contribution of this chapter to the literature is twofold. First, vehicle's utilization and depreciation costs are either ignored or assumed in modeling papers. While there is no study depicts how to control these variables, based on observations of humanitarian fleet management in practice, this chapter produces robust estimates of the different variables influencing a vehicle's utilization and depreciation. Therefore, results of this chapter can be used in further modeling works in this area. And second, while humanitarian literature mainly concentrate on how to provide resources and assets to sub-delegations, there is a serious lack of study on how to utilize the assets (i.e. vehicles) so as to maximize equipment utilization and minimize depreciation. We believe some of our results are not only limited to humanitarian area but can be useful for the commercial sector too.

\subsection{Hypotheses}

In this section we develop a set of hypotheses to discuss the impact of usage policy on vehicle utilization and physical depreciation. To estimate vehicle utilization, as indicated in the literature $[22,24,27]$, we consider its total mileage. It also is an appropriate proxy of the number of missions completed by a vehicle.

Used vehicles are subdivided into three groups: (1) vehicles that are in working conditions but are not proper for ICRC's operations. These are sold in the local secondary market. (2) Vehicles that are not in working conditions and are scrapped and, (3) vehicles, that are not in proper condi- 
tions for ICRC operations and are not of interest for the local market. These vehicles are donated to the local organizations. We use vehicle residual value as a proxy to evaluate vehicle depreciation (or its lack thereof). Usually there are huge losses in the residual value of vehicles, mainly due to their use in abnormal conditions and to the sharp drops in used vehicle prices when new models are introduced. As used vehicles are sold in the local secondary market, limiting depreciation is clearly a key goal for HOs. To minimize depreciation costs, the ICRC Standard Replacement Policy requires the replacement of vehicles after 5 years or $150,000 \mathrm{Km}$ whichever comes first.

The first set of hypotheses concerns vehicle-mission type allocation and the impact of mission type on vehicle residual value. There are two types of Land Cruisers in the field; normal and specially-equipped vehicles. Normal vehicles are ordinary Land Cruisers equipped with electronic devices. Specially-equipped vehicles are equipped with stronger suspension, strong bumpers and electronic devices. These vehicles are more resistance in hard terrain and are safer if an accident occurs. These vehicles are US\$ 4,200 more expensive than normal vehicles. Currently, HOs recommend that sub-delegations allocate all recently purchased specially-equipped vehicles to heavyduty missions and then assign them to light-duty missions, depending upon their age or total mileage (i.e. cumulative odometer). However, normal vehicles are purchased to use for light-duty missions.

Our data shows that vehicles are allocated either to heavy-duty or to light-duty missions at the beginning of their operational life and they are never switched to another mission type. As heavy-duty missions are implemented in difficult geographical conditions, and usually in areas with poor infrastructure, it is reasonable to assume that delegations assign specially-equipped vehicles to heavyduty missions and never change their mission type. Therefore, we formally state Hypothesis $4 \cdot 3.1$ as follows;

Hypothesis 4.3.1 There is alignment in the assignment of vehicles to missions: specially-equipped vehicles are assigned to heavy-duty missions more often than to light-duty missions while normal vehicles are assigned to light-duty missions more often than to heavy-duty missions.

Few studies have demonstrated that if an asset is used more intensively, it would depreciate 
more rapidly [13]. It therefore makes sense that we assume heavy-duty missions depreciate vehicles more than light-duty missions. Hypothesis 4.3.1 implies that heavy-duty missions 'attract' better vehicles (i.e. vehicles that tend to retain their value). Hence, due to their more intensive usage, better vehicles get depreciated quicker. Therefore a simple value comparison 'good vehicles versus bad vehicles' may produce biased results and so that mission type must heavily affect vehicle residual value. We therefore believe that a policy of allocating vehicles to missions based either on their age or total odometer may not be an effective policy, since other factors like vehicle model are not taken into consideration. Consequently, we consider the impact of selection bias on vehicle's residual value through Hypothesis 4.3.2.

Hypothesis 4.3.2 Controlling for vehicle model, age and cumulative odometer, heavy-duty missions have a more negative impact on a vehicle's residual value than light-duty missions.

The second set of our hypotheses considers the impact of the second component of the vehicle usage policy, vehicle usage trend, on vehicle utilization and depreciation. As mentioned in Introduction, vehicle usage trend is either decreasing or non-decreasing. A vehicle used more intensively at the beginning of its operational life but less so once it gets older is said to display a decreasing usage trend. Conversely, there are vehicles whose usage trend is non-decreasing. The second recommendation made by HOs, to use vehicles following a decreasing usage trend, is implemented on some vehicles.

HOs recommend to use vehicles following a decreasing usage trend mainly due to the safety reasons; the probability that an old vehicle fails during a field mission is high and therefore, it puts humanitarian workers in danger. However its impact on vehicle residual value and utilization is not clear. There are opposing, yet equally valid, arguments to specify how a vehicle's usage trend affects its residual value. As all vehicles receive similar preventive maintenance services, the residual value should be higher for vehicles that have been used following a decreasing usage trend. On the other hand, vehicles used in a non-decreasing fashion may still have enough potential for being used intensively. We suggest that the former mechanism is stronger, that is we believe that a decreasing 
usage trend should increase vehicles' residual value as specified by Hypothesis $4 \cdot 3 \cdot 3$.

In addition, it is assumed that a decreasing usage trend, in long term, would increase vehicle utilization [22]. However, the Headquarters recommend this policy for vehicles that are used for heavy-duty missions. Therefore, we posit that usage trend significantly influences the utilization of heavy-duty mission vehicles while it has limited impact on vehicles assigned to light-duty missions. Our reasoning is based on the fact that heavy-duty mission vehicles are used in difficult circumstances and in areas with poor infrastructures, while light-duty mission vehicles are mainly used for administrative purposes and city trips that are more similar to a normal vehicle's usage. Therefore, the recommendation on vehicle usage trend should be more applicable for heavy-duty mission vehicles. Hence, we propose Hypothesis 4.3.4 as follows.

Hypothesis 4.3.3 Controlling for vehicle model, age, cumulative odometer, mission type and the impact of local market, on average, a decreasing usage trend positively affects vehicle residual value.

Hypothesis 4.3.4 Controlling for the level of conflict in each area and the quality of infrastructure, the impact of a decreasing usage trend on vehicle utilization is stronger for vehicles used in heavy-duty missions than for vehicles used in light-duty missions.

Intuitively, higher vehicle utilization should be achieved at the expense of higher vehicle depreciation, which should also imply a lower residual value. It is also confirmed by the literature $[22,47]$. For example, [47] explain vehicle residual value is a decreasing function of vehicle's total mileage. It means increasing a vehicle utilization will negatively affect its residual value. To study this trade-off, we consider the average vehicle utilization and the average vehicle residual value of 21 sub-delegations whose fleets included at least 4 vehicles in all periods. Figure 4.3.1 suggests that there are sub-delegations that, on average, achieve higher vehicle utilization and also sell their used vehicles at a higher price. For example, the average residual values of vehicles at Mazar-i-Sharif (MAZ) is almost the same as in Kabul (KAB) but higher than in Herat (HER). At the same time, vehicle utilization at $M A Z$ is higher than $K A B$ and both are higher than at $\mathrm{HER}$. As these three 
sub-delegations locate in the same country (Afghanistan) and their vehicles receive similar preventive maintenance services, the comparison between them raises the question of whether these differences occur randomly or are due to differences in the fleet management policies adopted by delegations. Thus, Figure 4.3.1 suggests that there is an appropriate usage policy that both increases vehicle utilization and maximizes residual value.

Figure 4.3.1: Average fleet utilization vs. average residual values in 21 delegations

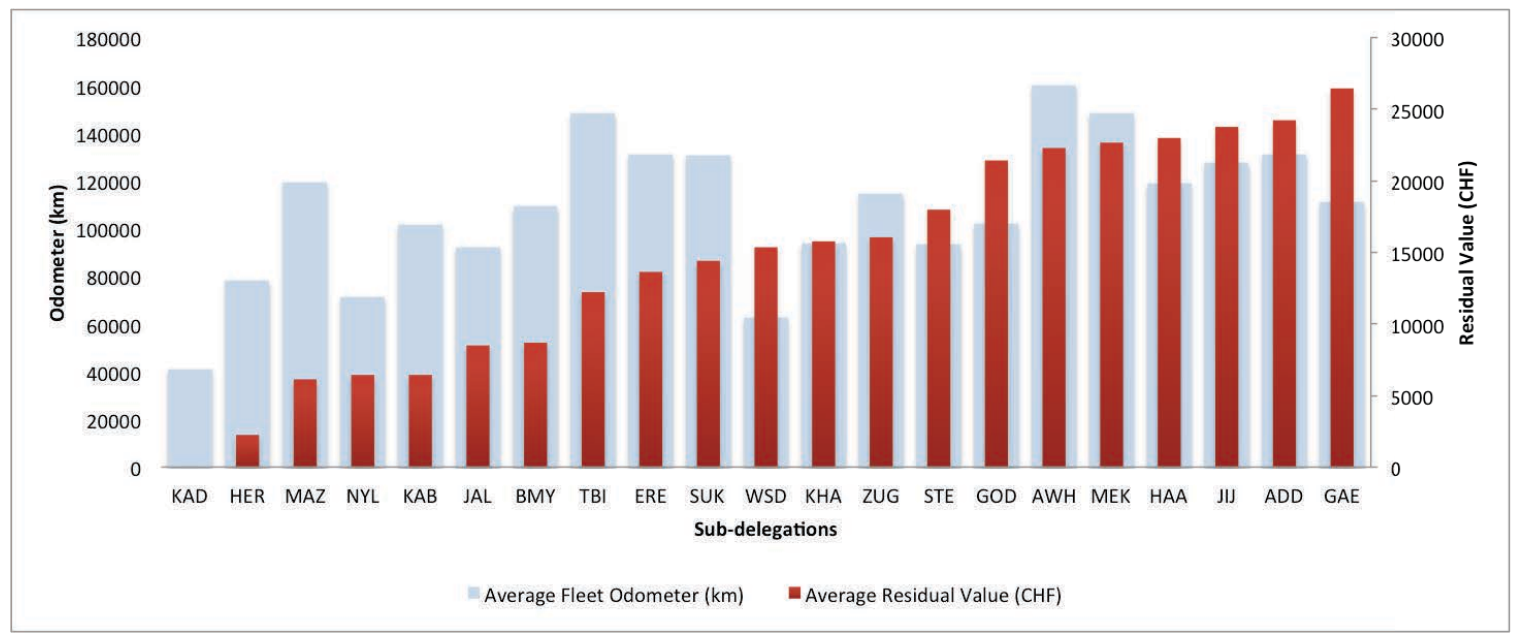

More formally we state Hypothesis 4.3.5.

Hypothesis 4.3.5 There is a trade-off between vehicle utilization and residual value: increasing a vehicle utilization decreases its residual value. 


\subsection{Methodology}

\subsubsection{Research Database}

The above hypotheses were tested using primary data collected from a large $\mathrm{HO}$ complemented by secondary data on the countries' operating conditions obtained from public sources. As a part of the collaboration between the INSEAD Humanitarian Research Group and the ICRC Fleet Management Unit, we received two data sets from the ICRC Headquarters in Geneva. In both data sets, the unit of observation was the vehicle. The first data set contained relevant information on vehicle fleets in four countries where ICRC had its largest fleets from 2000 to 2007: Afghanistan, Ethiopia, Georgia and Sudan. This unbalanced panel data covered 461 vehicles and contained the following variables: 'country of operations', 'vehicle ID code', 'cost center', 'period start' and 'period end', 'distance travelled' in each period, 'odometer end', vehicle 'purchasing date', 'age' of vehicle in months and vehicle 'mission type' in each period. 'Cost center' indicates the sub-delegation (typically: city) where the vehicle was used. 'Period start' and 'period end', indicate the time window (month) when the data was registered. 'Distance travelled' is the total odometer of the vehicle during the observation period (i.e. monthly odometer), whereas 'odometer end' indicates the cumulative odometer of the vehicle from purchasing date until the current period.

The second data set, in a cross sectional format, tracked fleet sizes by country and contained information on 'country of operations', 'cost center', vehicle 'ID code', vehicle 'total mileage', 'model', 'purchasing date', 'hand over date' and 'sold price' of all vehicles from 2000 to 2010.

Merging these two data sets, we built a new unbalanced panel data set that contains information on 655 vehicles. We restricted our analysis to those vehicles whose number of observations covered at least 12 periods (or months). The final data set included 313 vehicles ${ }^{3}$. The observation period covered either the whole operational life cycle of a vehicle or a large proportion of it, schematically described in Figure 4.4.1.

To estimate the characteristics of the operational conditions in which vehicles were used, (our

\footnotetext{
${ }^{3} 89$ vehicles in Afghanistan, 86 in Ethiopia, 69 in Georgia and 67 vehicles in Sudan.
} 


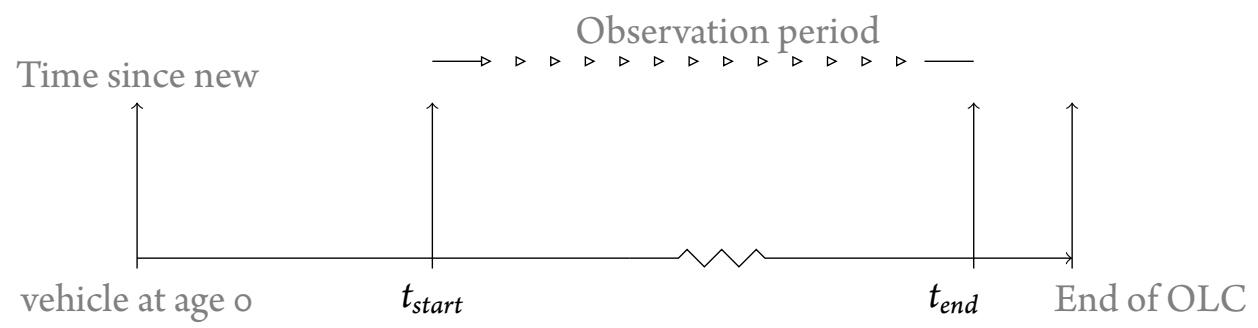

Figure 4.4.1: Example of observation period vs. vehicle operational life cycle (OLC)

control variables) we complemented our data set with some public data available on the World Bank and the International Crisis Group websites. The related variables and the method to estimate these proxies are covered in the next subsections.

\subsubsection{Operational Measures}

\section{Dependent Variables}

Our two dependent variables: vehicle utilization and vehicle residual value are defined as follows. In the literature, vehicle utilization has been defined either as total mileage driven $[24,27]$ or kilometers driven in a period of time $[16,22]$. Building upon these definitions, we operationalized the utilization for vehicle $i$ as vehicle's total mileage (during its life cycle) and we denoted it as $T M_{i}$.

Analyzing vehicle utilization is interesting for another reason. Due to the lack of data in humanitarian operations, it is often impossible to explicitly evaluate fleet performance. There is no monetary flow from underserved people to HOs. Likewise, the customers of humanitarian services cannot formally complain against HOs if they are not served properly [46]. In such a context, vehicle utilization can be conveniently considered as a proxy for fleet performance because it is closely correlated to the number of missions completed.

The second dependent variable, vehicle residual value, we simply operationalized through the used vehicles' selling price, which was available from our database and denoted by $R V_{i}$. While most studies in humanitarian operations focus on cost minimization, we explicitly study the conditions 
under which HOs can maximize the value of their assets (here vehicles).

\section{INDEPENDENT AND CONTROL VARIABLES}

The first group of independent variables include mission type and usage trend. As mentioned, there are two mission types: heavy-duty and light-duty missions. We therefore created a dummy variable, mission $_{i}$, and denoted 1 to vehicles assigned to heavy-duty missions and o to vehicles assigned to light-duty missions.

Usage trend, Utrend ${ }_{i}$, was simply approximated as follows. First, for each vehicle, we regressed vehicle monthly odometer on its age. If the estimate was significant and negative, we assigned 1 indicating the vehicle had been used following a decreasing usage trend, otherwise we allocated o. Fortunately, vehicles with a decreasing usage trend had a large negative slope. This facilitated the operationalization process because we did not need to identify a negative threshold to determine whether the vehicle was used following a decreasing trend or not.

Delegation manager decides when to sell a vehicle. Therefore, another endogenous variable that must be considered is vehicle age that can affect vehicle utilization (i.e. total mileage) and residual value. We therefore took vehicle sold-age into account and show it with $a g e_{i}$ (i.e. age of vehicle $i$ when it is sold).

[49] explain that demand variation has negative impact on fleet performance. Accordingly, for each vehicle $i$, we considered demvar ${ }_{i j}$ the standard deviation of average demand at sub-delegation $j$ during the periods when the target vehicle $i$ was active. To calculate demvar $i j$, we computed the total transportation demand $D_{t}$ as the sum of the actual odometers of individual vehicles at each subdelegation in each period. $D_{t}$ was then divided by the fleet size in period $t$, to compute the average of the demand in that period, $\bar{D}_{t}$. Finally, we computed the standard deviation of $\bar{D}_{t}, t=\left\{1, \ldots, T_{i}\right\}$, during the observation periods of vehicle $i$ and denoted that by demvar $i j$.

In addition, individual vehicles' usage variation might be affected by aggregated demand vari- 
ation. We therefore control the effect of individual vehicle usage variation in our model. Indicated by $U v a r_{i}$, usage variation was measured through the standard deviation of a vehicle's monthly odometer during its operational life that is consistent with our method to measure demand variation. Standard deviation is a measure of absolute variability. We preferred to use standard deviation over other measures such as the coefficient of variation. Because although independent of the unit of measurement and the number of observations, it can create an endogeneity problem with our utilization proxy.

In addition, we had to control for several exogenous variables reflecting the vehicle operational environment. As well as its technical characteristics. The quality of infrastructure, particularly roads, affects residual value because vehicles used in rougher terrain depreciate more quickly. It also affects utilization because vehicles used in more difficult environments require more maintenance and are less frequently available for undertaking missions. Finally, the quality of infrastructure also indirectly affects usage variation because in a country with better roads fleet managers have more flexibility in the choice of vehicles.

The quality of infrastructure in the country of operations, which has a significant impact on vehicle utilization and depreciation, was accounted through two proxies: the average Percentage of Paved Roads (PPR) and the Logistics Performance Indicator (LPI) of the country of operations. As the results of both proxies were consistent, we only report the results from models were PPR was used as a proxy. We considered PPR of the country of operations during the period vehicle $i$ was active in the fleet. The data to calculate PPR were collected from the World Bank database. We calculated the average PPR for each individual vehicle denoted by inf $f_{i}$ and and applied it to our model.

The level of conflict in the country of operations affects aggregated demand because when it reaches a critical level, HOs may decrease their activities and eventually, pull out from the country. We examined reports by the International Crisis Group (ICG), which monitors conflict levels in all countries from August 2003 onwards. For each country, we assumed a reference conflict level as of August 2003. If the ICG's monthly report indicated a higher (lower) conflict level, we increased (decreased) the indicator by one unit. conf $f_{i}$ represents the average level of conflict in the country of operations during the periods vehicle $i$ was used. Figure 4.4.2 displays the evaluation of the level 
of conflict in each country over the observation period.

Figure 4.4.2: Level of conflict in the countries of operations 2003-2011

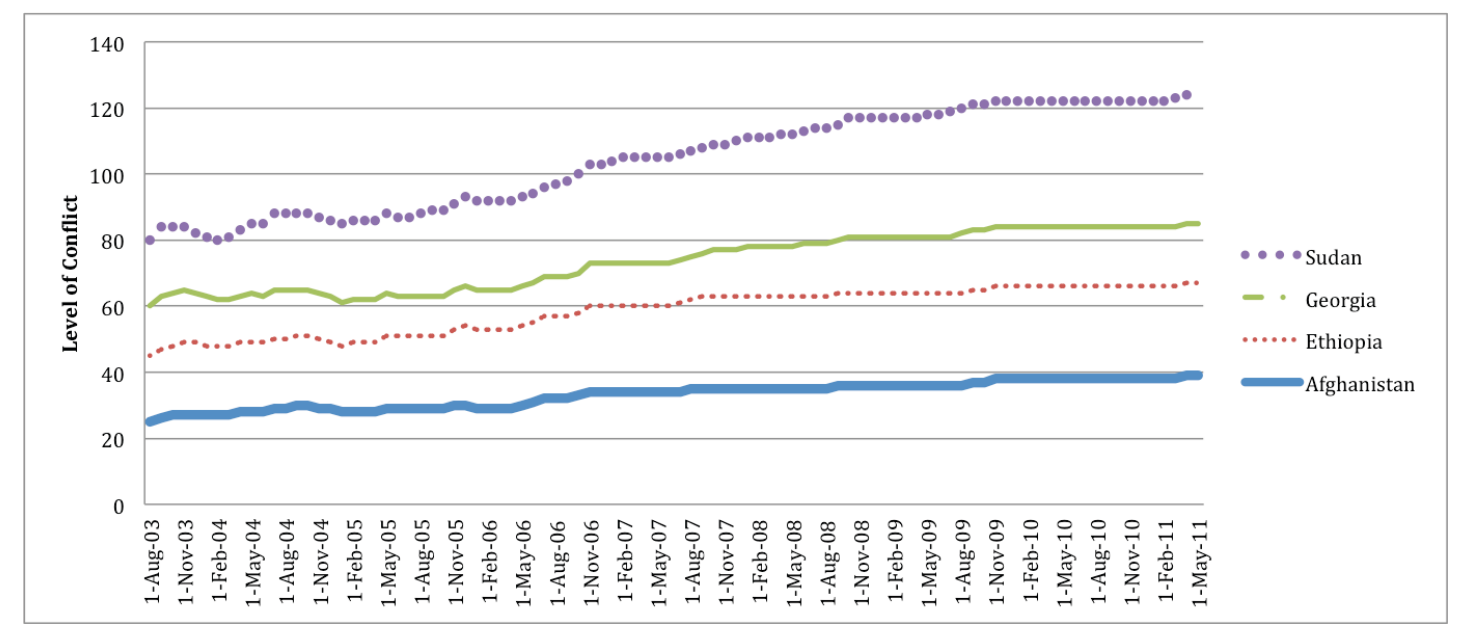

The sixth control variable accounted for the suitability of a vehicle to specific missions is indicated by model type. Although all vehicles in our data set are $4 \times 4$ Toyota Land Cruisers, the most frequently used vehicle for humanitarian missions, they were not identical. Some models, speciallyequipped vehicles, are supposedly more appropriate for long-distance journeys and heavy-duty missions. These vehicles are equipped with stronger suspension, stronger bumpers and are safer if an accident happens. Hence, we categorized vehicles into two groups and created a dummy variable model $_{i}$ to distinguish between them. Group one, denoted by 1 includes vehicles more suitable for heavy-duty missions (i.e., specially-equipped). Group two, denoted by o, includes the least suitable vehicles for heavy-duty missions (i.e. normal Land Cruiser).

Also, vehicle reliability is also expected to impact both utilization and residual value (i.e. vehicles that have a proved reliability record are obviously expected to sell at a higher price). Reliability can be estimated through the number of periods a vehicle was not available to work. Therefore, vehicle reliability, denoted by Reli $_{i}$, was measured by the number of periods that a vehicle was not active in the fleet i.e., a larger Reli $_{i}$ shows a less reliable vehicle. 
Finally to control the impact of local market on vehicle residual value, we considered the country of operations, count $i$, where vehicle $i$ was sold. Table 4.4.1 summarizes the notations and presents descriptive statistics and Table 4.4.2 shows the correlations between variables.

Table 4.4.1: Descriptive Statistics

\begin{tabular}{|c|c|c|c|c|c|c|}
\hline Notation & & Obs. & Mean & Std Dev & Min & $\operatorname{Max}$ \\
\hline$T M_{i}$ & Total Odometer & 253 & 108386.7 & 37372.33 & 9024.00 & 192037.00 \\
\hline Uvar $_{i}$ & Usage Variation & 307 & 1197.4 & 824.46 & 241.64 & 6211.54 \\
\hline Utrend $_{i}$ & Usage Trend & 307 & 0.24 & 0.42 & $\circ$ & 1 \\
\hline$R V_{i}$ & Residual Value & 253 & 14391.7 & 8874.74 & 0.00 & 54750.28 \\
\hline$a g e_{i}$ & Sold Age & 251 & 81.9 & 18.00 & 40.00 & 176.00 \\
\hline$C n t_{i}$ & Country & 307 & 2.3 & 1.10 & 1.00 & 4.00 \\
\hline mission $_{i}$ & Mission Type & 292 & 0.6 & 0.46 & 0.00 & 1.00 \\
\hline demvar $_{i j}$ & Average Demand Variation & 307 & 456.0 & 217.53 & 31.30 & 1181.23 \\
\hline $\operatorname{conf}_{i}$ & Average Conflict & 306 & 22.8 & 6.07 & 12.12 & 30.83 \\
\hline $\inf _{i}$ & Average PPR & 307 & 39.4 & 29.90 & 11.37 & 94.00 \\
\hline model $_{i}$ & Vehicle Model & 253 & 0.9 & 0.28 & 0.00 & 1.00 \\
\hline Reli $_{i}$ & Vehicle Reliability & 307 & 4.8 & 6.73 & 0.00 & 50.00 \\
\hline
\end{tabular}

\subsubsection{ECONOMETRIC ANALYSIS}

The nature of the dependent variables and the proxies used to evaluate vehicle usage policies convinced us to convert our unbalanced panel data into a cross sectional format. Hypothesis 4.3.1 was tested by Equations (4.1). Because mission $_{i}$ is a binary dependent variable, we run a probit regression.

$$
\text { mission }_{i}=a_{\circ}+a_{1} \text { Reli }_{i}+a_{2} \text { Model }_{i}+u_{i 1}
$$

We developed two models to test Hypotheses 4.3.2, 4.3.3 and 4.3.5. First, they were tested by estimating two sets of econometric models (Equations (4.1) and (4.2)). As noted earlier, a major problem in estimating the effect of usage policy on vehicle depreciation (i.e. residual value) is the 
Table 4.4.2: Correlations

\begin{tabular}{|c|c|c|c|c|c|c|c|c|c|c|c|c|}
\hline & $T M_{i}$ & Uvar $_{i}$ & Utrend $_{i}$ & $R V_{i}$ & $a g e_{i}$ & $\mathrm{Cnt}_{i}$ & mission $_{i}$ & demvar $_{i j}$ & $\operatorname{conf}_{i}$ & $\inf _{i}$ & model $_{i}$ & Reli $_{i}$ \\
\hline$T M_{i}$ & 1.00 & & & & & & & & & & & \\
\hline Uvar $_{i}$ & 0.08 & 1.00 & & & & & & & & & & \\
\hline Utrend $_{i}$ & 0.07 & -0.09 & 1.00 & & & & & & & & & \\
\hline$R V_{i}$ & 0.25 & 0.31 & -0.14 & 1.00 & & & & & & & & \\
\hline$a g e_{i}$ & -0.08 & -0.36 & 0.23 & -0.48 & 1.00 & & & & & & & \\
\hline $\mathrm{Cnt}_{i}$ & -0.06 & 0.19 & -0.36 & 0.30 & -0.39 & 1.00 & & & & & & \\
\hline mission $_{i}$ & 0.06 & -0.05 & -0.06 & -0.06 & -0.05 & 0.29 & 1.00 & & & & & \\
\hline demvar $_{i j}$ & 0.16 & 0.39 & -0.08 & 0.21 & -0.19 & 0.48 & 0.10 & 1.00 & & & & \\
\hline $\operatorname{conf}_{i}$ & -0.31 & -0.12 & 0.26 & -0.33 & 0.31 & -0.54 & -0.07 & -0.46 & 1.00 & & & \\
\hline $\inf _{i}$ & 0.13 & -0.09 & -0.26 & -0.12 & -0.10 & 0.45 & 0.19 & 0.36 & -0.77 & 1.00 & & \\
\hline model $_{i}$ & 0.04 & 0.11 & -0.08 & 0.00 & -0.33 & 0.00 & -0.15 & -0.10 & -0.01 & 0.07 & 1.00 & \\
\hline $\operatorname{Reli}_{i}$ & -0.31 & 0.00 & 0.01 & -0.21 & 0.26 & -0.16 & -0.19 & -0.12 & 0.24 & -0.18 & 0.08 & 1.00 \\
\hline
\end{tabular}

presence of selection bias. In fact, we assumed that more reliable vehicles (i.e. specially-equipped) are typically assigned to heavy-duty missions whereas less reliable vehicles are used for light-duty missions. Thus ceteris paribus, 'better' vehicles should depreciate more quickly because they get used more intensively and for more demanding missions. As a consequence, a naïv Ordinary Least Squares (OLS) estimation of the effect of mission type on residual value may not produce consistent estimates and may lead to biased results. A correct estimation of the effect of mission type on residual value must therefore take into account these effect. To circumvent this challenge, we employed a two-stage approach. First, we used Model (4.1) to estimate $\widehat{\operatorname{mission}_{I V}}$ (i.e. the fitted value of mission $_{i}$ ) using a probit regression on (4.1). Then, assuming a linear, additive model of residual value, we estimated:

$$
R V_{i}=\beta_{\circ}+\beta_{1}{\widehat{\operatorname{mission}_{I V}}}+\beta_{2} \text { Utrend }_{i}+\beta_{3} T M_{i}+\beta_{4} \text { age }_{i}+\beta_{5} \text { Cnt }_{i}+u_{i 2}
$$

where $u_{i_{2}}$ captures the effect of all unobservable variables. An essential assumption underlying an estimation of depreciation only based on Equation (4.2) (i.e. taking mission $n_{i}$ into account instead of $\widehat{\text { mission }_{I V}}$ ) is that $u_{i_{2}}$ is not correlated with any of the explanatory variables. In simple words, the model implicitly assumes that vehicles are allocated randomly to missions and not based on other vehicle characteristics such as the vehicle's reliability and suitability for the mission. Conversely, in 
this case, a two-stage approach provides a quasi-natural experiment and mimics a random vehicleto-mission assignment $[57]^{4}$.

The endogeneity assumption is a key assumption here. A potential endogeneity exits in empirical modeling the residual value of a vehicle as a function of the vehicle usage history. A forwardlooking manager would take the future residual values into consideration when she assigned the car to different tasks. As a result, the vehicle usage history may be a function of the future residual value (e.g., using current residual value of a similar vehicle as a proxy or forecast for the future residual value of a vehicle that is in use). However, this concern is alleviated after we use instrumental variable approach to control for this potential endogeneity issue. The empirical result show that the parameter estimates and model fit are not affected much when using the instrumental variables, indicating that the potential endogeneity is not an issue. This is because, as ICRC managers pointed out, the decision makers for assigning the vehicle tasks and those for selling the retired vehicle are different managers. In other words, the managers assigning vehicle tasks did not take the residual value of the vehicle into account. Our empirical results indirectly verify this organization inefficiency because, as economic theory predicts, there would be the endogeneity issue if the organization had functioned as a single rational agent. We therefore challenge the presence of selection bias and run a simple OLS on the following equation to test Hypotheses 4.3.2, 4.3.3 and $4 \cdot 3 \cdot 5$.

$$
R V_{i}=\beta_{\circ}+\beta_{1} \text { mission }_{i}+\beta_{2} \text { Utrend }_{i}+\beta_{3} T M_{i}+\beta_{4} \text { age }_{i}+\beta_{5} \text { Model }_{i}+\beta_{6} \text { Cnt }_{i}+u_{i_{3}}
$$

Legally, people who buy used vehicles from HOs must be informed what kind of mission these vehicles were used for. We therefore take the mission type, in our OLS regression, into account. In addition, given the small correlation between mission type and vehicle model (-0.15), model is not a proper instrument and a simple OLS provides unbiased results. Our approach is confirmed by a recently published article by [41]. They explicitly demonstrates that when the instrument is only

\footnotetext{
${ }^{4}$ [68] explain using fitted probabilities from a first-stage binary response model such as Probit, as an instrument (i.e. here for mission) is a nice way to exploit the binary nature of the endogenous explanatory variable. Otherwise, standard error and test statistics are not valid.
} 
weakly correlated with the regressor, IV methods can produce highly biased estimates when the instrumental variable is even slightly endogenous. In these cases, it is likely that IV estimates are more biased and more likely to provide the wrong statistical inference than simple OLS estimates that make no correction for endogeneity. They also explain 'some researchers use IV method to test the robustness of their OLS (if both OLS and IV produces the same results). Unfortunately, if there are theoretical reasons to suspect serious endogeneity concerns, the similarity of the results may also indicate that the selected IVs are inadequate, as opposed to the reported results being unaffected by endogeneity'. Consequently, we only report the results of our OLS regression on Equation (4.3).

There is another econometric issue with Equation (4.3). In our data set, the residual value of all vehicles that were either scrapped or donated are registered zero while the physical depreciation of these vehicles are not the same (i.e., donated vehicles are still in working conditions). Hence, we have a data censoring issue that causes our coefficient to be biased. To circumvent this challenge, we run a tobit regression on Equation (4.3).

To examine Hypothesis 4.3.4, we split the sample based on vehicle mission type (i.e. heavy-duty and light-duty) and run a split sample analysis. However, we noted that a simple OLS estimation could lead to biased results as a consequence of the possible correlation between usage variation and the error term, $u_{i 4}$. This is due to the inherent endogeneity attached to vehicle usage variation and aggregated demand variation. Consequently, we estimated a simultaneous system of equations and explained vehicle usage variation in a separate equation (Equation (4.5)). A challenge associated with estimating these equations simultaneously is the correlation between equations (4.4) and (4.5), which does not make the results efficient. Only if the correlation between the error terms is equal to zero, can the equations be estimated independently (i.e. both equations can be estimated by OLS). To cope with this issue, we estimated both equations (4.4) and (4.5) using OLS, Seemingly Unrelated Regression (SUR) and Two-Stage Least Square (2SLS). A Hausman Test suggested that SUR was the most efficient model. However, for sake of completeness we report the results of both OLS and SUR. 


$$
T M_{i}=\delta_{\circ}+\delta_{1} \text { Uvar }_{i}+\delta_{2} \text { Utrend }_{i}+\delta_{3} \text { Model }_{i}+\delta_{4} \inf _{i}+\delta_{5} \operatorname{conf}_{i}+\delta_{6} \text { Reli }_{i}+\delta_{7} a g e_{i}+u_{i_{4}}(4.4)
$$

$$
\text { Uvar }_{i}=\gamma_{0}+\gamma_{1} \text { demvar }_{i}+\gamma_{2} \text { Model }_{i}+\gamma_{3} \text { inf }_{i}+\gamma_{4} \operatorname{conf}_{i}+\gamma_{5} \text { Reli }_{i}+\gamma_{6} \text { age }_{i}+u_{i 5}
$$

Although Hypothesis 4.3.5 was tested through Equation 4.3, to understand in what conditions the probability of utilization-residual value trade-off might increase, we run another test inspired by a procedure developed by [40]. We defined $\mathrm{TO}_{i}$ as a binary variable that takes the value 1 if a trade-off exists and zero otherwise. To compute $T O_{i}$, we proceeded as follows. First, we computed $T \overline{M M}_{j}$ as the mean of total odometer of all vehicles in country $j$ and $\overline{R V}{ }_{j}$ as the mean of residual values of all vehicles in the same country. In the second stage, we computed the difference between individual vehicles' residual value and utilization and the average residual value and utilization in the country of operations. That is we set $T M_{i j}=T M_{i}-T M_{j}$ and $R V_{i j}=R V_{i}-R V_{j}$. We call these factors 'relative residual value' and 'relative utilization'. Then, for every vehicle observation (vehicle $i$ in country $j$ ), we determined whether (i) both relative residual value and relative utilization are higher than the average $\left(T M_{i j}>0\right.$ and $\left.R V_{i j}>0\right)$, (ii) a trade-off occurs $\left(T M_{i j}>0\right.$ and $R V_{i j}<0$ or $T M_{i j}<\mathrm{o}$ and $R V_{i j}>\mathrm{o}$ ), or (iii) both relative residual value and relative utilization for vehicle $i$ are less than the average $\left(T M_{i j}<0\right.$ and $\left.R V_{i j}<0\right)$. If a trade-off for vehicle $i$ occurred, we set $T O_{i}=1$, otherwise we set $T O_{i}=0$. Since we are interested in simultaneous improvement, we remove all observations where $T M_{i j}<\mathrm{o}$ and $R V_{i j}<\mathrm{o}$. Our dependent variable $\left(T O_{i}\right)$ is a binary variable, therefore we estimated the model using the following probit regression:

$$
\mathrm{TO}_{i}=\theta_{\circ}+\theta_{1} a g e_{i}+\theta_{2} \text { Uvar }_{i}
$$

The logic for using $a g e_{i}$ and $U v a r_{i}$ as independent variables are described in the next section after analyzing the results pertaining to the hypotheses. 


\subsection{Analysis And Discussion of Results}

All models, evaluated using STATA 12.0. show high chi-square statistics and R-square values, indicating an excellent overall fit. Results are illustrated in Tables 4.5.1, 4.5.2, 4.5.3 and 4.5.4.

The coefficient estimates in Table 4.5.1 suggests some counter-intuitive results. The coefficient estimate of Model $_{i}$ is negative and significant $(p \leq 0.05)$. Therefore, contrary to our initial assumption more reliable and specially-equipped vehicles are allocated to light-duty missions. Such a rational is questionable. Hence, Hypothesis 4.3.1 cannot be accepted. Our results show that about $95 \%$ of normal vehicles are used in field heavy-duty missions instead of light-duty missions. In addition, the impact of Reli $_{i}$ on mission is small (coefficient estimate -0.0291) implying that the vehicles used for light-duty missions are more likely to be out of service i.e., they display lower reliability.

Table 4.5.1: Probit regression estimates for vehicle-mission assignment

\begin{tabular}{lr}
\hline Constant $\left(a_{0}\right)$ & $-1.45^{* * *}(0.37)$ \\
$\operatorname{Model}_{i}\left(a_{1}\right)$ & $-0.87^{* *}(0.38)$ \\
$\operatorname{Reli}_{i}\left(a_{2}\right)$ & $-0.03^{* *}(0.01)$ \\
\hline Model $\chi^{2}(2)$ & $14.06^{* * *}$ \\
Log likelihood & -145.85 \\
Number of observations & 246 \\
\hline Note: ${ }^{*} 10 \%,{ }^{* *} 5 \%$ and ${ }^{* * *}{ }^{1} \%$ statistical significance respectively.
\end{tabular}

As shown in table 4.5.2 mission type has a significant impact on vehicle residual value. Considering the coefficient estimates of Equation (4.3), vehicles used for heavy-duty missions are on average sold at higher prices. Hence, the vehicles used for administrative duties depreciate more than the vehicles used for field missions. We therefore cannot accept Hypothesis 4.3.2.

Surprisingly, vehicles assigned to heavy-duty missions, on average, are used 10,000 $\mathrm{km}$ more than vehicles that are assigned to light-duty missions. The authors' correspondences with some field 
Table 4.5.2: Tobit and OLS regressions on Residual Value; Equation (4.3)

\begin{tabular}{|c|c|c|}
\hline & Tobit & OLS \\
\hline mission $_{i}$ & $3222.16^{* * *}(1174.53)$ & $3487.18^{* * *}(901.17)$ \\
\hline Utrend $_{i}$ & $-1849.66(894.60)$ & $-1741.20(838.97)$ \\
\hline$T M_{i}$ & $0.009(0.01)$ & $0.003(0.01)$ \\
\hline$a g e_{i}$ & $-202.62^{* * *}(33.72)$ & $-176.47^{* * *}(25.59)$ \\
\hline Model $_{i}$ & $-7537.63^{* * *}(1930.56)$ & $-6893.13^{* * *}(1631.32)$ \\
\hline Sudan & $7505.77^{* * *}(1286.31)$ & $7500.509^{* * *}(1212.51)$ \\
\hline Ethiopia & $7792.59^{* * *}(231.931)$ & $7583.57^{* * *}(164.34)$ \\
\hline Georgia & $7702.86^{* *}(1256.00)$ & $7708.87^{* * *}(1188.22)$ \\
\hline Intercept & $7014.03^{* *}(3618.98)$ & $7415.17^{* *}(3405.11)$ \\
\hline $\operatorname{LR} \chi^{2}(8)$ & $234.62^{* * *}$ & \\
\hline$R^{2}$ & & 0.64 \\
\hline$F(8,235)$ & & $53.27^{* * *}$ \\
\hline Obs & 244 & 244 \\
\hline
\end{tabular}

managers disclosed some reasons of these counter intuitive results. The specially-equipped vehicles are equipped with stronger suspensions. However, these vehicles are not comfortable for long trips while normal vehicles are more comfortable for long journeys. Therefore, humanitarian workers use the specially-equipped vehicles only for the short city trips. For the same reason, normal vehicles have a better reputation in the local market and therefore are sold at higher price.

The second reason that causes heavy-duty mission vehicles to be sold at higher price relies on vehicles' sold-age. As shown in table 4.5.2, vehicle age has a significant and negative impact on vehicle residual value. Our analysis shows that, on average, heavy-duty mission vehicles are replaced during shorter time intervals while light-duty mission vehicles are kept for a longer time. We will discuss this issue later in this section.

Results show the impact of usage trend on vehicle utilization and residual value is not as expected. As shown in Table 4.5.2, the parameter estimate of vehicle usage trend, Utrend ${ }_{i}$, is insignificant. This suggests that using a vehicle in a decreasing usage trend does not lead to selling it at higher price and therefore, Hypothesis 4.3.3 cannot be accepted. Also, results shown in Tables 4.5.3 
and 4.5.4 indicate that Hypothesis 4.3.4 cannot be accepted. Light-duty mission vehicles used in a decreasing usage fashion have even lower utilization during their operational life cycle (i.e., lower total mileage). The impact of usage trend on the utilization of heavy-duty mission vehicle is not significant. Therefore, the ICRC usage policy, which recommends using vehicles according to a decreasing trend, is not beneficial in term of vehicle utilization.

Our results show that the usage variation of all vehicles regardless of their mission type increases as a result of an increase in demand variation. In practice, demand for all vehicles, regardless of their mission type, is distributed identically among vehicles. In other words, there is no policy e.g. to overuse younger vehicles first.

Table 4.5.3: SUR and OLS results on Equations (4.4) and (4.5) for Heavy-Duty Mission vehicles

\begin{tabular}{|c|c|c|c|c|}
\hline & \multicolumn{2}{|c|}{ SUR Model } & \multicolumn{2}{|c|}{ OLS Model } \\
\hline & Utilization & Usage Variation & Utilization & Usage Variation \\
\hline Uvar $_{i}$ & $0.68(3.52)$ & & $-0.85(3.61)$ & \\
\hline Utrend $_{i}$ & $16023.07(6217.30)$ & & $16057.89(6377.78)$ & \\
\hline Model $_{i}$ & $23900.65^{* * *}(8612.57)$ & $249.92(164.90)$ & $23944.64^{* * *}(8827.92)$ & $249.22(168.49)$ \\
\hline $\operatorname{Reli}_{i}$ & $-1971.40^{* * *}(445.08)$ & $2.55(8.32)$ & $-1964.19^{* * *}(456.21)$ & $2.55(8.50)$ \\
\hline$a g e_{i}$ & $505.23^{* * *}(154.22)$ & $-12.02^{* * *}(3.34)$ & $480.79^{* *}(194.83)$ & $-12.04^{* * *}(3.41)$ \\
\hline $\inf _{i}$ & $-253.34(721.31)$ & $-11.06^{* * *}(2.80)$ & $-269.94^{*}(158.08)$ & $-11.06^{* * *}(2.86)$ \\
\hline $\operatorname{conf}_{i}$ & $-2948.07^{* * *}(721.31)$ & $-20.99(13.58)$ & $-3016.14^{* * *}(739.37)$ & $-21.06(13.88)$ \\
\hline demvar $r_{i}$ & & $1.80^{* * *}(0.21)$ & & $1.71^{* * *}(0.22)$ \\
\hline Intercept & $130957.3^{* * *}(28685.82)$ & $2037.80^{* * *}(529.11)$ & $136931.5^{* * *}(29407.08)$ & $1687.26^{* * *}(507.59)$ \\
\hline Chi-Square & $55 \cdot 3^{* * *}$ & $108.02^{* * *}$ & & \\
\hline$F$ & & & $13.57^{* * *}$ & $17 \cdot 17^{* * *}$ \\
\hline R-Squared & 0.38 & 0.39 & 0.37 & 0.39 \\
\hline Obs & 166 & 166 & 166 & 166 \\
\hline
\end{tabular}

Note: ${ }^{*} 10 \%,{ }^{* *} 5 \%$ and ${ }^{* * *} 1 \%$ statistical significance respectively. Numbers in parentheses show Standard Deviation.

The insignificant impact of utilization on vehicle residual value suggests another counter-intuitive result: on average, there is no trade-off between utilization and residual value and thus, Hypoth- 
Table 4.5.4: SUR and OLS results on Equations (4.4) and (4.5) for Light-Duty Mission vehicles

\begin{tabular}{|c|c|c|c|c|}
\hline & \multicolumn{2}{|c|}{ SUR Model } & \multicolumn{2}{|c|}{ OLS Model } \\
\hline & Utilization & Usage Variation & Usage Variation & Utilization \\
\hline Uvar $_{i}$ & $4.98(4.17)$ & & $4.27(4.41)$ & \\
\hline Utrend $_{i}$ & $-11509.16^{* *}(7208.18)$ & & $-11488.73^{* *}(7616.10)$ & \\
\hline Model $_{i}$ & $25135.4(23029.26)$ & $598.18(610.11)$ & $25587.64(24327.92)$ & $598.80(639.89)$ \\
\hline $\operatorname{Reli}_{i}$ & $-656.46^{*}(395.59)$ & $15.70(10.57)$ & $-644.15^{*}(417.90)$ & $15 \cdot 72(11.09)$ \\
\hline$a g e_{i}$ & $655.98^{* *}(287.88)$ & $-8.76(7.58)$ & $649.16^{* *}(304.12)$ & $-8.77(7.95)$ \\
\hline $\inf _{i}$ & $-1007.40^{* * *}(1291.993)$ & $-14.17^{* *}(6.02)$ & $-1016.79^{* * *}(249.26)$ & $-14.15^{* *}(6.32)$ \\
\hline $\operatorname{conf}_{i}$ & $-6280.11^{* * *}(1291.99)$ & $-53.24(36.35)$ & $-6333.13^{* * *}(1364.86)$ & $-53.51(38.13)$ \\
\hline demvar ${ }_{i}$ & & $1.56^{* *}(0.73)$ & & $1.09^{* *}(0.75)$ \\
\hline Intercept & $210227.9^{* * *}(33642.74)$ & $2520.27^{* *}(1030.11)$ & $212767.5^{* * *}(35540.84)$ & $2532.50^{* *}(1080.46)$ \\
\hline Chi-Square & $73.35^{* * *}$ & $27.58^{* * *}$ & & \\
\hline$F$ & & & $6.82^{* * *}$ & $4.17^{* * *}$ \\
\hline R-Squared & 0.48 & 0.26 & 0.41 & 0.26 \\
\hline Obs & 77 & 77 & 77 & 77 \\
\hline
\end{tabular}

Note: ${ }^{*} 10 \%,{ }^{* *} 5 \%$ and ${ }^{* * *} 1 \%$ statistical significance respectively. Numbers in parentheses show Standard Deviation.

esis 4.3.5 cannot be accepted. Therefore, a well-conceived fleet management policy can enhance both vehicle residual value and utilization. However, there might be another reason why our result does not show the tradeoff. The mean of total distance travelled of vehicles in our data set is only 108,387 kilometers. Although this is higher than the optimal replacement threshold suggested by [47], $100,000 \mathrm{~km}$, it still is below the critical odometer threshold ${ }^{5}$ indicated by the manufacturer. The critical odometer threshold for the specially-equipped and normal vehicles considered in this study are 200,000 and $150,000 \mathrm{~km}$ respectively. Through the maintenance planning literature, it is known when total mileage is below the critical odometer threshold, the failure rate is independent of vehicle total mileage. Therefore, ICRC recommendation to use vehicles following a decreasing usage trend for safety issues, seems not effective as well while all vehicles are replaced far below the critical odometer threshold.

\footnotetext{
${ }^{5}$ Critical odometer threshold is a point after which the failure rate of spare parts is a function of vehicle total mileage.
} 
Figure 4.5.1: Failure rate vs. total mileage

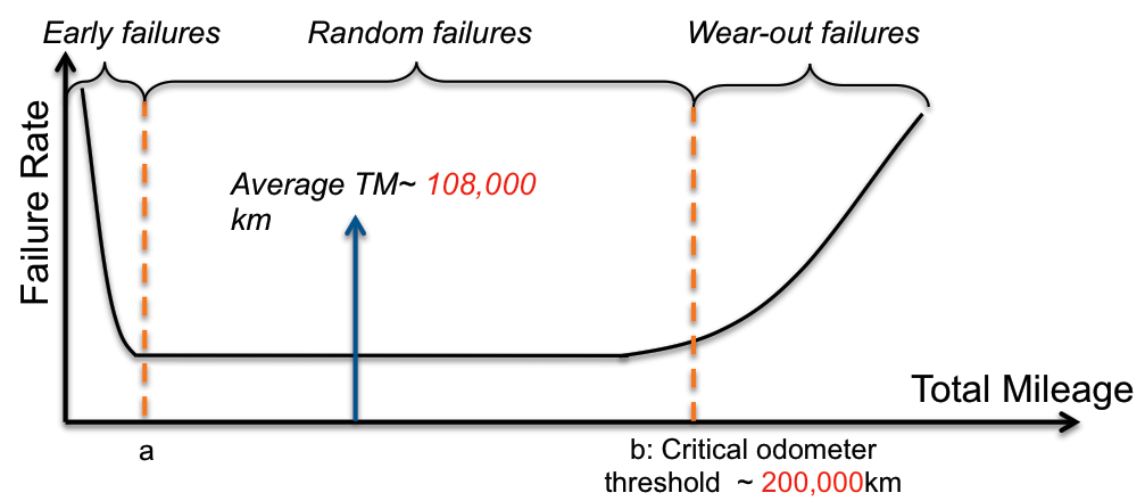

Results show us that utilization-depreciation tradeoff might be a function of other variables like age; as a vehicle ages any extra mileage affects its residual value. Another reason could be the density of vehicle usage (i.e., vehicles are sold at lower price if they have been used more intensively). For these reasons, we consider vehicle age and usage variation in Equation (4.6).

Results presented in Table 4.5.5 show that the probability that a trade-off between vehicle's residual value and utilization occurs is higher for vehicles that are older. Interestingly, our results show that older vehicles necessarily have not been utilized more. The average sold age of vehicles with $T M_{i j}>0$ is 71.91 months while the average of sold age of vehicle with $T M_{i j}<0$ is 90.93 months. Also, our result shows that usage density does not affect the probability of utilization-depreciation tradeoff. Taken together, it shows vehicles must be used intensively and replaced sooner.

Considering the impact of age and utilization on residual value (Table 4.5.2), we derived two sets of conclusions that are both counter-intuitive. The first result was explained for Hypothesis 4.3.5. The second result relates to vehicle replacement policy. In commercial sector, vehicle replacement policy is set as a multi-criteria decision that should take both age and total mileage into account [14]. Most of literature focuses on vehicle total mileage and determines vehicle optimal replacement policy only based on vehicle total mileage [47]. In contrast to the literature, our empirical analysis shows that HOs should determine replacement policy based on vehicle's age. The 
Table 4.5.5: Probit regression estimates for tradeoff occurrences

\begin{tabular}{lr}
\hline Constant $\left(\theta_{0}\right)$ & $-1.60^{* *}(0.62)$ \\
$\operatorname{age}_{i}\left(\theta_{1}\right)$ & $0.03^{* * *}(0.00)$ \\
$\operatorname{Uvar}_{i}\left(\theta_{2}\right)$ & $0.00^{* * *}(0.00)$ \\
\hline Model $\chi^{2}$ & $29.10^{* * *}$ \\
Log likelihood & -95.95 \\
Number of observations & 162 \\
\hline Note: ${ }^{*} 10 \%,{ }^{* *} 5 \%$ and ${ }^{* * *}{ }_{1 \%}$ statistical significance respectively.
\end{tabular}

reason is that in commercial sector a vehicle might be used after it reaches the critical odometer threshold while in humanitarian operations, all vehicles are sold before they reach to this threshold. Consequently, our results demonstrated that the replacement policy should be set based on vehicle's age.

\subsection{MANagerial Insights}

Our results provided interesting insights into how HOs use their fleets and how they can enhance their fleets performance. In the Introduction, we noted that a vehicle usage policy consists of decisions regarding the vehicle-mission allocation and the utilization of those vehicles by subdelegations. Our results suggest some practical suggestions to improve vehicle usage policy at two levels: at the operational and sub-delegation level and at the strategic and Headquarters level.

At the sub-delegation level, ICRC should reconsider how to allocate vehicles to heavy-duty or light-duty missions. Our data show that sub-delegations do not follow the ICRC's recommendation to shift vehicles' from one mission type to another after some time. Therefore, it is not clear whether this policy is beneficial or not. However, our results show that if delegations assign specially-equipped vehicles to heavy-duty missions, vehicle utilization would increase about $24,000 \mathrm{~km}$ that saves about US\$3,400 opportunity costs ${ }^{2}$. Obviously, HOs do not enforce their

\footnotetext{
${ }^{2}$ To provide this capacity through a third-party, ICRC has to pay about US\$ 0.145 per kilometer excluding the maintenance, fuel and insurance costs.
} 
recommendations properly. This result leads us to conclude that: (1) Either HOs should enforce their recommendations properly (e.g. right vehicles are not assigned to right missions), or (2) they should change the current purchasing policy and to procure all delegations only with normal vehicles (i.e., to save US\$ 4,200 for each vehicle).

Regardless of vehicle mission type, usage trend does not have positive impact on vehicle utilization or its residual value. Also, it does not improve the safety of humanitarian workers. Therefore, vehicles should be used intensively before they reach to the critical odometer threshold. Otherwise a percentage of transportation capacity is left idle. This result, in contrast to HOs' belief, shows that all vehicles can be used following the same usage pattern.

Our results demonstrate that vehicle age has the largest negative magnitude on vehicle residual value while total mileage does not affect residual value significantly. Hence, HOs should reconsider their vehicle replacement policy. Given vehicles are sold without reaching the critical threshold, they should be used intensively during a shorter time period and should be replaced more frequently. In this fashion, HOs have younger fleets with lower opportunity costs (i.e. higher residual values). This result is optimal for all vehicles regardless of their mission type. To achieve this goal, HOs should change their fleet management at the field level;

- Currently, delegations do not share vehicles. To increase the workload of each vehicle, we suggest delegations, in each country, share their vehicles. A pooled fleet at the national delegation level allows delegations to use vehicles whenever they need and return the extra vehicles to the pool when demand decreases. In this way, all vehicles are always in use.

- Currently a vehicle is assigned only to heavy-duty or to light-duty mission. To maximize a vehicle workload, it can be used for both mission types depending on the demand in each period. This policy, of course, increases the complication of scheduling at the field level.

Finally, as the income earned through selling a vehicle is directly sent back to the Headquarters, a sub-delegation may not have the incentive to sell the used vehicles at the best price. To align 
incentives HOs should design a mechanism to share the revenue from selling vehicles with subdelegations.

\subsection{Conclusions, Limitations and Future Research}

This chapter focuses on Last Mile Distribution (LMD) in humanitarian development projects. $\mathrm{Hu}-$ manitarian organizations engaged in LMD often operate in poor countries, in areas with rugged terrains, local conflicts, long distances and poor infrastructure, which all create serious challenges to their fleet management operations. In such conditions, cash-constrained HOs need to maximize the utilization of vehicles during their operational lives, while simultaneously preserving as much as possible the residual value of these vehicles. Despite contributing to about $50 \%$ of total fleet costs, fleet management at the field level have not received enough attention. HOs are interested in utilizing their vehicles as much as possible because they want to maximize demand coverage and the number of missions they perform. At the same time, over-utilizing vehicles may reduce their residual value and consequently also reduce the budget available for future operations. Through an empirical study, we shed light on the trade-off between these two objectives and we examine how they are affected by the operational decisions implemented by fleet operators.

The ICRC, a large $\mathrm{HO}$ that runs humanitarian projects worldwide has been the main source of data for our study. Analyzing the operations of 313 vehicles in 4 countries and 36 sub-delegations over 10 years, we examined the impact of three components of a vehicle's usage policy on vehicle utilization and residual value, namely: how to allocate vehicles to different types of missions, how to modify a vehicle's utilization over its life time and, when to replace a vehicle.

The analysis of the ICRC fleet management operations revealed several interesting insights. First, results show that the vehicle usage policy recommended by the ICRC is not properly implemented by its field delegations. Contrary to the ICRC recommended policy and to our expectations, we find that specially-equipped vehicles are assigned to light-duty missions whereas normal vehicles are assigned to heavy-duty missions (e.g. about $95 \%$ of normal vehicles are assigned to heavy-duty missions while sufficient number of specially-equipped vehicles were available). 
Given there is no selection bias (i.e. here vehicle-mission fit), we indirectly verify the organization inefficiency because, as economic theory predicts, there would be the endogeneity issue if the organization had functioned as a single rational agent. This is due to the lack of communication and incentive misalignment between the HQ and delegations and it is costly for HOs. For example, HOs' original recommendation regarding vehicle-mission assignment is optimal but it is not implemented properly. HQ purchases specially-equipped vehicles to improve humanitarians' safety but humanitarians, at the field, prefer to use normal vehicles (i.e. lack of communication and/or incentive misalignment). We find that the vehicle-mission mismatch costs over US\$3,000 for each vehicle. Our results suggest either a different vehicle-mission assignment policy, which can save over US $\$ 3,000$ per vehicle, or a different purchasing policy that can save over US $\$ 4,000$ per vehicle.

Second, the current utilization policy that determines a vehicle's workload over its life time is not optimal either. While ICRC recommends sub-delegations to use vehicles in a decreasing manner (i.e. more intensively when they are new and less intensively when they are closer to the end of their operational life), our results show that a decreasing usage trend does not have a positive impact on either residual value or utilization. In addition, they also show that vehicles are sold far below the critical odometer threshold. Therefore, using vehicles according to a decreasing usage trend does not improve the safety of humanitarian workers.

Third, our study suggests that there is no simple trade-off between utilization and residual value, i.e. a vehicle's residual value does not necessarily decrease when total mileage increases. Therefore, if vehicles are managed properly, they can be sold at a high price and still be used intensively. We also suggest that a utilization-residual value trade-off is more likely to occur for older vehicles than for younger vehicles. We demonstrate that vehicle residual value depends on different parameters including, but not limited to, vehicle's age, total mileage, model and mission type. However, age has the largest negative impact on residual value for all vehicles whose total mileage is below 200,000 $\mathrm{km}$. Combining this result with insights from [47], we suggests that to break away from the utilization - residual value trade off, HOs should use a vehicle intensively so to reach $100,000 \mathrm{~km}$ as quickly as possible, and then replace the vehicle soon before it gets too old. Through this policy, 
HOs can both minimize maintenance costs and maximize residual value.

Beyond the managerial insights directly gained through this study, this chapter provides a clear picture of humanitarian fleet management that can be useful for future research works. In this way, this chapter makes another contribution to the literature on fleet management in humanitarian development programs. At the field level, where data availability is extremely limited, and where most HOs do not even have a clear vision of their operations in remote areas, it is one of the first empirical studies that uses a large database with objective measures to examine the performance of fleet management policies in an objective manner. We believe the insights resulting from our analysis can be a useful input to further modeling-based research.

Similar to most empirical studies, this research has some limitations. First of all, the analysis is based on the operations of one organization only (although very large). Restricting the scope of our study was useful to eliminate confounding firm-level effects, but also a necessary compromise because HOs usually do not have appropriate systems to collect and register data on their fleets. Second, we could not control for a number of important variables such as accidents and vehicle breakdowns because data was not available either. Finally, as there are no true performance measures in humanitarian fleet management, we had to use vehicle utilization as a proxy for demand coverage. We plan to address these limitations in future research, to examine whether the phenomena we discussed remain valid in different operational contexts and for humanitarian organizations with different fleet management and organizational models. 


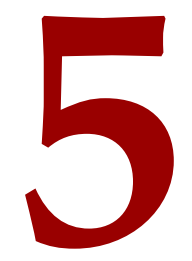

\section{Conclusion}

This dissertation provides an overview on how large international humanitarian organizations, the relief arm of the international community, manage their fleets worldwide. Fleet management is a critical process in humanitarian operations. It is crucial in order fulfillment process and forms the second largest expenditure in humanitarian operations. Challenges related to humanitarian operations limit humanitarian organizations copy the recommendations come from commercial supply chain. Therefore, there is a need to specifically focus on humanitarian operations.

To conduct this research, we used both empirical and analytical modeling methodologies. The empirical method was chosen to understand how operations are managed at the field level. Yin [70] explains that the type of research questions, extent of control a researcher has over actual behavioral events and the contemporary versus the historical nature of the phenomena under study determine the investigator's empirical approach. Although data availability is very limited in humanitarian operations, we could demonstrate how vehicles are managed in practice. Then, using 
the modeling approach, we illustrate the difference between the actual and the optimal policies and construct an optimal policy.

The literature in this area is nascent but, fortunately, growing. To contribute to the literature, two application-driven research questions are considered in this thesis. Each of these questions, developed following our discussions with fleet managers, directly links with important decisions that fleet managers must make.

This study (i) provides a better picture of humanitarian operations and, (ii) leads us to conclude useful managerial insights that can improve fleet management in humanitarian development programs. Consequently, given the lack of academic studies in this area, this research contributes to build a basis for future research works in humanitarian operations. In addition, this study contributes to the literature of fleet management in commercial sector. This chapter summarizes the key findings of this dissertation and the its main contributions to the academic literature.

\subsection{Key Findings and Contributions}

\subsubsection{Contribution to THE Literature}

In addition to the managerial findings, this dissertation contributes to humanitarian and commercial fleet management literature in several ways.

1. It provides a clear picture of humanitarian operations. We show humanitarian organizations suffer because of lack of communication and incentive misalignment. This is an important issue that should be taken into account in the future research studies. In humanitarian world, in contrast with commercial sector, even optimal policies are not implemented properly. Finding its reasons and designing solutions to overcome this challenge can be valuable.

2. In this dissertation, we developed a model to find a closed-form solution that optimizes fleet sizing over time. By our knowledge, this approach is novel in fleet management literature. Most of mathematical models in this area are data-intensive. These models optimize fleet sizing based on detail data. In addition, none of these models provides closed-form solution and interprets general managerial insights. 
3. Against the fleet management literature that focuses on individual replacement policy (fleet management at micro-level) or fleet sizing (fleet management at macro-level), our model considers the impact of individual replacement policy on fleet sizing and budget constraints.

4. To our knowledge, there is no study has been done similar to the second part of this thesis. In this part, an organization's fleet management is analyzed into the detail. We demonstrated how simple managerial decisions can improve the fleet performance and reduce the costs.

\subsubsection{Procurement Policy}

Our results suggest the following policy to humanitarian organizations:

- If they cannot monitor/enforce how delegations assign vehicles to missions, they should change their current purchasing policy. They should only purchase normal Land Cruisers and provide all delegations with the same type of vehicle.

- Humanitarian organizations should keep smaller fleet sizes at areas where demand variation is high. In this fashion, they maximize vehicle utilization.

- Procurement policy for each region should be set as follows:

1. If frequency of demand variation is high and the magnitude of demand variation is large: the optimal policy is a level strategy (i.e. keep an average number of vehicles and do not follow the demand variation).

2. If frequency of demand variation is high but the magnitude of demand variation is small: the optimal policy is a level strategy

3. If frequency of demand variation is low and the magnitude of demand variation is small: the optimal policy is a level strategy

4. If frequency of demand variation is low but the magnitude of demand variation is large: the optimal policy is a chase strategy (i.e. follow the demand variation)

- Humanitarian organizations should improve the level of communication and coordination with their delegations. Lack of communication is shown to be very costly for these agencies. 
- Replacement policy needs to be reconsidered. Humanitarian organizations should set their replacement policy only based on age of a vehicle and convince delegations to intensively utilize vehicles when the vehicle is still young.

\subsubsection{Field Fleet Management}

We suggest the following policy to improve fleet performance and decrease its costs:

- If delegations have access to different types of vehicles, they should assign specially-equipped vehicles to more difficult missions. In this fashion, they would increase vehicle utilization and decrease opportunity costs.

- All vehicles can be used following the same usage pattern regardless of vehicle mission type.

- The optimal usage pattern is to use all vehicles intensively when the vehicle is young and sell it sooner.

- Delegations should share vehicles. Consequently, they can have access to a larger fleet size and utilize vehicles more effectively.

\subsection{Limitations and Future Research}

Limitations and future research related to each chapter are discussed at the end of each chapter. In general, the scope of this research is limited. This study provides an overview of the humanitarian fleet management of one of the largest international humanitarian organizations. However, it could be better if we had access to a larger dataset and consider several organizations.

In the fleet sizing section, the thesis does not consider some detailed information for example number of available drivers and number of missions covered at each period. Unfortunately, the related data was not available to us. Also, we assume that a certain amount of budget is available to organization at all periods and thus, we did not consider earmarked budgets. Considering all these details can improve the model. 
In chapter 4, we did not consider other details like accident history of each vehicle, vehicle-driver allocation policy and number of missions implemented at each period by each delegation. A similar study that consider several large organizations would give us a richer picture of field vehicle fleet management in humanitarian world.

As we showed, lack of communication and incentive misalignment do not let humanitarian operations to be efficient. These issues need further investigation. For example, designing a coordination mechanism based on incentives for all parties involved, a coordination mechanism such that delegations share vehicles, and coordination mechanism between humanitarian organization at the field level are examples of interesting research questions that need to be considered. 
This section contains the appendix for Chapter 3.

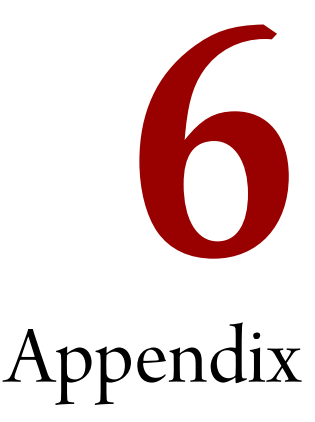

Proof of Proposition 1 For a review of optimal control and Pontryagin's minimum principle, the reader is referred to [33]. We first prove the unconstrained case of problem (6.1). The Pontryagin's minimum principle states that for the minimization problem

$$
\begin{aligned}
\min _{u(t)} J=\frac{1}{2} \int_{0}^{T}\left(q[x(t)-D(t)]^{2}+r[u(t)]^{2}\right) \mathrm{d} t \\
\dot{x}(t)=u(t)-\frac{x(t)}{\tau} \\
x(t) \geq \delta D(t) \\
-M \leq u(t) \leq M \\
x(\mathrm{o})=\mathrm{o}
\end{aligned}
$$


the minimizing $u$ is the one that minimizing the Hamiltonian function

$$
\mathcal{H}=\frac{1}{2} q[x(t)-D(t)]^{2}+\frac{1}{2} r u(t)^{2}+\lambda\left[u(t)-\frac{x(t)}{\tau}\right]
$$

and that at optimality

$$
\begin{aligned}
\frac{\partial \mathcal{H}}{\partial u} & =0 \\
u^{*}(t) & =-\frac{\lambda}{r}
\end{aligned}
$$

The function $\lambda(t)$ represents the marginal rate of change of the minimum value of the objective function $J$ with respect to the change in $x$. The terminal condition for $\lambda$ depends on the assumptions of the problem with regards to the terminal value of $x$. In our case, the terminal state is free and we have

$$
\lambda(t)=P(t) x(t)-g(t)
$$

The function $P(t)$ is found through solving the following differential Riccati equation

$$
\dot{P}(t)=\frac{P(t)^{2}}{r}-{ }_{2} P(t)-q
$$

Assuming the terminal cost equal to zero, we approximate a steady state $P(t)$ that is

$$
P(t)=r\left(\sqrt{\frac{1}{\tau^{2}}+\frac{q}{r}}-\frac{1}{\tau}\right)
$$

and $g(t)$ is found through a first order differential equation as follows

$$
\dot{g}(t)=\left[\frac{P(t)}{r}+\frac{1}{\tau}\right] g(t)-q d(t)
$$


with the terminal condition $g(T)=0$. Then, $x^{*}(t)$ and $u^{*}(t)$ are found through the following equations

$$
\begin{aligned}
& \dot{x}^{*}(t)=\left[-\frac{1}{\tau}-\frac{P(t)}{r}\right] x^{*}(t)+\frac{g(t)}{r} \\
& u^{*}(t)=-\frac{P(t)}{r} x^{*}(t)+\frac{g(t)}{r}
\end{aligned}
$$

In the case when constraint $(3.3)$ is binding, we also need to form the Lagrangian as follows

$$
\mathcal{L}=\mathcal{H}+\mu[x(t)-\delta D(t)]
$$

and from Karush Kuhn Tucker condition, we have

$$
\mu \geq 0 \quad x(t)-\delta D(t) \geq 0, \quad \mu[x(t)-\delta D(t)]=0
$$

therefore, $x^{*}(t)=\delta D(t)$ whenever constraint (3.3) is binding. Thus, the optimal control is

$$
u^{*}(t)=\delta\left(\dot{D}(t)+\frac{D(t)}{\tau}\right)
$$

Considering the demand function (3.6) and substituting equations (3.6) and (6.10) into equation (6.11), we find

$$
g(t)=C e^{\sqrt{\frac{q}{r}} t}+\operatorname{ar}\left(1+\sqrt{\frac{q}{r}} t\right)+\frac{\beta q r\left(\omega \cos (\omega t)+\sqrt{\frac{q}{r}} \sin (\omega t)\right)}{q+r \omega^{2}}
$$

for a large $t$, the constant $C=$ o hence,

$$
x^{*}(t)=\frac{a q t \tau^{2}}{q \tau^{2}+r}+\frac{\beta q \sin (\omega t)}{q+r\left(\frac{1}{\tau^{2}}+\omega^{2}\right)}
$$

and the optimal control is

$$
u^{*}(t)=\frac{q \tau^{2} a}{r+q \tau^{2}}+\frac{q \tau a t}{r+q \tau^{2}}+\frac{\tau \beta(\alpha \omega \cos (\omega t)+q \sin (\omega t))}{r+\tau^{2}\left(r \omega^{2}+q\right)}
$$


Therefore, if constraint $(3.3)$ is binding, the optimal available fleet size is set $x^{*}(t)=\delta(a t+$ $\beta \sin (\omega t))$ and the optimal control will be

$$
u^{*}(t)=\delta \alpha\left(1+\frac{t}{\tau}\right)+\delta \beta\left(\omega \cos (\omega t)+\frac{\sin (\omega t)}{\tau}\right)
$$

If constraint (3.4) is binding, then by solving the first order differential equation, $\dot{x}(t)=M-$ $\frac{x(t)}{\tau}$, we find a steady state solution that indicates $x(t)=M \tau$.

If both, constraints (3.3) and (3.4) are binding, then based on the Karush Kuhn Tucker condition

$$
\left\{\begin{array}{lcc}
\mu_{1} \geq 0 & x(t)-\delta D(t) \geq 0, & \mu_{1}[x(t)-\delta D(t)]=0 \\
\mu_{2} \geq 0 & M-u(t) \geq 0, & \mu_{2}[M-u(t)]=0
\end{array}\right.
$$

The only $u^{*}(t)$ that satisfies the condition is $u^{*}(t)=\min \left\{\delta\left(\dot{D}(t)+\frac{D(t)}{\tau}\right), M\right\}$.

Proof of Proposition 2 We will present the proof for the demand function $\alpha+\beta \sin (\omega t)$. The proof for the demand function $a t+\beta \sin (\omega t)$ is similar. The maximum budget $\bar{B}$ is found by using equations (3.17) and (3.18) and setting $\sin (\omega t)=1$ for the case of $x(t)$, and $\sin (\omega t)=0$ and $\cos (\omega t)=1$ for the case of $u(t)$. Thus, we have

$$
\bar{B}=h\left(\frac{a q \tau^{2}}{q \tau^{2}+r}+\frac{\beta q}{q+\frac{r}{\tau^{2}}+r \omega^{2}}\right)+p\left(\frac{a q \tau}{q \tau^{2}+r}+\frac{\beta q \tau^{2} \omega}{q \tau^{2}+r \tau^{2} \omega^{2}+r}\right)
$$

taking the derivative of this function with respect to $\omega$ and after some simplifications, we update

$$
\frac{\beta q \tau^{2}\left(p\left(q \tau^{2}-r \tau^{2} \omega^{2}+r\right)-2 h r \tau^{2} \omega\right)}{\left(q \tau^{2}+r \tau^{2} \omega^{2}+r\right)^{2}}
$$

Setting equation (6.23) equal to zero and solving for $\omega$, we find that this derivative is negative if

$$
\frac{\omega}{\omega_{R}}>\frac{\sqrt{r\left(h^{2} r \tau^{2}+p^{2}\left(q \tau^{2}+r\right)\right)}-h r \tau}{p r \tau^{2}}
$$


and it is positive otherwise.

Proof of Propositions 3 and 4 is similar to the proof of Proposition 1. The only difference is that we substitute demand functions into equation (6.1 1) instead of demand function (3.6); for Proposition 3 , we substitute demand function at into the equation (6.11) and, for Proposition 4 we substitute demand function $\alpha+\beta \sin (\omega t)$. 


\section{References}

[1] Open Source Database, 2012.

[2] Fleet Management Benchmark Report, April 2012.

[3] Anna Alberini, Winston Harrington, and Virginia McConnell. Determinants of participation in accelerated vehicle retirement programs. Rand Journal of Economics, 26:93 112, 1995.

[4] Anna Alberini, Winston Harrington, and Virginia McConnell. Fleet turnover and old car scrap policies. Resources for the Future, Discussion Paper:98-23, 1998.

[5] Nezih Altay and Walter G. Green. OR/MS research in disaster operations management. European Journal of Operational Research, 175:475-493, 2006.

[6] Aruna Apte. Humanitarian logistics - a new field of research and action. Foundations and Trends in Technology, Information and Operations Management, 3(1), 2009.

[7] Burcu Balcik and Benita M. Beamon. Facility location in humanitarian relief. International Journal of Logistics: Research and Applications, 11 (2):101-121, 2008.

[8] Burcu. Balcik, Benita M. Beamon, and Karen. Smilowitz. Last mile distribution in humanitarian relief. Journal of Intelligent Transportation Systems, 12(2):51-63, 2008.

[9] G. Barbarosoglu and Y Arda. A two-stage stochastic programming framework for transportation planning in disaster response. Journal of Operational Research Society, 5 5:43-53, 2004.

[10] G. Barbarosoglu, L. Ozdamar, and A. Cevik. An interactive approach for hierarchical analysis of helicopter logistics in disaster relief operations. European Journal of Operational Research, 140:118-133, 2002.

[11] Benita Beamon and M. Burcu Balcik. Performance measurement in humanitarian relief chains. International Journal of Public Sector Management, 2 1(1):4-25, 2008. 
[12] Maria Besiou, Alfonso Pedraza-Martinez, and Luk N. Van Wassenhove. Decentralization and earmarked funding in humanitarian logistics for relief and development. INSEAD Working Papers Series, (2012/10/TOM/ISIC), 2012.

[13] Charles W. Bischoff and Edward C. Kokkelenberg. Capacity utilization and depreciation-inuse. Applied Economics, 19:995 1007, 1987.

[14] I. Brosh, E. Shlifer, and Y. Zeira. Optimal maintenance policy for a fleet of vehicles. Management Science, 22(4):401-410, 1975.

[15] A.M. Campbell, D. Vanderbussche, and W. Hermann. Routing for relief efforts. Transportation Science, 42(2):127-145, 2008.

[16] Joyce Dargay. Vehicle ownership to 2015: implications for energy use and emissions. Energy Policy, 25(14-15):1121-1127, 1997.

[17] V. De Angelis, M. Mecoli, C. Nikoi, and G. Storchi. Multiperiod integrated routing and scheduling of world food programme cargo planes in angola. Computers and Operations Research, 34:1601 1615, 2007.

[18] D. Disparte. The Postman Parallel. CarNation, 2:22-27, 2007.

[19] Yafeng Du and Radolph Hall. Redistribution for center-terminal transportation networks. Management Science, 43(2):145-157, 1997.

[20] M. Edwards and D. Hulme. Too close for comfort? The impact of official aid on Nongovernmental Organizations. World Development, 24(6):961-973, 1996.

[21] Mahyar Eftekhar, Andreas Robotis, and Luk N. Van Wassenhove. Vehicle procurement policy for humanitarian development programs. Working Paper, 2012.

[22] Maxim Engers, Monica Hartmann, and Steven Stern. Annual miles drive used car prices. Journal of Applied Econometrics, 24:1 33, 2009.

[23] T. Esper, T. D. Jensen, F. L. Turnipseed, and S. Burton. The last mile: an examination of effects of online retail delivery strategies on consumers. Journal of Business Logistics, 24(2): 177-203, 2003.

[24] Hao Audrey Fang. A discrete-continuous model of households vehicle choice and usage, with an application to the effects of residential density. Transportation Research Part B: Methodological, 42:736 758, 2008.

[25] Fritz Fritz Institute. Logistics and the effective delivery of humanitarian relief, 2005. 
[26] Pinelopi Koujianou Goldberg. The effects of the corporate average fuel efficiency standards in the US. Journal of Industrial Economics, 46:1 33, 1998.

[27] Thomas F. Golob. Projecting use of electric vehicles from household vehicle trials. Transportation Research Part B: Methodological, 32 (7):441-454, 1998.

[28] Paulo Goncalves. System dynamics modeling of humanitarian relief operations. MIT Sloan School Working Paper, (4704-08), 2008.

[29] Lee D. Han, Fang Yuan, Shih-Miao Chin, and Holing Hwang. Global optimization of emergency evacuation assignments. Interfaces, 36(6):502-513, 2006.

[30] Roy Herrmann. Evaluation of the utilization and management of UNHCR's light vehicle fleet. www.unhcr.org/epau, EPAU/2006/o2(February), 2006.

[31] Armann Ingolfsson, Susan Budge, and Erhan Erkut. Optimal ambulance location with random delays and travel times. Health Care Management Science, 1 1:262-274, 2008.

[32] H. Jia, F. Ordonez, and M. Dessouky. A modeling framework for facility location of medical services for large-scale emergencies. IIE Transactions, 39:41 55, 2007.

[33] M.I. Kamien and N.L. Schwartz. Dynamic optimization: the calculus of variations and optimal control in economics and management. ELSEVIER., 1991.

[34] John Klincewicz, Hanan Luss, and Martha G. Pilcher. Fleet size planning when outside carrier services are available. Transportation Science, 24(3):169-182, 1990.

[35] Gyongyi Kovacs and Karen Spens. Humanitarian logistics in disaster relief operations. International Journal of Physical Distribution \& Logistics Management, 37(2):99-1 14, 2007.

[36] Gyongyi Kovacs and Karen Spens. Identifying challenges in humanitarian logistics. International Journal of Physical Distribution \& Logistics Management, 39(6):506-528, 2009.

[37] Gyongyi Kovacs and Peter Tatham. Humanitarian logistics performance in the light of gender. International Journal of Physical Distribution \& Logistics Management, 58(2):174-187, 2009.

[38] Ufuk Kula, Ozden Tozanli, and Saniye Tarakcio. Emergency vehicle routing in disaster response operations. POMS 23rd Annual Conference, Chicago, (April 20-23), 2012.

[39] Michael A. Lapre, Amit Shankar Mukherjee, and Luk N. Van Wassenhove. Behind the learning curve: linking learning activities to waste reduction. Management Science, 46(5): $597-611,2000$. 
[40] Michael A. Lapre « and Gary D. Scudder. Performance improvement paths in the U.S. airline industry: linking trade-offs to asset frontiers. Production and Operations Management, 13(2): $123134,2004$.

[41] David F. Larcker and Tjomme O. Rusticus. On the use of instrumental variables in accounting research. Journal of Accounting and Economics, 49(3):186-205, 2010.

[42] George F. List, Bryan Wood, Linda K. Nozick, Mark A. Turnquist, Dean A. Jones, Edwin A. Kjeldgaard, and Craig R. Lawton. Robust Optimization for Fleet Planning Under Uncertainty. Transportation Research Part E, 39:209-227, 2003.

[43] Natarajarathinam Malini, Ismail Capar, and Arunachalam Narayanan. Managing supply chains in times of crisis: a review of literature and insights. International Journal of Physical Distribution \& Logistics Management, 39(7):535-573, 2009.

[44] Fred L. Mannering and Clifford Winston. A dynamic empirical analysis of household vehicle ownership and utilization. The RAND Journal of Economics, 16(2):215-236, 1985.

[45] Jessica McCoy. Overcoming the challenges of the last mile: a model of Riders for Health. In Brian Denton, editor, Healthcare Operations Management. Springer, NY, 2012.

[46] Richard Oloruntoba and Richard Gray. Customer service in emergency relief chains. International Journal of Physical Distribution \& Logistics Management, 39(6):486-505, 2009.

[47] Alfonso Pedraza Martinez and Luk N. Van Wassenhove. Vehicle replacement in the international committee of red cross. Production and Operations Management, forthcoming, 2012.

[48] Alfonso Pedraza Martinez, Sameer Hasija, and Luk N. Van Wassenhove. An operational mechanism design for fleet management coordination in humanitarian operations, 2010.

[49] Alfonso Pedraza Martinez, Orla Stapleton, and Luk N. Van Wassenhove. Last mile fleet management in humanitarian operations: a case-based approach. Journal of Operations Management, 29(5):404-42 1, 2011.

[50] Eva Regnier. Public evacuation decisions and hurricane track uncertainty. Management Science, 54(1):16-28, 2008.

[51] M. Saadatseresht, A. Mansourian, and M. Taleai. Evacuation planning using multi-objective evolutionary optimization approach. European Journal of Operational Research, 198:305-3 14, 2009.

[52] J. Salmeron and Aruna Apte. Stochastic optimization for natural disaster asset prepositioning. Production and Operations Management, 19(5):561-574, 2010. 
[53] Ramina Samii. Leveraging Logistics Partnerships: lessons from humanitarian organizations. ERIM PhD. Series in Research in Management, 153, (ISBN 978-90-5892-1 86-4), 2008.

[54] Hanif D. Sherali, Ebru K. Bish, and Xiaomei Zhu. Airline fleet assignment concepts, models and algorithms. European Journal of Operational Research, 172:1-30, 2006.

[55] NC Simpson. Modeling of residential structure fire response: exploring the hyper-project. Journal of Operations Management, 24:530-541, 2006.

[56] NC Simpson and PG Hancock. Fifty years of operational research and emergency response. Journal of the Operational Research Society, 60:126-139, 2009.

[57] Diwas Singh KC and Christian Terwiesch. The effects of focus on performance: evidence from california hospitals. Management Science, 57(11):1897-1912, 2011.

[58] Nigel Slack, Stuart Chambers, Robert Johnston, and Alan Betts. Operations and process management - principles and practice for strategic impact. Prentice Hall., 2006.

[59] Dong-Ping Song and Christopher F. Earl. Optimal empty vehicle repositioning and fleetsizing for two-depot service systems. European Journal of Operational Research, 1 85:760-777, 2008.

[6o] Orla Stapleton, Alfonso Pedraza Martinez, and Luk N. Van Wassenhove. Keep on truckin': managing vehicles at the International Committee of the Red Cross. 2008.

[61] Alexander Stepanov and James MacGregor Smith. Multi-objective evacuation routing in transportation networks. European Journal of Operational Research, 198:435-446, 2009.

[62] Rolando Tomasini and Luk N. Van Wassenhove. Humanitarian Logistics. INSEAD Business Press, 2009.

[63] Gwo-Hshiung Tzeng, Hsin-Jung Cheng, and Tsung Dow Huang. Multi-objective optimal planning for designing relief delivery systems. Transportation Research, Part E, 43:673-686, 2007.

[64] Luk N. Van Wassenhove. Blackett Memorial Lecture Humanitarian aid logistics: supply chain management in high gear. Journal of the Operational Research Society, 57:475-489, 2006.

[65] R.R. Vemuganti, M. Oblak, and A. Aggarwal. Network models for fleet management. Decision Sciences, 20(1):182-197, 1989. 
[66] K. Viswanath and S. Peeta. Multi-commodity maximal covering network design problem for planning critical routes for earthquake response. Transportation Research Record, 1857:1-10, 2003.

[67] Michael C. Whiting and Beatriz E. Ayala-Ostrom. Advocacy to promote logistics in humanitarian aid. Management Research News, 32 (11):1081-1089, 2009.

[68] Jeffrey M. Wooldridge. Econometric Analysis of Cross Section and Panel Data. The MIT Press, Cambridge, Massachusetts, 2002.

[69] Wei Yi and Linet Ozdamar. A dynamic logistics coordination model for evacuation and support in disaster response activities. European Journal of Operational Research, 179(3): 1177-1193, 2007.

[70] R. K. Yin. Case Study Research: design and methods. Number Third Edition. Thousand Oaks (CA): Sage, 2003. 


\section{Fleet Management in the Humanitarian Sector \\ Abstract}

Fleet management is a major concern for international humanitarian organizations because of (1) the magnitude of transportation-related costs in humanitarian operations, second only to personnel cost and, (2) the pivotal role that transportation plays in the order-fulfillment process. Humanitarian organizations face unusual operating constraints, which include working in areas with poor infrastructure, extreme environmental conditions as well as budget limitations. Most of the existing models derived from commercial supply chains are inapplicable in such a context. Therefore, a new set of tools and theories is required. This dissertation contributes to the development of such a new set of tools. It is composed of two parts that address two related questions in humanitarian fleet management: (1) how to determine the optimal fleet size and the optimal procurement strategy at an aggregate level and, (2) how to optimally manage an existing fleet the field level. Lack of data is the main challenge that prevents humanitarian organizations from adopting data-intensive models developed for commercial supply chains. Accordingly, the first part of this thesis studies how to determine optimal fleet capacity over time and how to minimize procurement costs for different demand profiles in the absence of detailed data. Contrary to conventional wisdom in humanitarian organizations, its findings show that a mixed policy of level and chase procurement strategies minimizes procurement costs and that a level strategy is the optimal approach to procurement in most humanitarian missions. The second part of the dissertation concentrates on fleet management policies at the field level. To optimize fleet performance and maximize demand coverage, humanitarian organizations implement policies to enhance the utilization of vehicles and minimize their physical depreciation. Through the analysis of a large humanitarian organization's fleet in four representative countries (Sudan, Ethiopia, Afghanistan and Georgia) the results of this dissertation suggest that: (1) it is not necessary to assign different vehicles to specific mission types (2) all vehicles should be used following the same usage policy regardless of their mission type and, (3) the vehicle replacement policy implemented by most humanitarian organizations is not effective and needs to be reconsidered. Results also demonstrate that, on average, a utilization-depreciation trade-off does not exist and that a wellconceived fleet management policy can allow for both higher vehicle utilization and lower depreciation.

Keywords: Fleet management, humanitarian operations.

\section{La gestion de la flotte dans le secteur des opérations humanitaires} Résumé

La gestion de flottes est un défi important pour ces organisations pour deux raisons principales (1) dans les opérations humanitaires les coûts liés au transport sont très élevés (les plus importants après les frais du personnel) et, (2) le rôle central joué par le transport pour répondre à la demande et réduire les délais de livraison. Les organisations humanitaires font face à des conditions très particulières, par exemple ils opèrent dans des zones avec des infrastructures insuffisantes avec des conditions environnementales extrêmes et ont des contraintes budgétaires très strictes. Dans un pareil contexte, les modèles d'optimisation développés pour des supply chains de type commercial ne sont pas toujours applicables. Par conséquent, une nouvelle série d'outils et des nouvelles théories sont envisageables et même nécessaires. Cette thèse contribue au développement de ces outils. Elle est composée de deux parties qui abordent deux questions clés pour la gestion d'une flotte humanitaire: (1) quelle est la taille optimale de la flotte au fil du temps et quelle est la meilleure stratégie d'achat, (2) quelle sont les meilleures politiques de gestion une fois la flotte sur le terrain. Le manque de données est un vrai souci pour les organisations humanitaires et il empêche l'utilisation de modèles développés pour le secteur commercial qui requièrent un volume de données très important. Par conséquent, la première partie de cette thèse de l'étude propose une méthode pour déterminer la capacité optimale d'une flotte, de manière à réduire les coûts d'approvisionnement tout en répondant aux besoins de la demande, sans faire recours à des données détaillées. Contrairement aux idées reçues dans les organisations humanitaires, les résultats suggèrent qu'un mix de stratégies d'approvisionnement qui suivent la demande et de stratégies qui gardent un niveau de stock constant minimise les coûts. Le modèle suggère aussi que la stratégie d'approvisionnement qui suit la demande est optimale dans la plupart de missions humanitaires. La deuxième partie de l'étude analyse les politiques de gestion de flotte sur le terrain. Pour optimiser les performances de leurs flottes et satisfaire au mieux la demande, les organisations humanitaires mettent en œuvre des politiques visant à accroître l'utilisation des véhicules tout en préservant leur valeur résiduelle. L'étude analyse la flotte d'une importante organisation humanitaire dans quatre pays (Soudan, Ethiopie, Afghanistan et Géorgie). Les résultats de l'étude montrent que (1) une allocation de véhicules par type de mission n'est pas nécessaire, (2) tous les véhicules doivent être utilisés conformément à la même politique d'utilisation quelle que soit leur mission et, (3) la politique de remplacement des véhicules mise en œuvre par la plupart des organisations humanitaires n'est pas efficace et doit être revue. L'étude démontre aussi que la maximisation du taux d'utilisation et la maximisation de la valeur résiduelle ne sont pas forcément des objectifs opposés : une politique bien conçue permet de les atteindre simultanément.

Mots clés: Gestion de flotte, opérations humanitaires 